\title{
Temperature Measurement Using Infrared Spectral Band Emissions From H2O
}

Daniel Jared Ellis

Brigham Young University - Provo

Follow this and additional works at: https://scholarsarchive.byu.edu/etd

Part of the Mechanical Engineering Commons

\section{BYU ScholarsArchive Citation}

Ellis, Daniel Jared, "Temperature Measurement Using Infrared Spectral Band Emissions From H2O" (2015). Theses and Dissertations. 5488.

https://scholarsarchive.byu.edu/etd/5488

This Thesis is brought to you for free and open access by BYU ScholarsArchive. It has been accepted for inclusion in Theses and Dissertations by an authorized administrator of BYU ScholarsArchive. For more information, please contact scholarsarchive@byu.edu, ellen_amatangelo@byu.edu. 
Temperature Measurement Using Infrared Spectral Band Emissions From $\mathrm{H}_{2} \mathrm{O}$

Daniel Jared Ellis

A thesis submitted to the faculty of

Brigham Young University

in partial fulfillment of the requirements for the degree of

Master of Science

Dale R. Tree, Chair

Julie Crockett

Brian D. Iverson

Department of Mechanical Engineering

Brigham Young University

July 2015

Copyright (C) 2015 Daniel Jared Ellis

All Rights Reserved 


\begin{abstract}
Temperature Measurement Using Infrared Spectral Band Emissions From $\mathrm{H}_{2} \mathrm{O}$
\end{abstract}

\author{
Daniel Jared Ellis \\ Department of Mechanical Engineering, BYU \\ Master of Science
}

Currently there is no known method for accurately measuring the temperature of the gas phase of combustion products within a solid fuel flame. The industry standard is a suction pyrometer and thermocouple which is intrusive, both spatially and temporally averaging, and difficult to use. In this work a new method utilizing the spectral emission from water vapor is investigated through modeling and experimental measurements. This method was demonstrated along a $0.75 \mathrm{~m}$ line of sight, averaged over 1 minute in the products of a natural gas flame but has the potential to produce a spatial resolution on the order of $5 \mathrm{~cm}$ and a temporal resolution of less than 1 millisecond. The method employs the collection of infrared emission from water vapor over discrete wavelength bands and then uses the ratio of those emissions to infer temperature. A 12.5 $\mathrm{mm}$ lens has been positioned within a water cooled probe to focus flame product gas emission into an optical fiber where the light is transmitted to a Fourier Transform Infrared Spectrometer (FTIR). The same optical setup was also used to collect light from a black body cavity at a known temperature in order to calibrate the spectral sensitivity of the optical system and FTIR detector. Experiments were conducted in the product gas of a $150 \mathrm{~kW}_{\text {th }}$ methane flame comparing the optical emission results to a suction pyrometer with type $\mathrm{K}$ thermocouple. The optical measurement produced gas temperatures approximately $1-4 \%$ higher than the suction pyrometer. Broadband background emission was also seen by the optical measurement and was removed assuming grey body radiation. This background emission can be used to determine particle emission temperature and intensity. Additional work will be needed to demonstrate the method under conditions with significant particle emission. Additional work is also needed to demonstrate the work over a smaller path length and shorter time scale.

Keywords: infrared, spectral, temperature, $\mathrm{H}_{2} \mathrm{O}$, FTIR 


\section{ACKNOWLEDGEMENTS}

I would like to acknowledge help from many different sources. Above all, I acknowledge the help I have received from Heavenly Father during the course of this project. Secondly I would like to thank Air Liquide for the project's funding. I would not have been able to complete this thesis without Dr. Dale Tree's continued guidance and advice. Lastly I would like to thank my family, friends and co-workers for all their support. 


\section{TABLE OF CONTENTS}

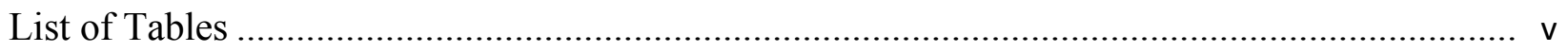

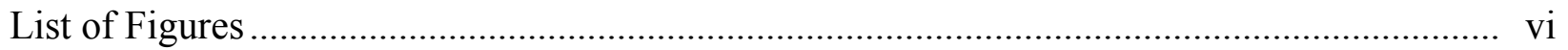

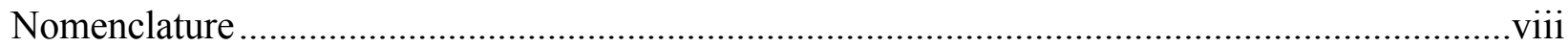

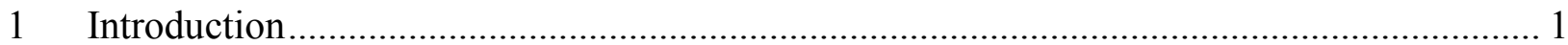

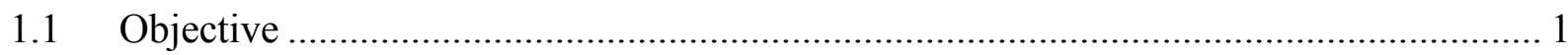

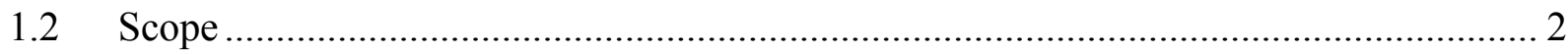

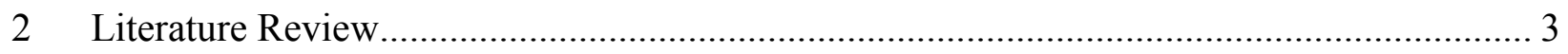

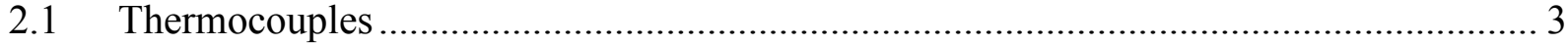

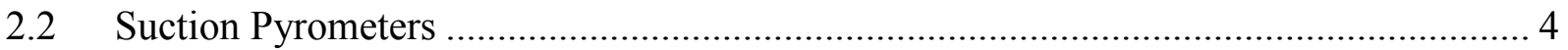

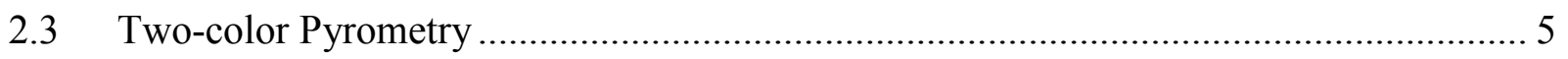

2.4 Coherent Anti Stokes Raman Spectroscopy (CARS) ……………............................. 6

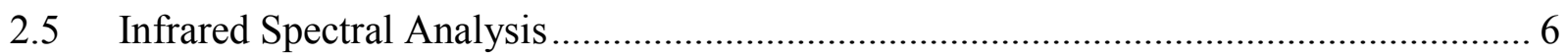

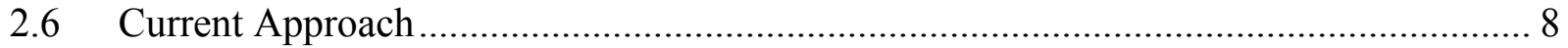

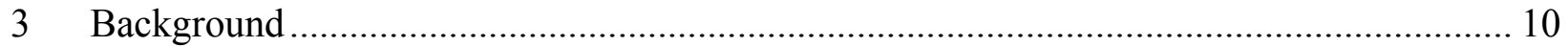

3.1 Radiative Transfer Equation - Theory ................................................................... 10

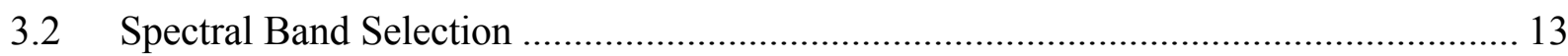

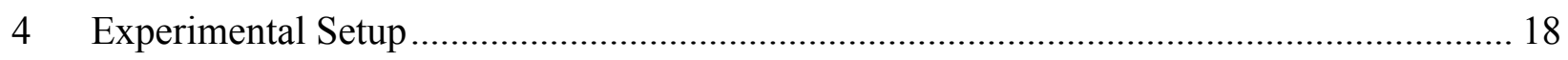

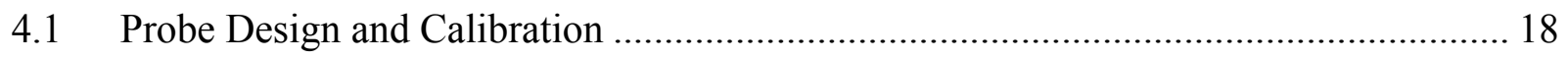

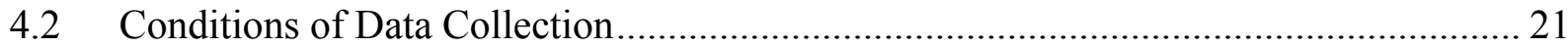

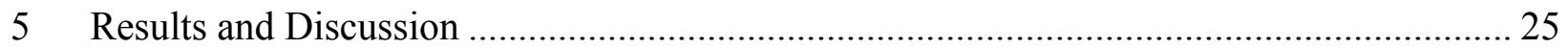

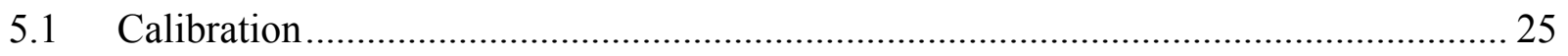

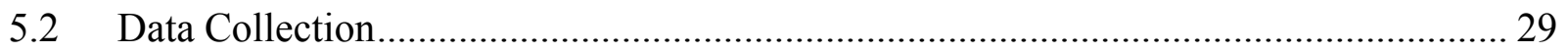

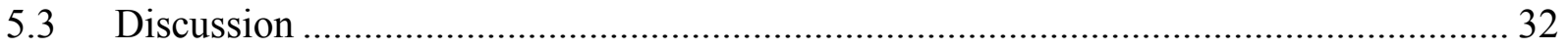

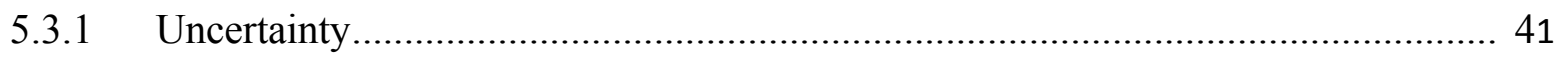

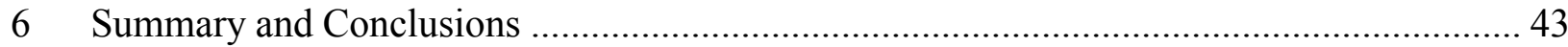

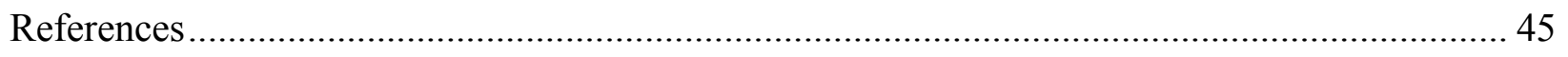

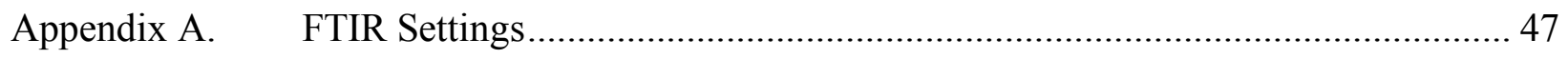

Appendix B. Optical Time Progression Data........................................................................ 48 


\section{LIST OF TABLES}

Table 3.1 - Subsections and their wavenumber bands 16

Table 4.1 - Test conditions using the BFR .......................................................................... 24

Table 5.1 - Steady state values of the broadband removal temperature for all three conditions compared to the wall temperature

Table 5.2 - Steady state values of the three integrated ratio pairs for all three conditions compared to suction pyrometer temperatures with background correction........................ 42

Table 5.3 Calculation of the total uncertainty at two temperatures ........................................ 44 


\section{LIST OF FIGURES}

Figure $3.1-\mathrm{CO}_{2}$ and $\mathrm{H}_{2} \mathrm{O}$ emission intensity between $600-7400 \mathrm{~cm}^{-1}$ at a temperature of $1200 \mathrm{~K}$, optical path length of $0.5 \mathrm{~m}$, pressure of $1 \mathrm{~atm}$, and a concentration of $10 \% \ldots . .13$

Figure $3.2-\mathrm{H}_{2} \mathrm{O}$ emission intensity between $5185-5800 \mathrm{~cm}^{-1}$ at a temperature of $1200 \mathrm{~K}$, optical path length of $0.5 \mathrm{~m}$, pressure of $1 \mathrm{~atm}$, and a concentration of $10 \% \ldots \ldots \ldots . . .15$

Figure $3.3-\mathrm{H}_{2} \mathrm{O}$ emission intensity between $5185-5800 \mathrm{~cm}^{-1}$ at a temperature of $1200 \mathrm{~K}$, optical path length of $0.5 \mathrm{~m}$, pressure of $1 \mathrm{~atm}$, and a concentration of $10 \%$, split into subsections A-E by color 16

Figure 3.4 - Correlation lines for the ratios E/A, E/B, and E/C between $300-3000 \mathrm{~K} \ldots \ldots \ldots \ldots . . . .17$

Figure 3.5 - Intensity values for integrated band A for increasing concentrations of $\mathrm{H}_{2} \mathrm{O} \ldots \ldots \ldots . .18$

Figure 3.6 - Integrated band ratio E/B values for increasing concentrations of $\mathrm{H}_{2} \mathrm{O} \ldots \ldots \ldots \ldots \ldots . . \ldots$

Figure 4.1 - Diagram of optical probe comprised of outer casing, lens holder, lens, fiber holder, fiber, and argon purge lines............................................................. 20

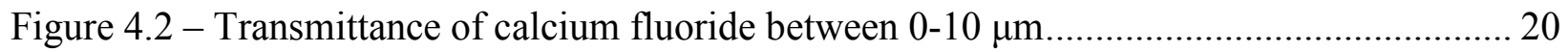

Figure 4.3 - Optical Pyrometer and FTIR interface ......................................................... 21

Figure 4.4 - Experimental setup featuring the BFR, Optical Pyrometer, Suction

Pyrometer and the FTIR 22

Figure 5.1 - Measured FTIR signal at a BB temperature of $1100^{\circ} \mathrm{C}$ (approx.

$1373 \mathrm{~K}$ ) from $3600-5900 \mathrm{~cm}^{-1}$ with the calculated Planck curve at the same temperature... 28

Figure 5.2 - A comparison of the FTIR signal versus the calculated Planck equation 29

Figure 5.3 - A comparison of a smooth FTIR signal versus the calculated Planck equation ...... 29

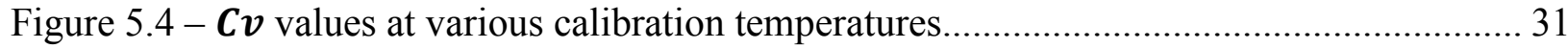

Figure 5.5 - Temperatures measured with the suction pyrometer..................................... 32

Figure 5.6- FTIR measured signal for Condition 1 ........................................................ 33

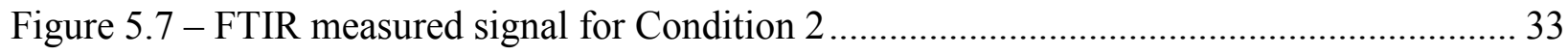

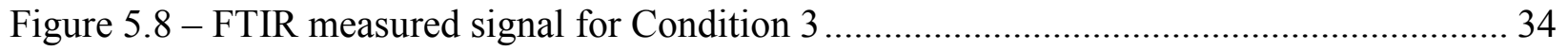


Figure 5.9 - Intensity data showing two gray body fit sections (red) with the proposed gray body Planck line for correction (green)

Figure 5.10 - Corrected intensity data

Figure 5.11 - Resultant temperatures for Condition 1 during a startup time progression for the three integrated ratio pairs without background correction compared to the suction pyrometer, adiabatic and wall temperature, time (x-axis) is from the initial ignition of the reactor

Figure 5.12 - Resultant temperatures for Condition 1 during a startup time progression for the three integrated ratio pairs with background correction compared to the suction pyrometer, adiabatic and wall temperature, time (x-axis) is from the initial ignition of the reactor.

Figure 5.13 - Resultant temperatures for Condition 2 during a startup time progression for the three integrated ratio pairs without background correction compared to the suction pyrometer, adiabatic and wall temperature, time (x-axis) is from the initial ignition of the reactor

Figure 5.14 - Resultant temperatures for Condition 2 during a startup time progression for the three integrated ratio pairs with background correction compared to the suction pyrometer, adiabatic and wall temperature, time (x-axis) is from the initial ignition of the reactor

Figure 5.15 - Resultant temperatures for Condition 3 during a startup time progression for the three integrated ratio pairs without background correction compared to the suction pyrometer, adiabatic and wall temperature, time (x-axis) is from the initial ignition of the reactor

Figure 5.16 - Resultant temperatures for Condition 3 during a startup time progression for the three integrated ratio pairs with background correction compared to the suction pyrometer, adiabatic and wall temperature, time (x-axis) is from the initial ignition of the reactor

Figure 5.17 - Steady state data of the three integrated ratio pairs for all three conditions compared to suction pyrometer temperatures with background correction 
$I$ is the intensity $\left(\mathrm{W} / \mathrm{m}^{2} / \mathrm{sr} / \mu \mathrm{m}\right)$

$I_{b}$ is the intensity of a black body radiator $\left(\mathrm{W} / \mathrm{m}^{2} / \mathrm{sr} / \mu \mathrm{m}\right)$

$\kappa$ is the absorption coefficient $\left(\mu \mathrm{m}^{-1}\right)$

$\eta$ is the wave number $\left(\mathrm{cm}^{-1}\right)$

$\hat{s}$ is the path coordinate $(\mu \mathrm{m})$

$\beta$ is the extinction coefficient $\beta=\kappa+\sigma\left(\mu \mathrm{m}^{-1}\right)$

$\sigma$ is the scattering coefficient $\left(\mu \mathrm{m}^{-1}\right)$

$\Phi$ is the scattering phase function

$s$ is the path length $(\mathrm{mm})$

$C_{l}$ is a radiation constant

$C_{2}$ is a radiation constant 


\section{INTRODUCTION}

Temperature measurements used to assess, characterize, and understand the physical processes occurring in flames are notoriously difficult to make and are of questionable accuracy. High temperatures and corrosive environments make it very difficult to acquire in situ measurements with good temporal and spatial resolution. Additionally, thermocouples are limited to temperatures below $1650^{\circ} \mathrm{C}$. The most common optical method for measuring temperature is two-color pyrometry. This technique provides the solid particle temperature of either soot or burning char or some combination of the two but does not provide a gas temperature.

\subsection{Objective}

The objective of this work is to explore a method for measuring temperature using the infrared emission from combustion products. The focus resides in three major areas, the development of a theoretical model that provides the transfer function needed for the temperature measurement, the design and fabrication of a probe to collect the infrared emission from a flame, and experimental validation of the method comparing the optical emission measurement with a suction pyrometer temperature.

The model utilizes spectral absorption coefficients developed by (J.T. Pearson 2014) to model spectral emission as a function of gas pressure and temperature. Spectral bands are then integrated to determine the bands that can be integrated and correlated to the temperature. The

probe design and fabrication consists of designing a probe that can collect emission from the 
Burner Flow Reactor (BFR) at BYU. The probe will be required to collect emission in a high temperature particle laden environment and transmit the emission to a Fourier Transform InfraRed (FTIR) spectrometer for measurement. Lastly, the probe and FTIR will be used to collect emission data and using a calibration, convert voltages to intensities and produce a gas temperature which will be compared to the temperature measured by a suction pyrometer. These tests will be performed primarily in natural gas flames where soot loading is low.

\subsection{Scope}

As was previously discussed, the work presented in this research spans from the development of a model showing spectral emission for $\mathrm{H}_{2} \mathrm{O}$ at different temperatures and concentrations to the collection of actual emission data from a reactor. This included: 1) The development of a method for identifying spectral bands that could be used to measure temperature and establishing a correlation between temperature and spectral emission; 2) The designing and fabrication of an optical probe; 3) The collection of data using the probe and validation using a suction pyrometer. The work used an existing reactor for the data collection portion. This work did not involve the development of the spectral absorption distribution function. It also does not include the demonstration of this technique in particle laden flames or for situations with high spatial and temporal resolution.

Future work in this area could lead to the determination of separate heat flux intensities for gaseous and particle emissions, gas species concentrations for $\mathrm{H}_{2} \mathrm{O}$ and $\mathrm{CO}_{2}$, and separate gas and particle temperatures. However, these outcomes are not within the scope of this project. 


\section{LITERATURE REVIEW}

This chapter provides a literature review of current temperature measurement methods including physical probes and optical methods. While not all methods are presented, the focus is on those commonly used and those most closely related to the method being investigated. These sections provide context for the methods and results found in this research, as well as the motivation for developing a new method of temperature measurement. The most common methods employed in flames include: 1) Thermocouples; 2) Suction Pyrometers; and 3) Two-color Pyrometry. Following these methods are a variety of optical methods that employ spectral characteristics of gases to infer the temperature.

\subsection{Thermocouples}

Thermocouples are widely used in many different temperature measurement applications. This is due to the fact that they are inexpensive, robust and easy to implement. Thermocouples are comprised of two dissimilar conductors that contact each other at the measuring end called the bead. A temperature can be measured due to the voltage differential that is produced. One issue with directly measuring the temperature of a flame is the fact that material property limitations prevent thermocouples from measuring temperatures above $1650^{\circ} \mathrm{C}$. Flame temperatures routinely exceed this limit, preventing thermocouples from taking in situ measurements. When using thermocouples in gases surrounded by cool walls, large errors due to both radiative and conductive heat loss occur (Heitor 1993). The use of fine wires removes the majority of conduction losses, 
however radiative losses continue to be an issue at higher temperatures and can contribute to errors of hundreds of degrees (D. Bradley 1968). Soot particles and reactor wall temperatures higher than the gas temperature can also produce emissions which contribute significantly to radiation error when using thermocouples (F.C. Lockwood 1982). Correcting for these effects can be difficult as the uncertainties due to the convective heat transfer coefficient, the bead size, shape and emissivity as well as the temperature and emissivity of the surroundings all affect the signal (A.H.K. Sato 1975, R. Viskanta 1987). Currently no models exist that completely solve these issues, and as a result, suction pyrometers are often used for high temperature combustion environments (L.G. Blevins 1999).

\subsection{Suction Pyrometers}

Suction pyrometers, or aspirated thermocouples, work by extracting the combustion gases into a probe in order to pass the sample at high velocity over a shielded thermocouple. This results in a high convective heat transfer which more closely represents the actual gas temperature and avoids complications due to radiative heat losses (J.S. Newman 1979, A. Z'Graggen 2007). This method also allows for extended thermocouple life by protecting the bead from oxidizing agents or species which might react at the surface. As a result, this process is an improvement upon a bare wire thermocouple for some applications, however, a sacrifice to the spatial and temporal resolution of the measurement occurs. The level of spatial resolution as well as the accuracy of the measurement depends on the aspiration rate of the probe. At higher aspiration rates, the agreement between the thermocouple and gas temperature measurement improves, but the spatial resolution decreases significantly as the volume of the gas sampled is related to the velocity of the aspirated air. The ASTM recommended rate for the aspirated air is $5 \mathrm{~m} / \mathrm{s}$, which shows a significant improvement over an open wire thermocouple measurement, however, other sources recommend 
rates upwards of $150 \mathrm{~m} / \mathrm{s}$ in an attempt to more accurately characterize the true temperature (L.G. Blevins 1999). Smaller burners are not able to support such high aspiration rates due to the volume flow rate required. Even with high aspiration rates, time response can be an issue as the probe can take up to 3 minutes to reach equilibrium temperature and then 1 minute for every change in $100^{\circ} \mathrm{C}$ (S.C. Kim 2008). In solid fuel flames, molten ash particles can produce rapid deposition, which can become a problem as the sampling probe can become clogged and will not allow for the desired flow velocity (L.G. Blevins 1999).

\subsection{Two-color Pyrometry}

Two-color pyrometry is an optical method that compares two colors of the visible broadband spectrum in order to determine a temperature. Initially this method was applied along a single line of sight using band pass filters and detectors. More recently, the method has been demonstrated and used with a color digital camera where each pixel in the camera acts as a detector. An RGB camera records intensity values for the red, blue and green light collected for each pixel. Each pixel is evaluated and analyzed in order to determine a respective temperature and an emissivity. This method has been known to work well in applications with broadband emission and is widely used. The main drawback of this method is the fact that it works only when solid particles such as soot, coal or ash are present. It also provides only a line-of-sight result that is weighted toward the higher temperatures along the line. Gray or spectrally dependent radiative emission models are necessary to process results (T. Draper 2012). While this method can be applied successfully to objects that fit the gray body assumption, coal flames have been found to be more complex and the models used to determine temperature show significant temperature differences when compared to each other (T. Draper 2012). 


\subsection{Coherent Anti Stokes Raman Spectroscopy (CARS)}

A method known as Coherent anti-Stokes Raman Spectroscopy (CARS) has been investigated as a possible method for determining temperature and concentrations in combustion environments. CARS combines three coherent beams (a probe beam, pump beam, and stokes beam) to produce a coherent excited beam. Because this excited beam is coherent and at a specific wavelength, the signal can be isolated using optical filters. This relatively large signal strength has the potential to be larger than background or particle radiation. The measurement volume being made of intersecting laser beams provides good spatial as well as excellent temporal resolution (R.L. Farrow 1982). The primary disadvantages to this method include the need for laser sources that have excellent intensity stabilization, optical alignment, and a fairly complicated and expensive experimental setup and significant post processing of the data (R.L. Farrow 1982). CARS has only been demonstrated in coal flames assisted by natural gas which reduces particle loading and interference. It has not been demonstrated in unassisted coal flames, and is difficult to implement in industrial settings.

\subsection{Infrared Spectral Analysis}

While there are many other techniques employed to measure temperature, this section focuses on those most similar to the new method being investigated, or methods which employ spectral band emission from gases.

The initial concept of measuring temperature from gas rotational spectra was introduced in 1977 by Griffith and Anderson (R.J. Anderson 1977). Two methods were used to measure the temperature of $\mathrm{CO}$ between the ranges of $300-425 \mathrm{~K}$ with an FTIR. The first method used peak values of measured CO spectra and compared them against stored spectrum of an empty test cell, the second used line width calculations. These methods resulted in excellent error levels at room 
temperature with steadily increasing error as the temperature increased to $425 \mathrm{~K}$ (R.J. Anderson 1977). The first method of least-squares regression fit for peak values of absorbance lines was demonstrated on pure $\mathrm{CO}_{2}$ by infrared absorption spectroscopy just over a decade later using an electrically heated gas cell at temperatures ranging from 363-463 K (L.A. Gross 1988). At the same time, work was being done that reported the use of $\mathrm{CO}_{2}$ emission measurements to infer gas temperature on a coal flame using emission transmission spectroscopy (P.R. Solomon 1988). This work used the peak emission from the $4.3 \mu \mathrm{m}\left(2325 \mathrm{~cm}^{-1}\right)$ band of $\mathrm{CO}_{2}$, and fit a Planck, black body, intensity function to the measured spectra to infer temperature. The approach requires the concentration of $\mathrm{CO}_{2}$ to be high enough that the absorption coefficient is unity for a significant fraction of the band. This also prevents the data from being used to determine $\mathrm{CO}_{2}$ concentration.

High-resolution transmission data of $\mathrm{CO}_{2}$ using a heated gas cell have been measured, however thus far the data has been used to compare against and validate line by line high temperature $\mathrm{CO}_{2}$ absorption models, not for the measurement of temperature and not for combustion products (Evseev 2012).

Recently, Modest et al. developed a method which utilizes a radiation model and FTIR measurement to infer temperature (T. Ren 2013). In this method, the model and measurement spectrum are compared by adjusting $\mathrm{CO}_{2}$ concentration and temperature in the model until they fit the measured spectrum. The model predicts the transmissivity of $\mathrm{CO}_{2}$ as would be measured by an FTIR as a function of pressure, temperature, concentration and path length. The temperature and concentration are then varied in the model until the predicted spectra best fits the measured spectra. The resolution used is $4 \mathrm{~cm}^{-1}$ for $\mathrm{CO}_{2}$ in $\mathrm{N}_{2}$.

An experiment using a shock tube system was used to diagnose the possibilities of using $\mathrm{H}_{2} \mathrm{O}$ bands to determine temperature and concentration in scramjet engine flows (T.E. Parker 
1996). Known mixtures of $\mathrm{H}_{2} \mathrm{O}, \mathrm{N}_{2}, \mathrm{O}_{2}$, and $\mathrm{Ar}$ were shock heated to temperatures ranging from $1400 \mathrm{~K}$ to $3000 \mathrm{~K}$ and measured data were compared to known band models. The temperature was determined by fitting modeled spectra to the measured data and using the temperature which provided the best fit. While this demonstrated the use of the spectra to obtain temperature, the concentration of gases needs to be known in order to use the method.

Clausen (1996) performed optical temperature measurements using $\mathrm{CO}_{2}$ as the subject gas with a water cooled probe, optical fiber, and FTIR. Measurements of emission were taken near the $2350 \mathrm{~cm}^{-1}$ band, and as with work done by Solomon et al. (P.R. Solomon 1988), the peaks of the $\mathrm{CO}_{2}$ band emissions were fit with a Planck curve to infer temperature. The experiment mapped the cross section of a 1.3 MW reactor and data were validated using a suction pyrometer, good agreement was observed between the suction pyrometer and the optical measurement (Clausen 1996).

More recently, an optical probe measuring a lignite coal flame in a $77 \mathrm{~kW}_{\text {th }}$ reactor was used to measure particle radiation using a least squares regression fit of a Planck curve on the broadband sections of the measured spectra. Gas temperature was not calculated from $\mathrm{CO}_{2}$ or $\mathrm{H}_{2} \mathrm{O}$ emission bands. The experiment showed that within the coal flame region, particle radiation was the dominant radiation source due to high particle densities (D. Backstrom 2014).

\subsection{Current Approach}

The method proposed in this work differs significantly from all other methods previously discussed in that this technique will ratio the measured integrated spectral signal over bands of $100-150 \mathrm{~cm}^{-1}$ between 5185 and $5800 \mathrm{~cm}^{-1}$ and then utilize the ratio of those integrated bands to infer the temperature. The relationship between the ratio of band emissions and temperature is determined through the modeled integrated emission. Previous methods used direct line 
comparison of collected spectra or Planck curve line fitting with a unity assumption. These methods require data acquisition at high resolution and the uncertainty is dependent on the absolute value of the calibration. Any deposition on the probe or misalignment of optical components that alter the signal produce a shift in the inferred temperature. In other methods, it is assumed that $\mathrm{CO}_{2}$ emissivity is unity, limiting the method to instances where higher concentrations of $\mathrm{CO}_{2}$ are present. The use of an FTIR is necessary for these methods, limiting commercial application. By utilizing the integrated ratios, the need for spectral resolution and precise measurement of the spectrum with the FTIR is reduced. The ratio method also reduces the need for absolute calibration of the detectors and optical system and enables the technique to be used in future work with optical filters and detectors, without the need for an FTIR. Using filters and detectors would increase the temporal resolution of the method dramatically and allow for response times of less than a second without the need for post processing to determine the temperature. This flexibility is a major improvement and allows for the method to be commercially viable in future iterations. 


\section{BACKGROUND}

This chapter provides the background information needed to understand and evaluate the integral band method for temperature measurement. The chapter begins by reviewing the radiative transfer equation and the assumptions applicable for this application that enable a solution relating the measured intensity to the temperature and concentration of $\mathrm{H}_{2} \mathrm{O}$. A discussion is then provided describing how a model was used to determine the relationship between the ratio of integrated band intensities and the temperature.

\subsection{Radiative Transfer Equation - Theory}

Radiative emission from participating media can be characterized by the radiative transfer equation shown in Equation (3.1).

$$
\frac{d I_{n}}{d s}=\kappa_{n} I_{b, n}-\beta_{n} I_{n}+\frac{\sigma_{s, n}}{4 \pi} \int_{4 \pi} I_{n}\left(\hat{s}_{i}\right) \Phi_{n}\left(\hat{s}_{i}, \hat{s}\right) d \Omega
$$

Assuming scattering to be negligible the equation simplifies to:

$$
\frac{d I_{n}}{d s}=\kappa_{n} I_{b, n}-\kappa_{n} I_{n}
$$

Negligible scattering is an excellent assumption for gases and is normally acceptable for soot particles because their size is so small that the concentration must be unusually large for scattering. This assumption is also typically good for most combustion flows because the concentration of the larger particles is relatively low compared to the fine particles for which scattering is negligible. In this work, particles were not present except for a few exploratory cases. 
A further assumption of a uniform temperature and a uniform absorption coefficient along the path, s, produces the solution shown in Equation 3.3.

$$
I_{n}(s)=I_{b, n}\left(1-\exp \left(-\kappa_{n} s\right)\right)
$$

Where:

$$
\begin{gathered}
I_{b, \eta}=\frac{C_{1}}{\pi * \eta^{5} *\left(\exp \left(\frac{C_{2}}{\eta T}\right)-1\right)} \\
\kappa_{n}=C_{a b s} \frac{P_{i} N_{A}}{R T}
\end{gathered}
$$

and $C_{a b s}, P_{i}, R, N_{A}$ and $T$ are the absorption cross section, partial pressure, Avogadro's number, the ideal gas constant and absolute temperature respectively.

By definition, a flame is a region of high temperature and concentration gradients and therefore the uniform temperature assumption is only valid in post flame regions. The assumption is also more likely to be valid in post flame regions where the path length is short. The measurements obtained in this work will be done in post flame regions of uniform temperature and concentration over a long path length $(750 \mathrm{~mm})$. Future work will look at reducing the path length and quantify errors associated with non-uniform temperature and species distributions.

The absorption cross sections required to produce an intensity from a known concentration and temperature were obtained from the work of Pearson (2013) who used the Voigt profile and the spectroscopic data from the HITEMP 2010 database (L.S. Rothman. I.E.G 2010). The cross sections were tabulated according to pressure and concentration at intervals of $0.005 \mathrm{~cm}^{-1}$.

Figure 3.1 shows the spectral intensity for $\mathrm{CO}_{2}(10 \%)$ and $\mathrm{H}_{2} \mathrm{O}(10 \%)$ at an optical path length of $0.5 \mathrm{~m}$ at $1200 \mathrm{~K}$ using the spectral absorption cross sections developed by Pearson (2013). These concentrations and temperatures are values similar to those expected in the products of coal 
and natural gas flames and therefore provide some indication of the spectral regions where IR emissions will be highest for these gases.

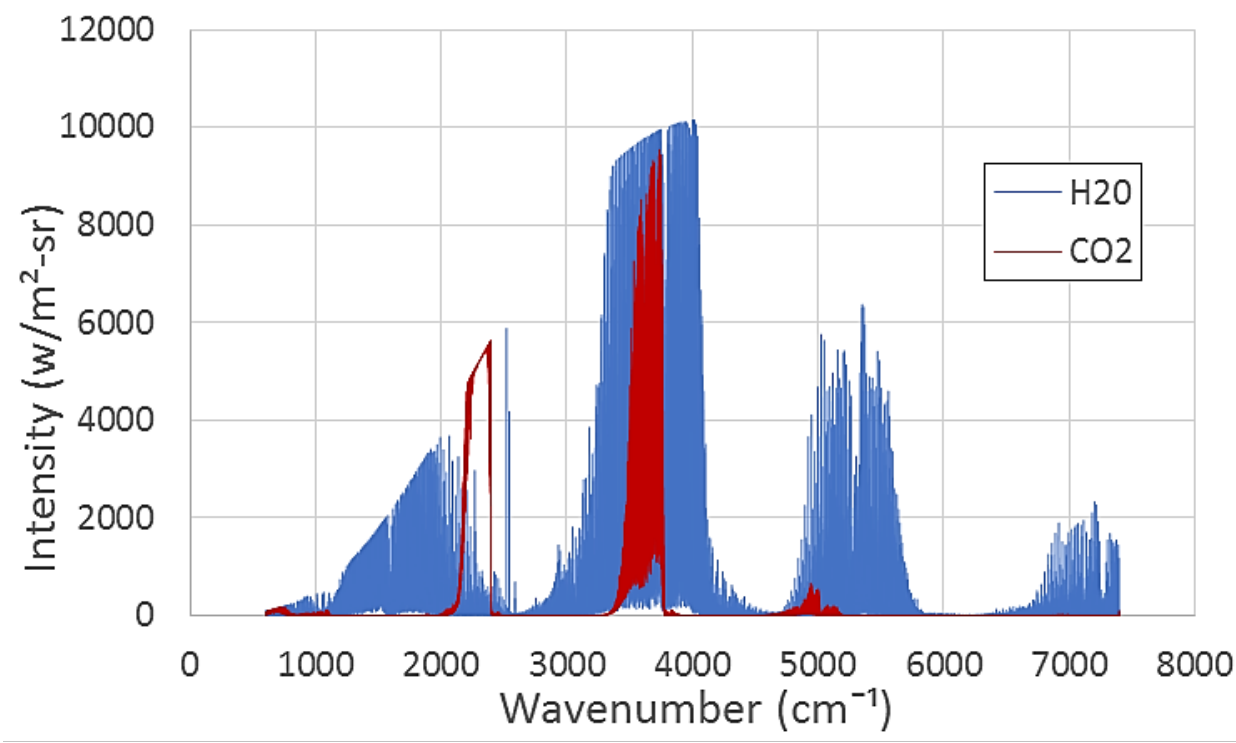

Figure 3.1 - $\mathrm{CO}_{2}$ and $\mathrm{H}_{2} \mathrm{O}$ emission intensity between $600-7400 \mathrm{~cm}^{-1}$ at a temperature of $1200 \mathrm{~K}$, optical path length of $0.5 \mathrm{~m}$, pressure of $1 \mathrm{~atm}$, and a concentration of $10 \%$

Inspection of these gaseous emissions allows for a better understanding of the temperature measurement methods discussed previously. For $\mathrm{CO}_{2}$ in the $2100-2400 \mathrm{~cm}^{-1}$ region and for $\mathrm{H}_{2} \mathrm{O}$ between 1100 and 2000 and between 3500 and $4200 \mathrm{~cm}^{-1}$, many of the emission peaks are saturated and the bands take on the shape of the Planck distribution. As discussed earlier, existing techniques by Clausen et al. (Clausen 1996) and Solomon et al. (P.R. Solomon 1988) fit these regions with the Planck equation (Equation (3.4)) to obtain a gas temperature. This can work well when the combined concentration and path length are large but cannot be utilized over smaller path lengths and lower concentrations.

Ren et al. (T. Ren 2013) changed temperature and concentration in their model of the gas transmission in an attempt to match the measured transmission spectra in the FTIR. This technique is challenging because the FTIR truncates and shifts the individual spectral line peaks as a result 
of the Fourier Transform process used to measure the data. This requires Ren et al. (T. Ren 2013) to also transform the modeled spectrum in order to match the measured result.

The method proposed in this work develops a relationship between the ratio of two integrated spectral bands and the temperature. Both processes, integration and the use of a measured ratio rather than an absolute value, result in a reduction of possible error associated with the use of emission measurements for temperature. Utilizing an integrated spectral band also enables the emission data to eventually be collected with a single detector and band pass filter rather than requiring detailed spectral data. The approach used here is to determine and test appropriate bands with the FTIR and then utilize band pass filters and detectors in future work.

\subsection{Spectral Band Selection}

The spectral bands were selected by a study of the modeled spectrum and by testing numerous integrated ratios and their relation to temperature. Saturated bands were not necessary with the ratio method used in this work.

The FTIR has a preferred range of $600-7400 \mathrm{~cm}^{-1}$ when using an MCT detector coupled with a KBr beam-splitter. This enables collection over the entire spectrum shown in Figure 3.1. The collection of IR emission from hot $\mathrm{H}_{2} \mathrm{O}$ and $\mathrm{CO}_{2}$ requires that there is no absorption of colder $\mathrm{H}_{2} \mathrm{O}$ and $\mathrm{CO}_{2}$ between the gas and the detector. This is most easily accomplished by the use of optical fibers. While expensive optical fibers can be found which transmit in the longer IR wavelengths, inexpensive optical fibers are available with a transmissivity above $90 \%$ within 4545 to 25000 $\mathrm{cm}^{-1}$. Focusing on the region between 4545 and $7400 \mathrm{~cm}^{-1}$, in Figure 3.1, it can be seen that $\mathrm{H}_{2} \mathrm{O}$ will produce a stronger signal than $\mathrm{CO}_{2}$. Furthermore, $\mathrm{CO}_{2}$ will produce a significant fraction of the emission in the range from 4545 to $5185 \mathrm{~cm}^{-1}$ that would interfere or add to the $\mathrm{H}_{2} \mathrm{O}$ signal. It was therefore decided to focus on the $\mathrm{H}_{2} \mathrm{O}$ emission between 5185 and $5800 \mathrm{~cm}^{-1}$ which is shown 
as an isolated region in Figure 3.2. The desired spectral region will vary based on the optimal optical transmissivity of the equipment used.

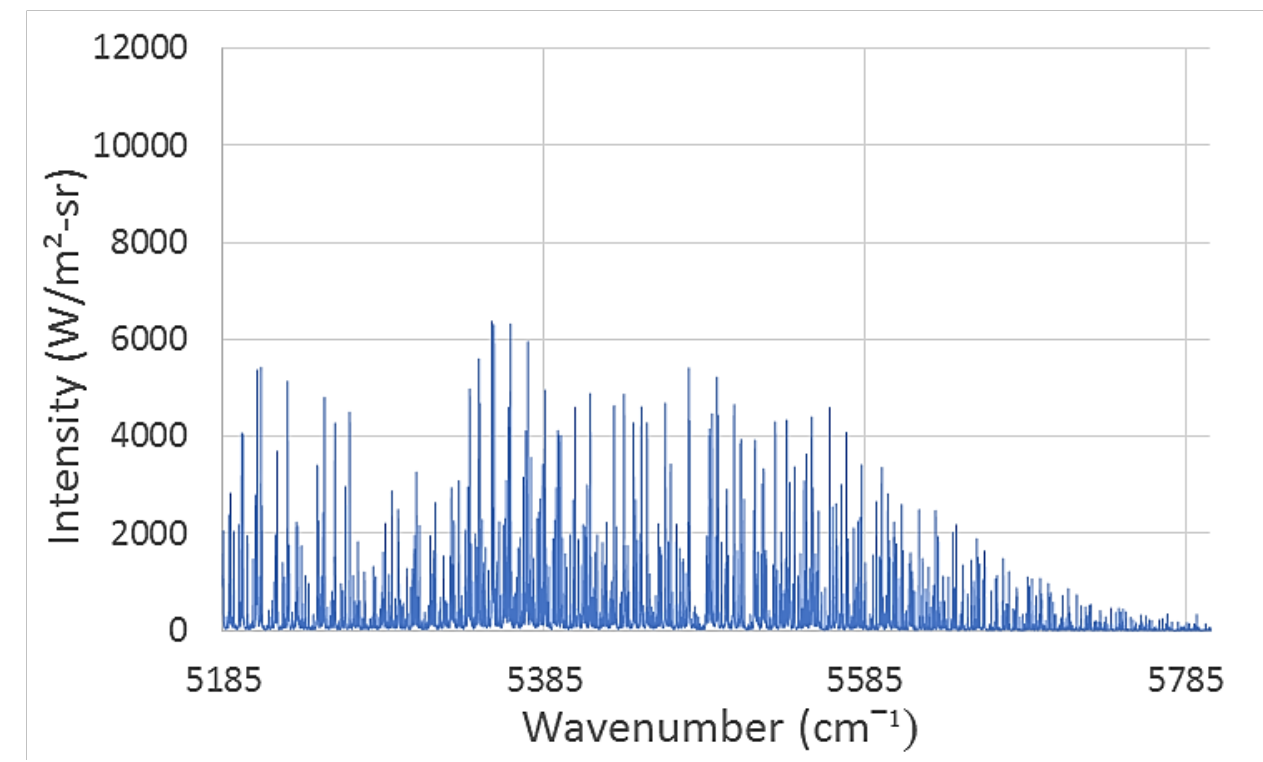

Figure $3.2-\mathrm{H}_{2} \mathrm{O}$ emission intensity between $5185-5800 \mathrm{~cm}^{-1}$ at a temperature of $1200 \mathrm{~K}$, optical path length of $0.5 \mathrm{~m}$, pressure of $1 \mathrm{~atm}$, and a concentration of $10 \%$

Once the spectral region was selected, bands, or subsections were chosen somewhat arbitrarily, in order to create subsections of equal size. It was desired to select a large enough band that a line would not dominate the signal and to avoid phase shift influence, but small enough that several bands could be considered. Figure 3.3 shows five different bands selected which are identified by letters A through E. The numerical values for each band are given in Table 3.1. 


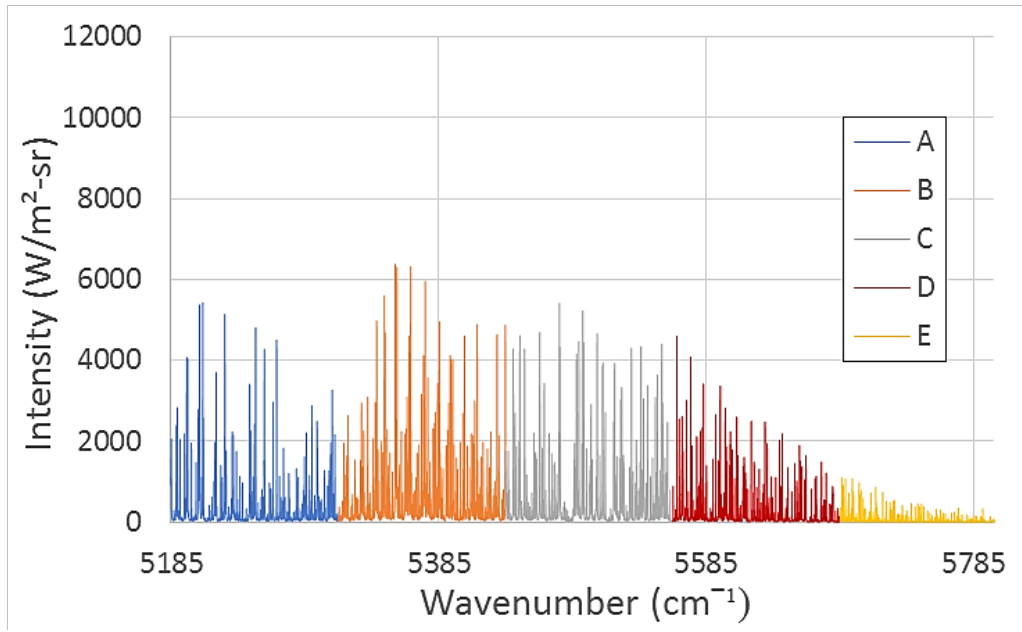

Figure $3.3-\mathrm{H}_{2} \mathrm{O}$ emission intensity between $5185-5800 \mathrm{~cm}^{-1}$ at a temperature of $1200 \mathrm{~K}$, optical path length of $0.5 \mathrm{~m}$, pressure of $1 \mathrm{~atm}$, and a concentration of $10 \%$, split into subsections A-E by color

Table 3.1 - Subsections and their wavenumber bands

\begin{tabular}{|c|c|}
\hline Section & Range $\left(\mathrm{cm}^{-1}\right)$ \\
\hline A & $5185-5310$ \\
\hline B & $5310-5435$ \\
\hline C & $5435-5560$ \\
\hline D & $5560-5685$ \\
\hline E & $5685-5800$ \\
\hline
\end{tabular}

Once the bands were chosen, the sections were integrated numerically using Newton's method as shown in Equation (3.6):

$$
I_{\text {band }}=\int I_{v} d v=\sum_{v_{1}}^{v_{2}} I_{v_{i}} \Delta v_{i}
$$

Which reduces to Newton's method:

$$
I_{\text {band }}=\sum_{v 1}^{v 2} I_{v} \Delta v_{i}
$$

The integral values for each band were then compared using ratios in order to determine if there was a correlation between temperature and resultant intensity:

$$
R_{a / b}=\frac{I_{\text {band }, a}}{I_{\text {band }, b}}
$$


Results for three pairs of integral bands as a function of temperature are shown in Figure 3.4. With five bands, ten possible correlations can be made. All possible correlations for the chosen bands have been tested, however, this work focuses on E/A, E/B and E/C due to several factors. As can be seen in Figure 3.4, these ratio pairs produce monotonic functions where a single temperature is associated with a specific ratio of integrated band emissions. In addition to this, the slope is favorable with the ratio changing a significant and easily measurable amount over the temperatures of interest. Some of the other ratio pairs produced exponentially changing ratios which were with a small slope at low temperature rapidly transitioning to a steep slope. Temperature ratios using region D looked favorable and were initially utilized but for unknown reasons the integrated value of " $D$ " relative to the other integral regions seemed to be larger than predicted. For a given set of data, all three correlations should be in agreement. Any deviation between the correlations indicates a form of bias error.

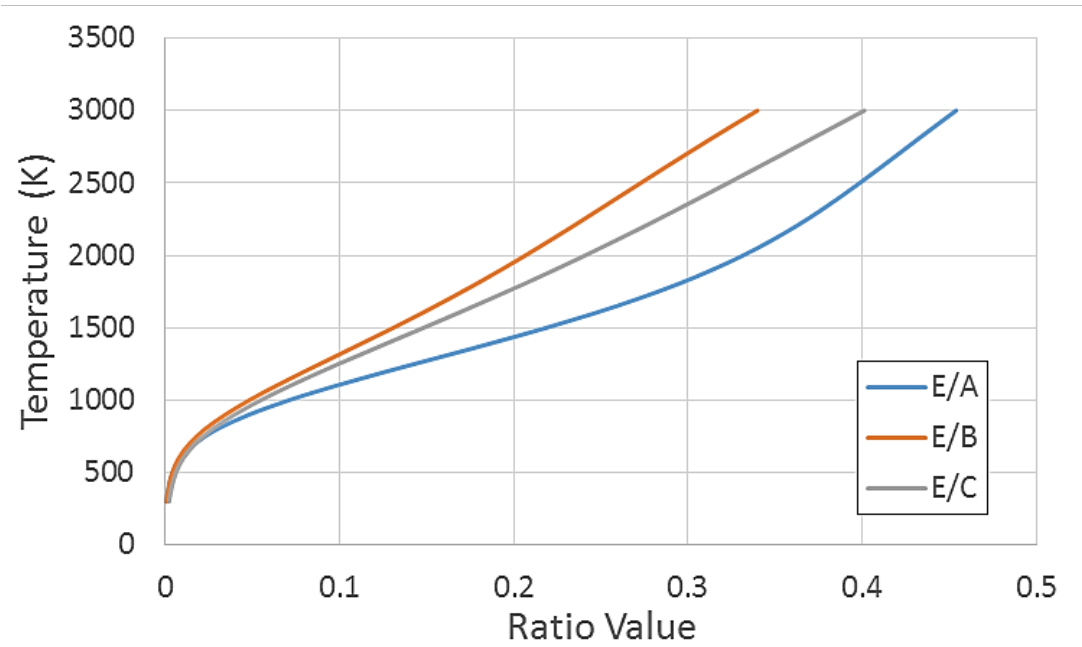

Figure 3.4 - Correlation lines for the ratios E/A, E/B, and E/C between 300 - $3000 \mathrm{~K}$

The integrated band values were tested at multiple concentrations of $\mathrm{H}_{2} \mathrm{O}$ in order to determine the sensitivity of the correlations with respect to changing concentration. Figure 3.5 
demonstrates an increase in intensity with concentration over band A. This increase of magnitude with concentration can be seen with band A-E, and is effectively removed once Equation (3.8) is applied as can be seen in Figure 3.6 for the integrated band ratio of $\mathrm{E} / \mathrm{B}$. These data are representative of all integrated bands as well as each ratio combination used in this work.

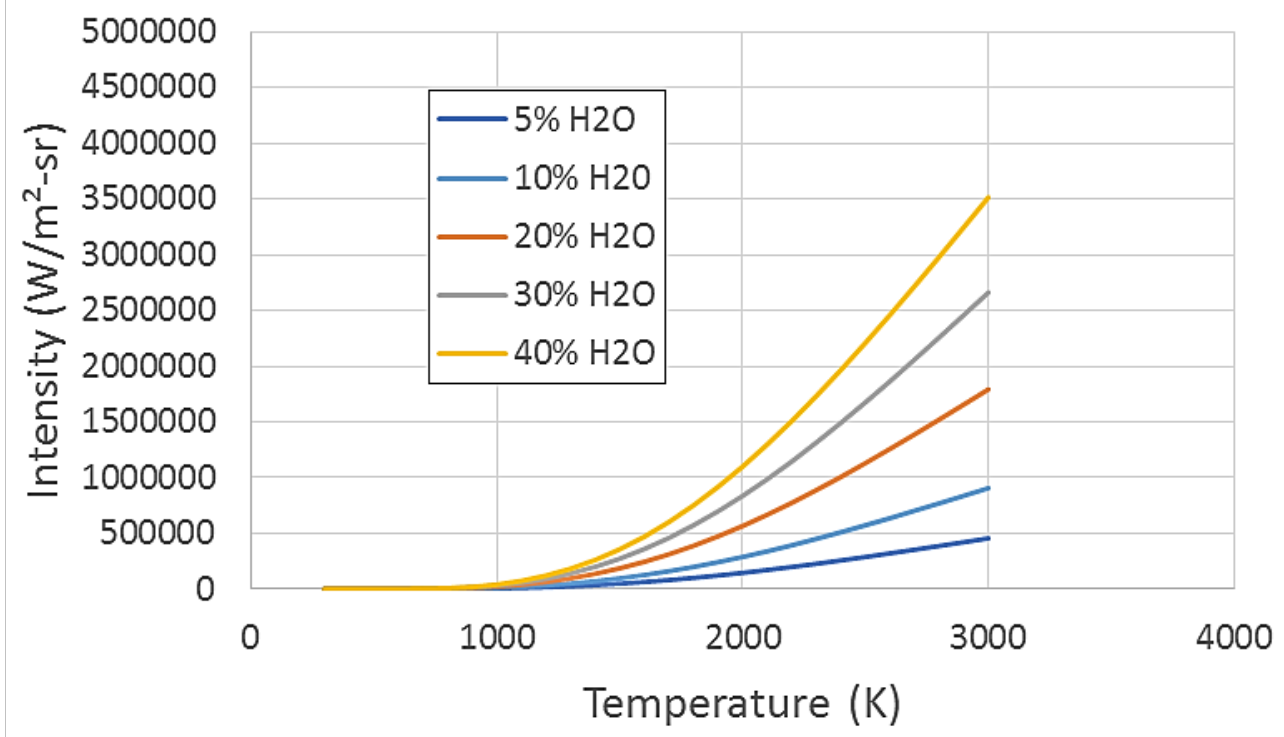

Figure 3.5 - Intensity values for integrated band A for increasing concentrations of $\mathrm{H}_{2} \mathrm{O}$

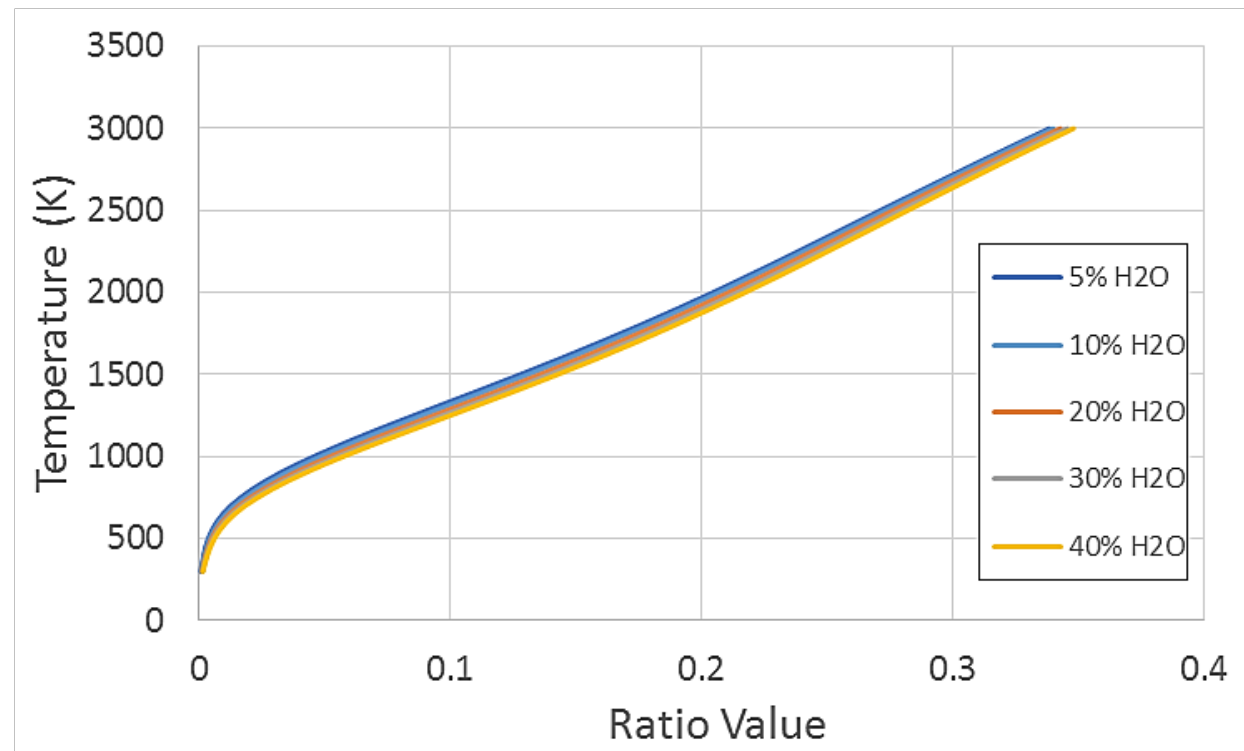

Figure 3.6 - Integrated band ratio E/B values for increasing concentrations of $\mathrm{H}_{2} \mathrm{O}$ 


\section{EXPERIMENTAL SETUP}

This chapter will describe the experimental apparatus and operating conditions used to calibrate the optical pyrometer and to collect the demonstration data.

\subsection{Probe Design and Calibration}

Absorption of water vapor emission by cold water vapor between the measurement volume and the detector (self-absorption) will interfere with the measurement. As a result, a probe including an optical path free of interference was needed. This was accomplished by creating a probe that could be inserted into a water cooled jacket adjacent to the measurement volume with the intent to focus incident intensity into an optical fiber. The fiber acted as a conduit to deliver the intensity to an FTIR spectrometer which was purged with nitrogen. The probe was able to view the horizontal distance $0.75 \mathrm{~m}$ across the reactor. Future testing will involve a cold target and shorter path lengths but in these tests the probe was positioned where the temperature profile was expected to be relatively constant across the diameter of the reactor. The probe tip design shown in Figure 4.1 includes the housing, a focusing lens, and the optical fiber. The probe was purged with argon to avoid absorption by cold gases within the probe. The lens and fiber holders were fabricated out of stainless steel. A plano-convex lens made of calcium fluoride, with a focal length of $25 \mathrm{~mm}$, and a diameter of $12.7 \mathrm{~mm}$ is located within the probe. Calcium fluoride was selected as the lens material because of high transmittance in the IR region as seen in Figure 4.2. 


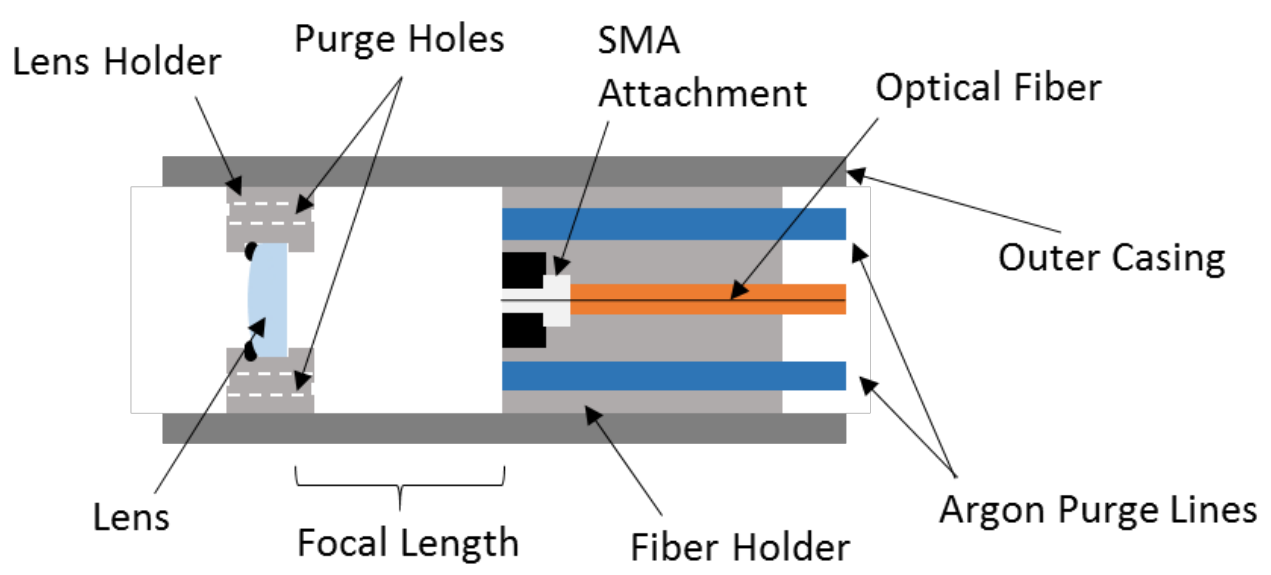

Figure 4.1 - Diagram of optical probe comprised of outer casing, lens holder, lens, fiber holder, fiber, and argon purge lines

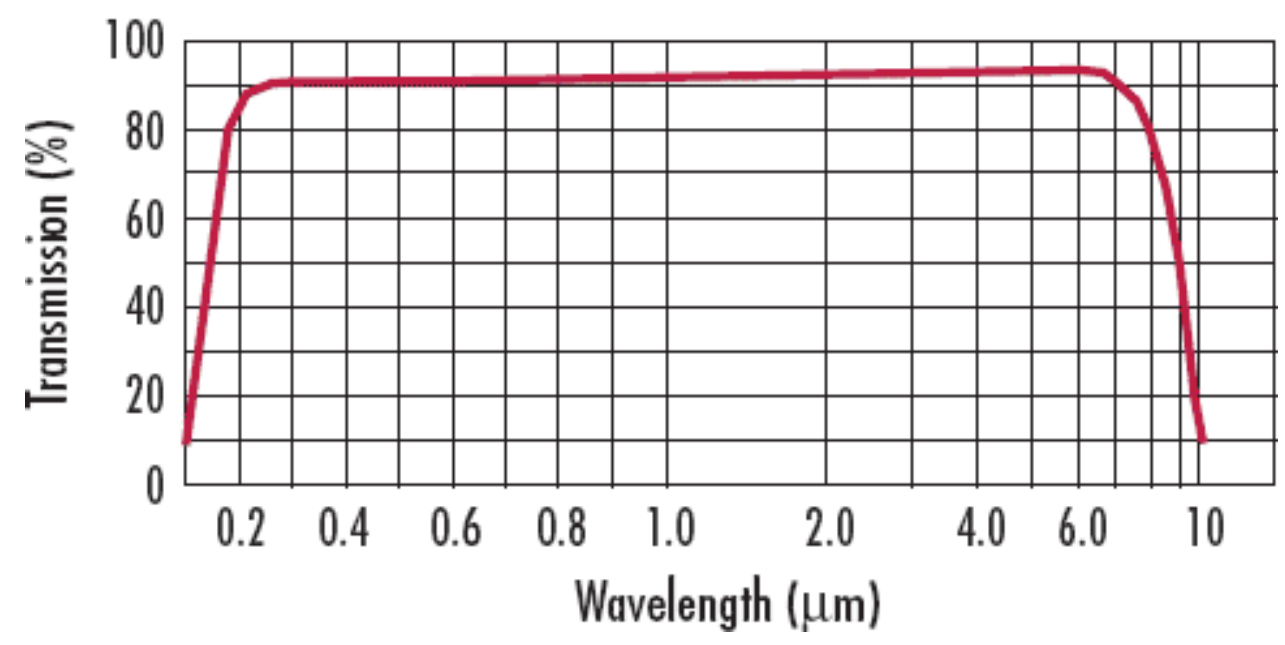

Figure 4.2 - Transmittance of calcium fluoride between 0-10 $\mu \mathrm{m}$

The optical fiber is pure silica, $\varnothing 400 \mu \mathrm{m}, 0.39$ NA, SMA-SMA Fiber Patch Cable, 2 meters in length purchased from Thorlabs (item no. M28L02). The design of the probe allows any SMA905 fiber coupling to be easily attached or detached in case there is a need to change the type of fiber or replace the existing fiber due to damage. In addition, the distance between the lens and the fiber can be adjusted with set screws which allows for different focal lengths in case the lens is changed or replaced. In order to assure that the fiber was positioned at the focal length of the lens, 
measurements were calculated and the fiber was shown to produce a peak signal with the FTIR when placed in front of a Black Body Emitter. With the fiber placed at the focal length of the lens, the collection of the emission of the gas will be a column perpendicular to the lens. In order to reduce particle build up and to assure a lack of self-absorption within the water cooled jacket, a low flow Argon purge was used to inhibit flow into the probe. The light collected was then delivered to the FTIR as shown in Figure 4.3.

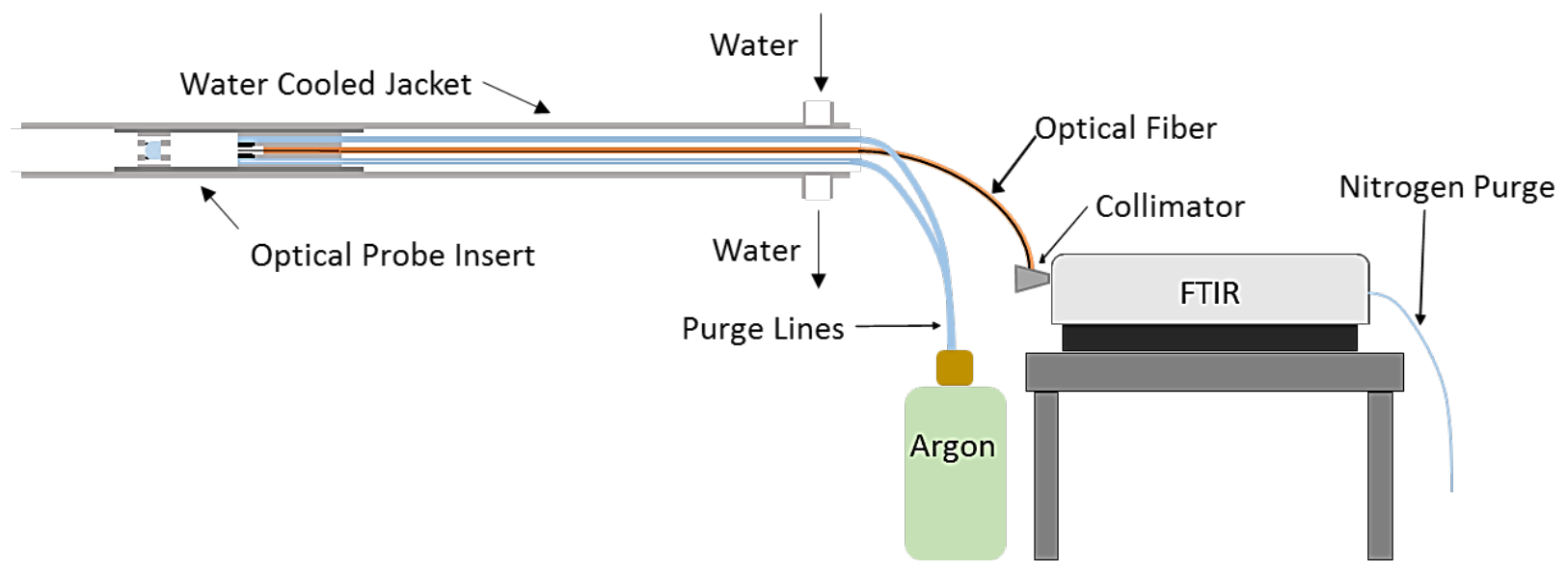

Figure 4.3 - Optical Pyrometer and FTIR interface

The SMA fiber attachment that is not connected to the probe will be connected to a collimator just outside the FTIR that has an SMA fiber attachment. The collimator will transmit a collimated beam of light to the interferometer within the FTIR. The FTIR then performs a Fourier transform on the light source, converting it into a voltage signal as a function of wavenumber. In order to minimize self-absorption effects, a nitrogen purge was used within the FTIR.

Before data collection could begin, the probe signal needed to be calibrated with a Black Body Emitter (BB). The probe was recessed $20.3 \mathrm{~cm}$ from the end of the water cooled jacket, which was placed in front of the BB cavity at a known temperature to produce a measured signal that was compared to a calculated Planck curve. An Argon purge was used in the probe, and a 
Nitrogen purge was used in the FTIR during calibration in order to minimize self-absorption. The object of the calibration process was to account for the transmittance loss of the system (including lens, fiber, and air absorption) and the sensitivity of the FTIR detector as a function of wavenumber in order to accurately determine intensity. The results of the calibration are given in the results section.

\subsection{Conditions of Data Collection}

Once calibration was complete, testing was performed on the BFR with a methane flame. The BFR is a $150 \mathrm{~kW}_{\text {th }}$ down-fired, refractory lined, water cooled, cylindrical furnace. Figure 4.4 shows a partial schematic diagram of the combustion facility as well as the experimental setup used to collect data.

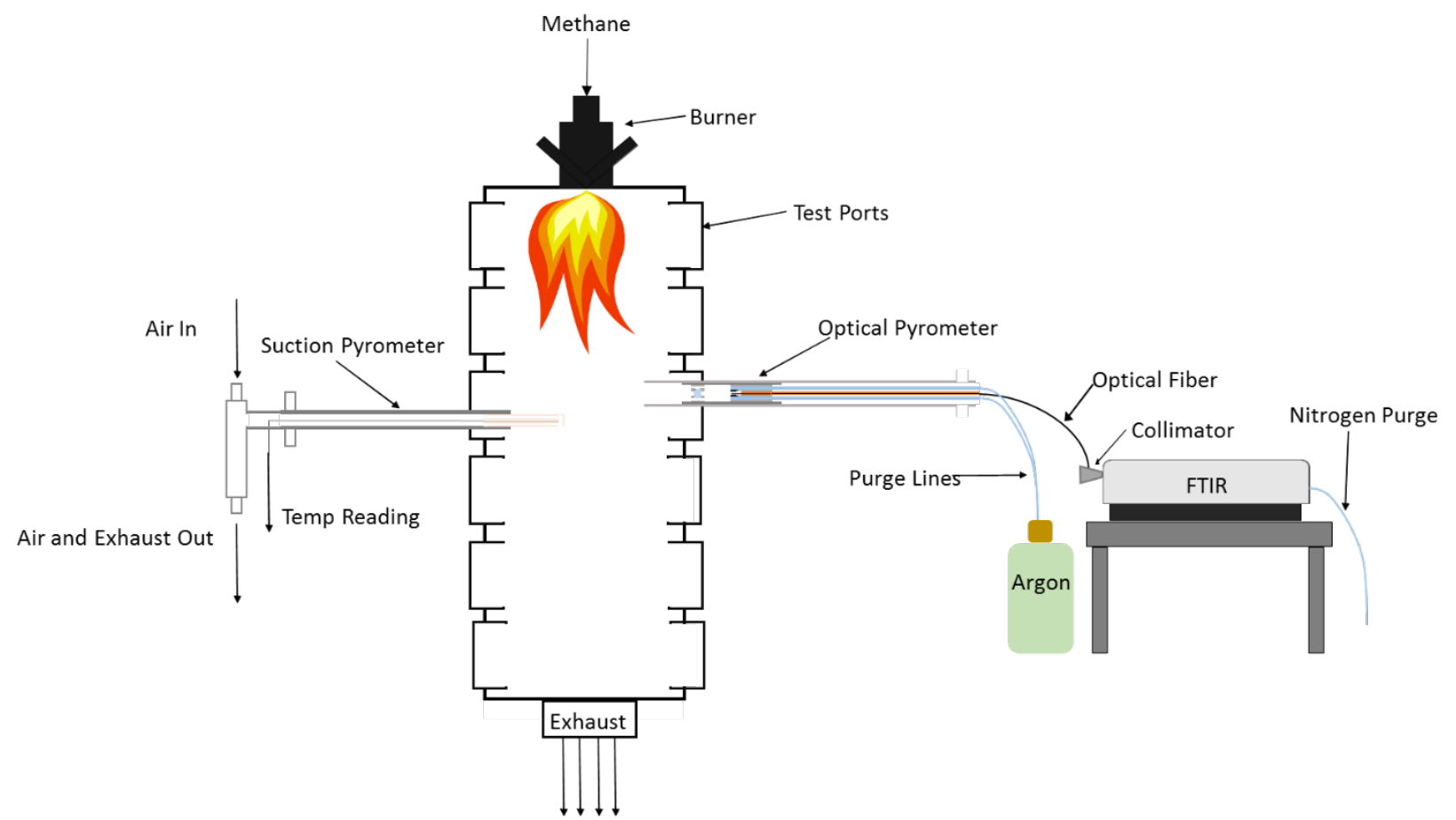

Figure 4.4 - Experimental setup featuring the BFR, Optical Pyrometer, Suction Pyrometer and the FTIR 
Validation of the data was achieved by using a suction pyrometer with a type $\mathrm{K}$ thermocouple in conjunction with the optical probe. It should be noted that the suction pyrometer was used on the same side of the reactor in the same location as the optical pyrometer, but the two measurements were not taken at the same time. Each measurement was taken beginning at startup when the natural gas flame was first lit and the walls were initially at ambient temperature. The fuel and air flow rates were constant for each test and it was assumed that the reactor heated at the same rate each time. Figure 4.4 depicts the probe and suction pyrometer on the opposite sides to enable labeling. In order to have a sufficient rate of convection to avoid radiation loss, the ASTM standard for suction pyrometer flow rates is $5 \mathrm{~m} / \mathrm{s}$, but studies have shown that radiative losses are lower as the flow rate increases (L.G. Blevins 1999). For this reason the suction pyrometer was operated at a flow rate of $40 \mathrm{~m} / \mathrm{s}$, the maximum flow rate possible by the eductor and air pressure available. The suction pyrometer was inserted into the lower half of the third port, approximately $105 \mathrm{~cm}$ from the burner exit, and data were collected at $10 \mathrm{~cm}$ intervals starting at the edge of the interior wall in order to assess the validity of the uniform temperate assumption. As was previously addressed, suction pyrometers attempt to reduce radiation error, which cause a gas temperature to be artificially low (in the direction of the wall temperature) and the spatial resolution of the measurements is quite poor due to the large flow rates. Due to the fact that the flow rate of the suction pyrometer is limited by existing equipment design, the measured temperature is expected to be slightly less than the actual temperature of the combustion gases, but the amount is difficult to determine. The suction pyrometer along with a calculated adiabatic flame temperature based on the operating condition were used as reference points to determine the reasonability of the optically determined temperature. 
The three operating conditions listed in Table 4.1 were selected in order to provide a simple way to change temperature without changing probe position. The fuel used was natural gas which was modeled as methane for the calculation of adiabatic flame temperature. The three operating conditions were tested in two ways by both the suction pyrometer and the optical pyrometer. The first test was a time progression documenting the reactor warming up from the time of ignition to approximately 240 minutes. The second test was performed once the reactor reached steady state. Due to the fact that the testing of the two pyrometers was executed in the same location, they were performed sequentially over two days for each condition. Multiple tests were performed at steady state for each condition in order to determine the variability of the methods.

The air entering the reactor was preheated to an average temperature of $500^{\circ} \mathrm{F}$ (approx. 533 $\mathrm{K})$ using an electric heater and was used as the reactant temperature in calculating the adiabatic flame temperature. The temperature of the gases in the reactor should be well below the adiabatic flame temperature due to large heat losses in the reactor, however, the adiabatic flame temperature provides a limit for the temperature difference that is produced by the change in equivalence ratio and some indication of how large that temperature difference might be.

Table 4.1 - Test conditions using the BFR

\begin{tabular}{|c|c|c|c|c|}
\hline Condition & Methane (SCFH) & Air (kg/hr.) & Equivalence $(\phi)$ & Adiabatic Flame Temp (K) \\
\hline 1 & 300 & 200 & 0.600 & 1664 \\
\hline 2 & 350 & 200 & 0.715 & 1862 \\
\hline 3 & 400 & 200 & 0.820 & 2024 \\
\hline
\end{tabular}

The optical probe was inserted into the water cooled jacket and tests were performed with the probe recessed $20.3 \mathrm{~cm}$ from the end of the jacket. Argon was used to purge the $20.3 \mathrm{~cm}$ of the recessed portion of the water cooled jacket with a flow rate such that a positive pressure was created and self-absorbance was minimized. The assembly was inserted into the BFR in the lower 
half of the third window from the top, on the south side of the reactor (approximately $105 \mathrm{~cm}$ from the burner exit). This location was chosen due to the fact that the visible flame did not reach the line of sight of the probe at the majority of the conditions, thereby making soot free measurements possible. However, at $400 \mathrm{SCFH}$ methane, the sooting flame was observed to occasionally appear in the measurement volume.

The assembly was inserted into the BFR such that the optical path length of the signal was the entire width of the reactor $(0.75 \mathrm{~m})$. Data were collected with a nitrogen purged FTIR using an external collimator, a $\mathrm{KBr}$ beam-splitter, and the $\mathrm{MCT}$ detector. The maximum FTIR resolution setting (0.125) was used which corresponds to data spacing of $0.06 \mathrm{~cm}^{-1}$ for the aforementioned range of 5185 to $5800 \mathrm{~cm}^{-1}$. This resolution was chosen in order to more closely approximate the resolution seen in the model correlations.

Once the data were collected, Equations (3.7), (3.8) and (5.3) were used in conjunction with background radiation removal (discussed in the following section) in order to determine a resultant temperature. The results of the calibration process, the BFR experiments, and an uncertainty analysis will be discussed in the following section. 


\section{RESULTS AND DISCUSSION}

Results include calibration, development of a transfer function, and example temperature measurements in the BFR. A comparison of optical and suction pyrometer temperatures, the need to remove background radiation, and the uncertainty of the proposed method will all be discussed.

\subsection{Calibration}

During calibration, the collection probe and optical fiber were placed in front of a black body cavity close enough that the collection angle of the probe only includes the black body surface of the cavity. The measured voltage $\left(M_{\eta}\right)$ at a given wavelength is given by Equation (5.1), where: $\varepsilon_{b}$, is the emissivity of the cavity (assumed to be 1.0 ), $I_{b, \eta}$ is the Planck black body intensity at the known temperature of the radiating cavity, $A_{l}$ is the area of the collection lens, $S_{\eta}$ is a constant representing the sensitivity of the FTIR in converting incident intensity to output voltage, and $\tau_{\eta}$ is the spectral transmittance of the optical fiber. The lens area, spectral sensitivity and fiber transmittance were combined into a single constant, $C_{\eta}$, to be found by the calibration.

$$
M_{\eta}=\varepsilon_{b} I_{b, \eta} A_{l} S_{\eta} \tau_{\eta}=\varepsilon_{b} I_{b, \eta} C_{\eta}
$$

Figure 5.1 shows the measured FTIR signal from black body emission at $1100^{\circ} \mathrm{C}$ and a Planck blackbody intensity equation plotted as a function of wavenumber for the same temperature. The shape of the measured signal differs from the Planck curve because of the spectral dependence of the detector response and the spectral dependence of the transmittance of the receiving optics and optical fiber. Also despite purging the FTIR and the optical probe, a small 
layer of cold air was present between the collection optics and the black body. This air contained $\mathrm{H}_{2} \mathrm{O}$ and $\mathrm{CO}_{2}$ vapor which can be seen as spectral absorption bands between $3700-4000 \mathrm{~cm}^{-1}$ and $5100-5600 \mathrm{~cm}^{-1}$. This self-absorbance is not present in experiments because the probe is inserted in a water cooled jacket into the hot combustion products and the cooled volume within the probe is purged with argon.

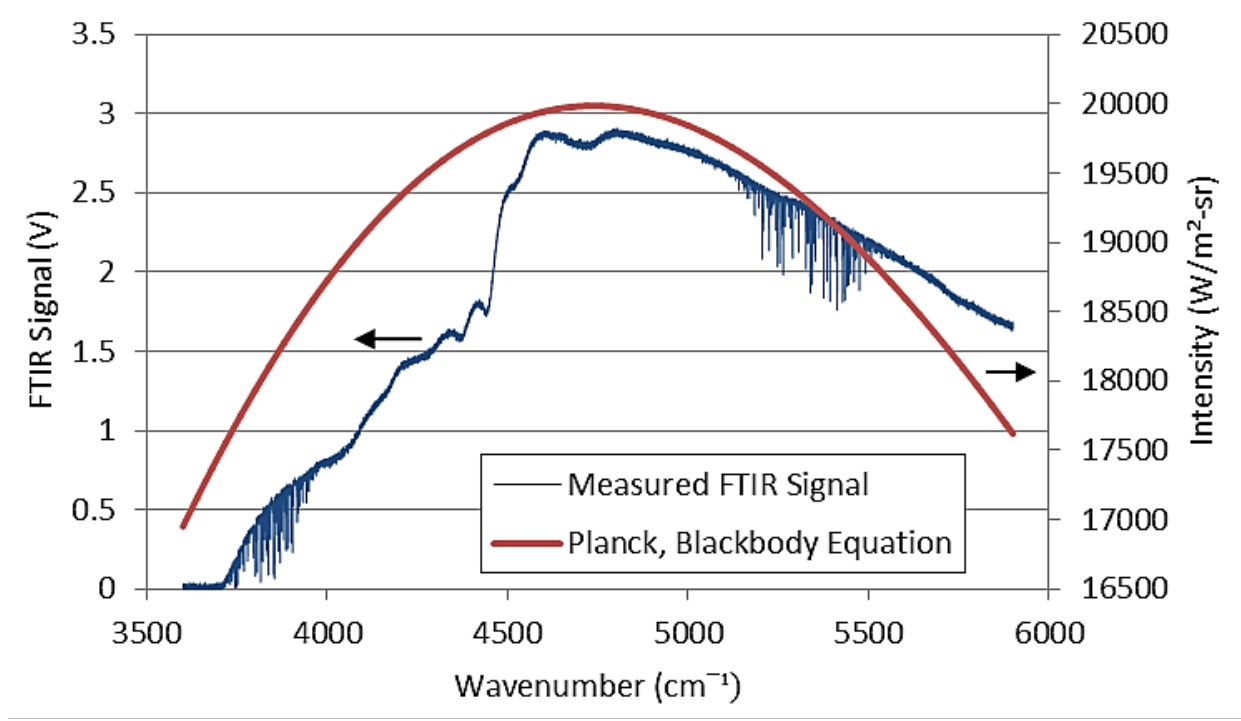

Figure 5.1 - Measured FTIR signal at a BB temperature of $1100^{\circ} \mathrm{C}$ (approx. $1373 \mathrm{~K}$ ) from $3600-5900 \mathrm{~cm}^{-1}$ with the calculated Planck curve at the same temperature

In order to calculate a transfer function relating FTIR signal output to intensity, the spectral region between 5018-5900 $\mathrm{cm}^{-1}$ was used as shown in Figure 5.2. This region is larger than the region where measurements were collected in order to facilitate curve fitting the data in regions where self-absorption was not present. The influence of the $\mathrm{H}_{2} \mathrm{O}$ absorption was removed by fitting the measured signal data with a smooth function as shown in Figure 5.3. 


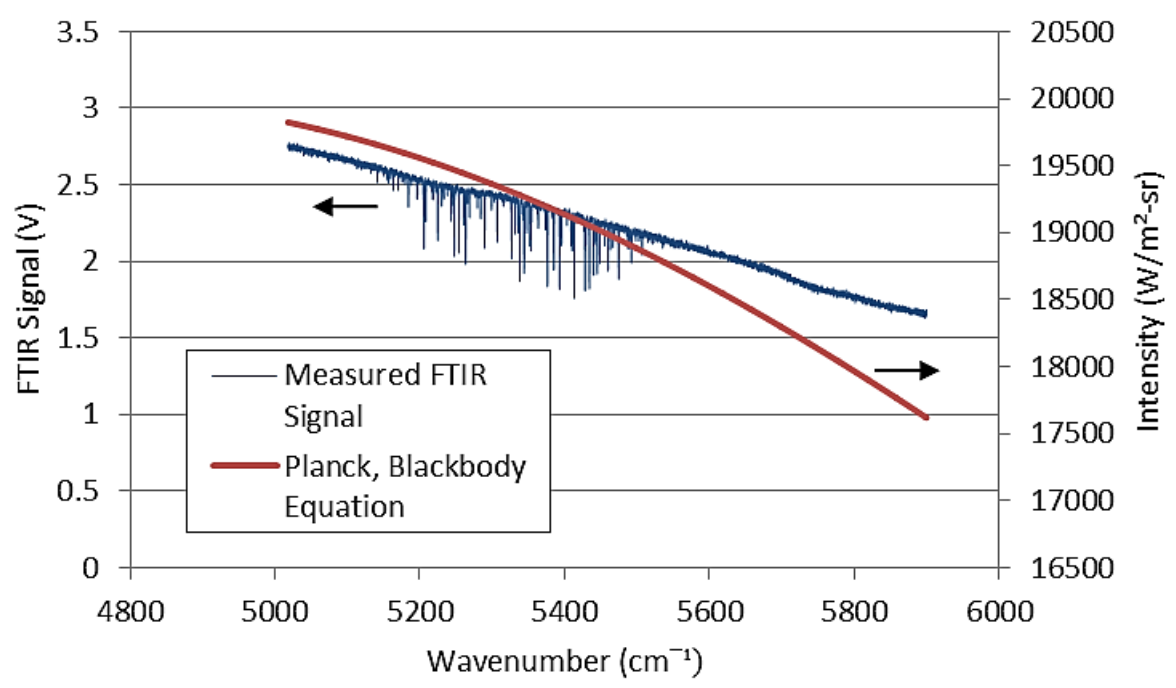

Figure 5.2 - A comparison of the FTIR signal versus the calculated Planck equation

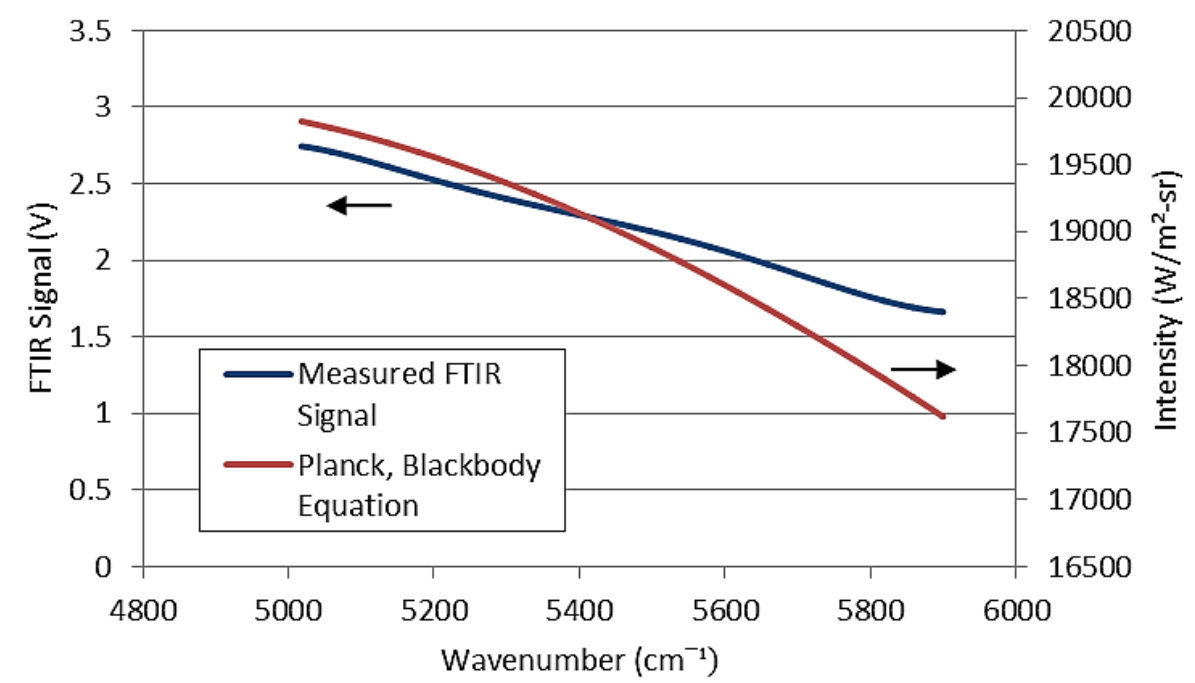

Figure 5.3 - A comparison of a smooth FTIR signal versus the calculated Planck equation

The spectral ratio of measured data to blackbody intensity was then used to define the spectral transfer function, $\mathrm{C}_{v}$, as shown using the following equation:

$$
C_{v}=\frac{M_{v}}{I_{b, \eta}} \frac{\text { Volts }}{W / m^{2} / s r}
$$

The measured $\mathrm{C}_{v}$ for three blackbody temperatures are shown in Figure 5.4. The figure shows that the FTIR detector is not linear with incident intensity but the shape of the spectral 
response is similar. The $\mathrm{C}_{\mathrm{v}}$ used in this work is unique to the experimental setup used in this work and takes into account the unique optical setup combined with the FTIR used to collect data. Because the transfer function is dependent on the temperature or intensity of the emission and that temperature is unknown, the selection of the transfer function becomes an iterative process. A guessed temperature is used to provide the initial transfer function and the resulting temperature is used to determine the new transfer function. Fortunately, given the fact that the temperature is dependent on the ratio of intensities and not the absolute temperature, there is little error involved in guessing a temperature for the transfer function, on the order of $1 \%$ for an initial guess without iterations. The iteration process converges rapidly and allows an absolute intensity to be determined.

The algorithm for determining temperature from a measured FTIR voltage is completed as follows:

- A guessed temperature is used along with calibration constant $C_{v}$ for that temperature to provide the spectral intensity as shown in Equation (5.3).

- The spectral intensity is then integrated numerically over the spectral bands A thru E as shown in Figure 3.3 according to Equation (5.3).

- Ratios of integrated band intensities are then calculated for various combinations of bands as shown in Equation (3.8).

- The temperature for a given band ratio is then calculated according the theoretical correlations shown in Figure 3.4

- The temperature obtained is compared to the guessed temperature. If they are not within a tolerance limit, the process is repeated starting with the new temperature. 
The equations used for the iteration process are shown below:

$$
\begin{gathered}
I_{v}=\frac{M_{v}}{C_{v}} \\
I_{\text {band }}=\int I_{v} d v=d v * \sum_{v 1}^{v 2} I_{v} \\
R_{a / b}=\frac{I_{\text {band }, a}}{I_{\text {band }, b}}
\end{gathered}
$$

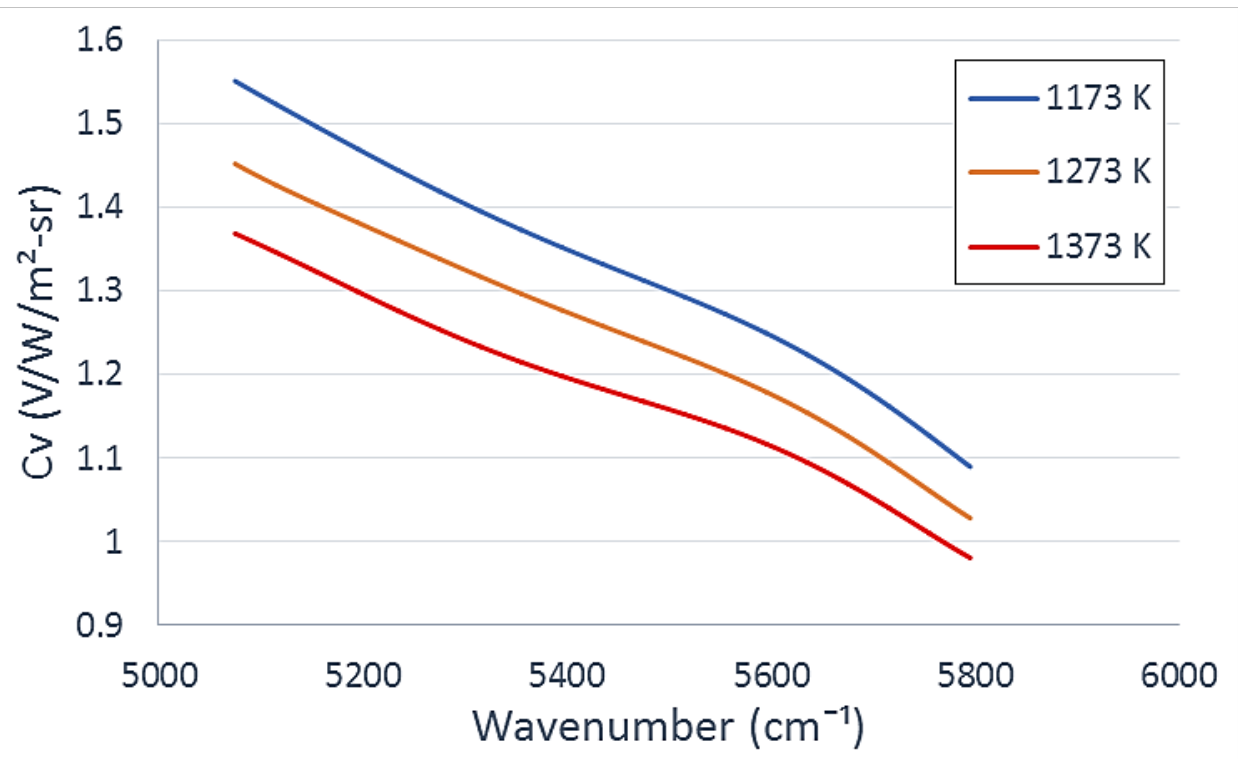

Figure $5.4-C_{v}$ values at various calibration temperatures

\subsection{Data Collection}

Once the calibration process was completed, data were taken with the suction pyrometer using the method previously outlined at steady state. Results obtained with the suction pyrometer as a function of radial position for the three operating conditions are shown in Figure 5.5. The temperature across the majority of the reactor is uniform but the temperature is lower near the walls. Note the temperature increased as the amount of natural gas was increased and the overall fuel air mixture becomes closer to stoichiometric. Temperature differences in the adiabatic flame temperature between Conditions 1 and 2 is on the order of $200 \mathrm{~K}$ and about $160 \mathrm{~K}$ between Condition 2 and 3, however the change in suction pyrometer temperature is lower, on the order of 
$60 \mathrm{~K}$, with slightly larger difference between Conditions 1 and 2 than seen between Conditions 2 and 3. This smaller difference between suction pyrometer data compared to the adiabatic flame temperature data is consistent with the fact that a large amount of heat is lost to the reactor walls and the temperatures are all well below the adiabatic flame temperature. Data taken with the optical pyrometer were taken at a position $10 \mathrm{~cm}$ from the wall edge to avoid absorption in the low temperature region and allow emission to be collected from a constant temperature region.

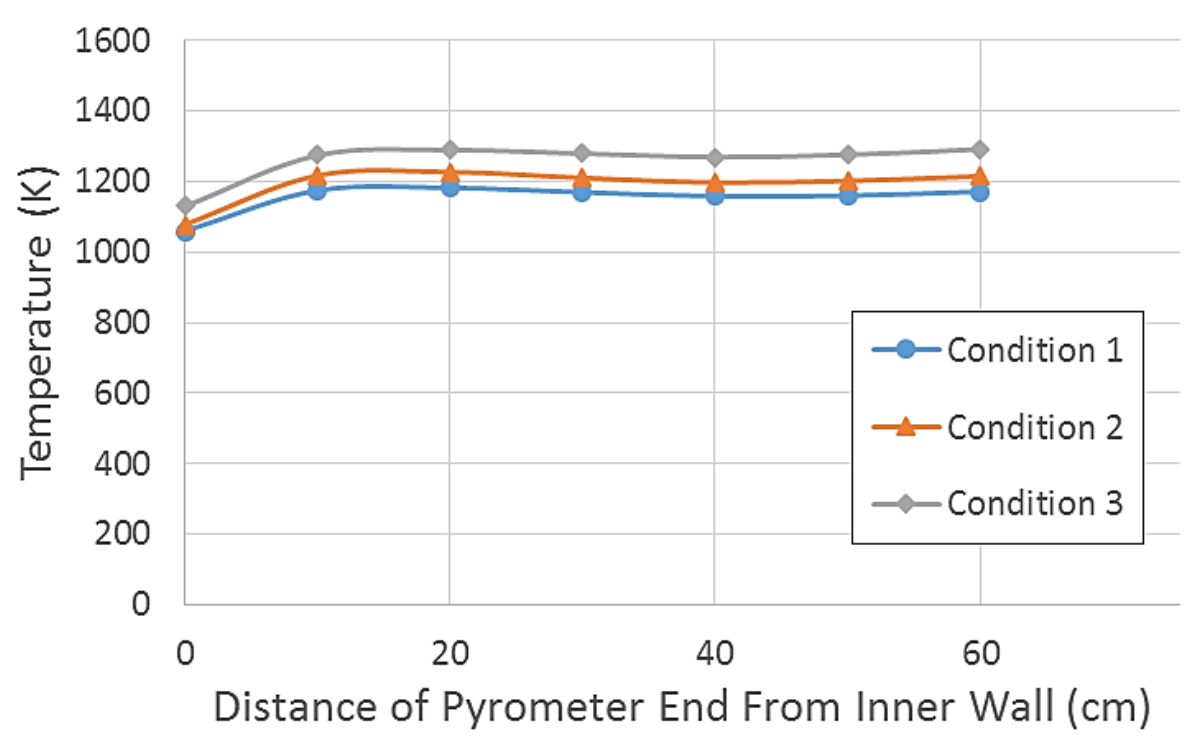

Figure 5.5 - Temperatures measured with the suction pyrometer

The following figures show raw spectral data from the FTIR in the region $3600-5800 \mathrm{~cm}^{-}$ ${ }^{1}$ for the three operating conditions. Spectral emission lines from $\mathrm{H}_{2} \mathrm{O}$ are apparent. As a general rule, as the temperature of the gas increased from Condition 1 to Condition 3, the magnitude of the intensity also increased (note the scales on each graph are different). This is an indication that the emission is increasing with increasing temperature. The relative size of the noise also decreases with increasing temperature as would be expected. 
The spectral region between $4200-4800 \mathrm{~cm}^{-1}$ and above $5700 \mathrm{~cm}^{-1}$ do not show absorption from $\mathrm{H}_{2} \mathrm{O}$ but instead indicate the level of broad band emission from background walls or soot particles. At low temperature, these emissions are relatively low but as the temperature increased, as was the case for Condition 3, the background emission became more apparent (above zero). Because this background solid surface emission is additive to the gas emission of interest, it must be removed from the data. This can be done by eliminating the hot background during data collection or by subtracting the broadband emission from the signal during data processing.

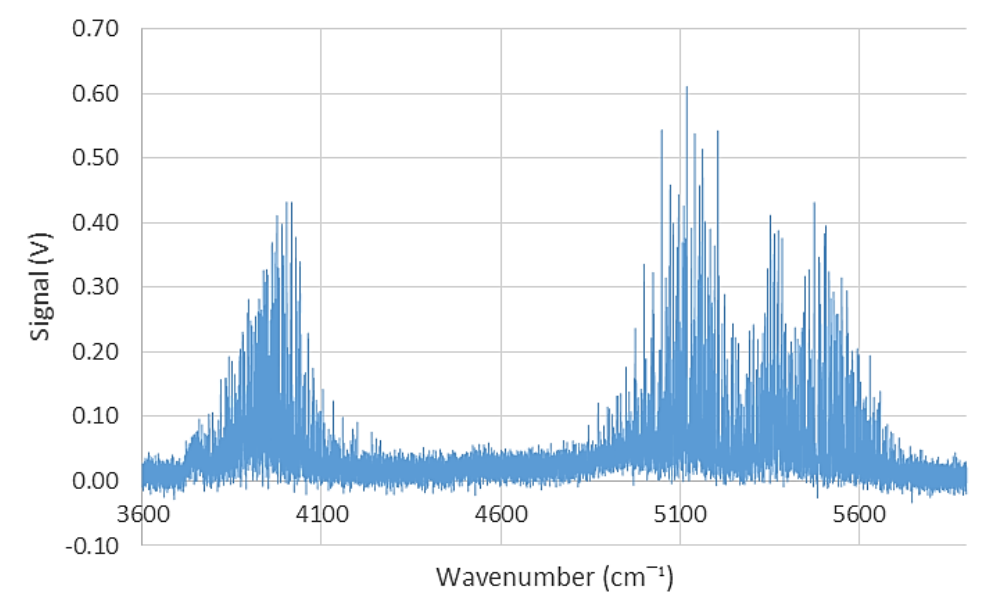

Figure 5.6- FTIR measured signal for Condition 1

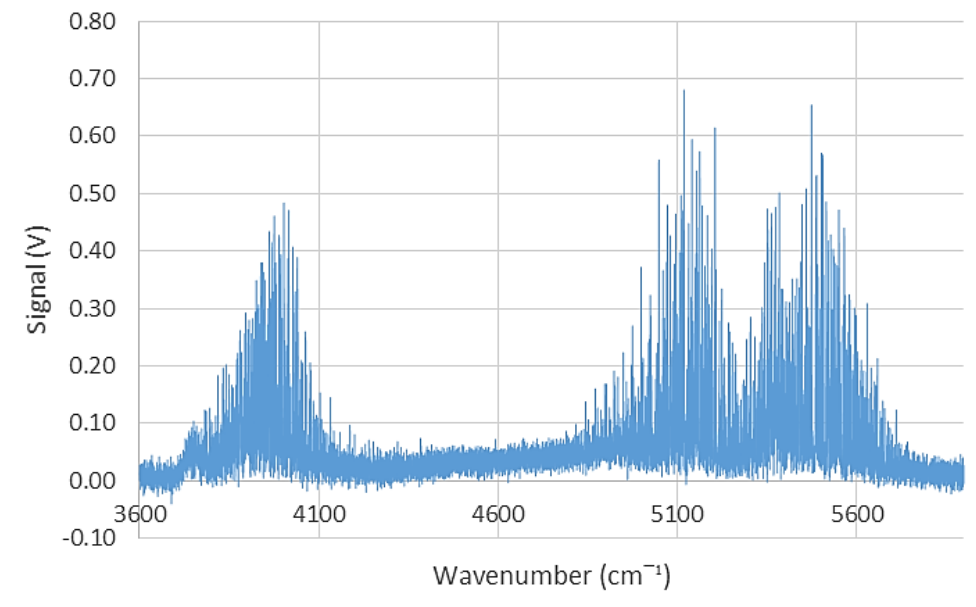

Figure 5.7 - FTIR measured signal for Condition 2 


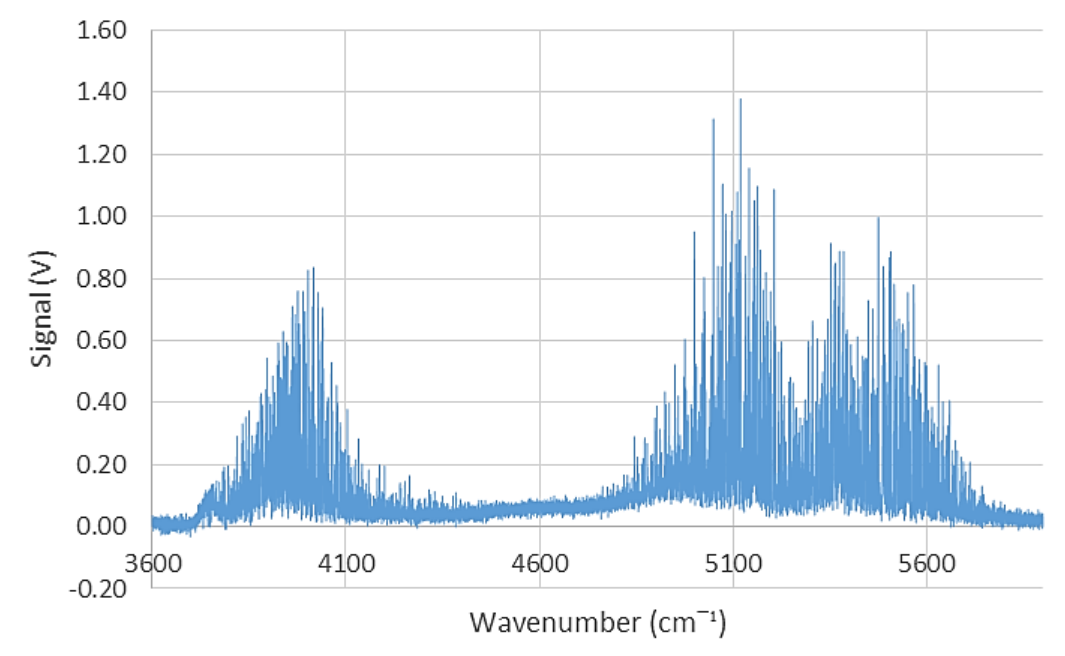

Figure 5.8 - FTIR measured signal for Condition 3

\subsection{Discussion}

The magnitude of the measured signal increases as temperature and $\mathrm{H}_{2} \mathrm{O}$ concentration increases. The ratios of integrated bands remove concentration effects as discussed earlier, and the resulting change in integrated band ratio values can be fully attributed to a change in temperature.

The raw data show evidence of broadband emission coming from sources other than the desired emission from $\mathrm{H}_{2} \mathrm{O}$. The amount of broadband emission was observed to depend primarily in the length of time the reactor had been running suggesting it could be attributed to emission from walls which are slow to heat. These emissions were also observed to increase dramatically when the flame was observed to move into the path of the measurement. Data without broadband emissions should be centered at zero magnitude in regions where $\mathrm{H}_{2} \mathrm{O}$ and $\mathrm{CO}_{2}$ do not emit.

In order to remove this background signal, a method was developed to remove the broadband radiation based on the assumption that it had a Planck intensity with an emissivity value independent of wavenumber, i.e. a gray body emission. Possible explanations for the source of this interference that fit with a gray body assumption include radiation from the opposite wall as well as soot radiation from the flame itself. 
The method used to remove this background emission involved selecting an appropriate temperature for the Planck curve which fit through the two sections (bands) of the data were chosen that exhibited zero emission from $\mathrm{H}_{2} \mathrm{O}$ or $\mathrm{CO}_{2}$ to be used to fit the background emission with a Planck curve as shown in Figure 5.9. Two parameters, the temperature and emissivity of the Planck equation were varied to produce the minimum least squares difference between the equation and the data. The green line represents the best fit Planck equation through the data in red. The Planck spectral intensity was then subtracted from the data at all wavelengths to produce the broadband corrected results shown in Figure 5.10. After the subtraction was performed, the red spectral regions are seen to be centered on a null magnitude instead of the initial offset value (approx. 800 $\mathrm{w} / \mathrm{m}^{2}$-sr). The offset values seen in the data varies from case to case. Once the data has been corrected and the broadband radiation removed, the intensity data can be integrated to determine the resultant gas temperature.

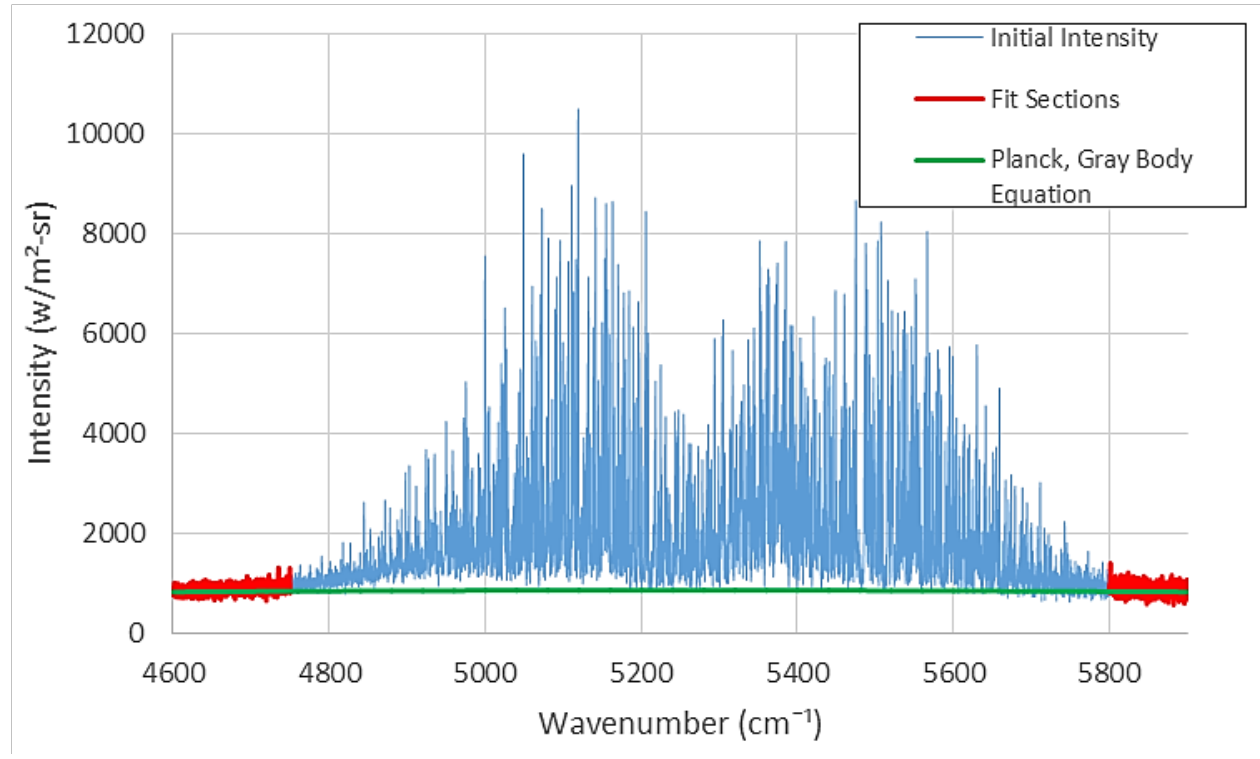

Figure 5.9 - Intensity data showing two gray body fit sections (red) with the proposed gray body Planck line for correction (green) 


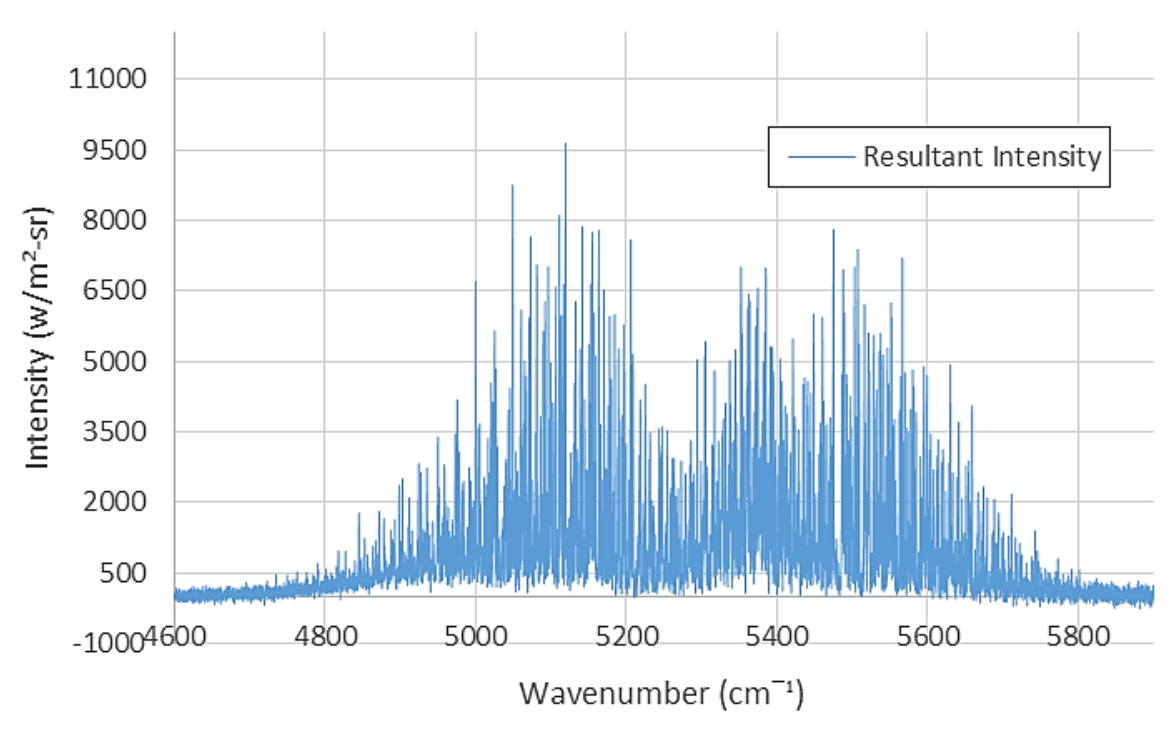

Figure 5.10 - Corrected intensity data

The influence of broadband emission removal can be seen by comparing temperature results with and without removal. Figure 5.11 shows measured optical temperature, calculated for each of three different integral ratios, E/A. E/B, and E/C as a function of time for Condition 1 without broadband removal. Also shown in the figure is the wall temperature of the reactor section where gaseous emissions were collected (Wall Temp 3). The optical temperatures increase steadily with time until they exceed the calculated adiabatic flame temperature for this condition $(1664 \mathrm{~K})$. It can be seen that the optical data follow the same trend as the increasing wall temperature suggesting that the wall emissions are influencing the gas measurement. It is also important to note that one of the three integrated band ratios (E/A) produced a temperature significantly lower than the other three indicating the integrated emissions are not solely from $\mathrm{H}_{2} \mathrm{O}$. 


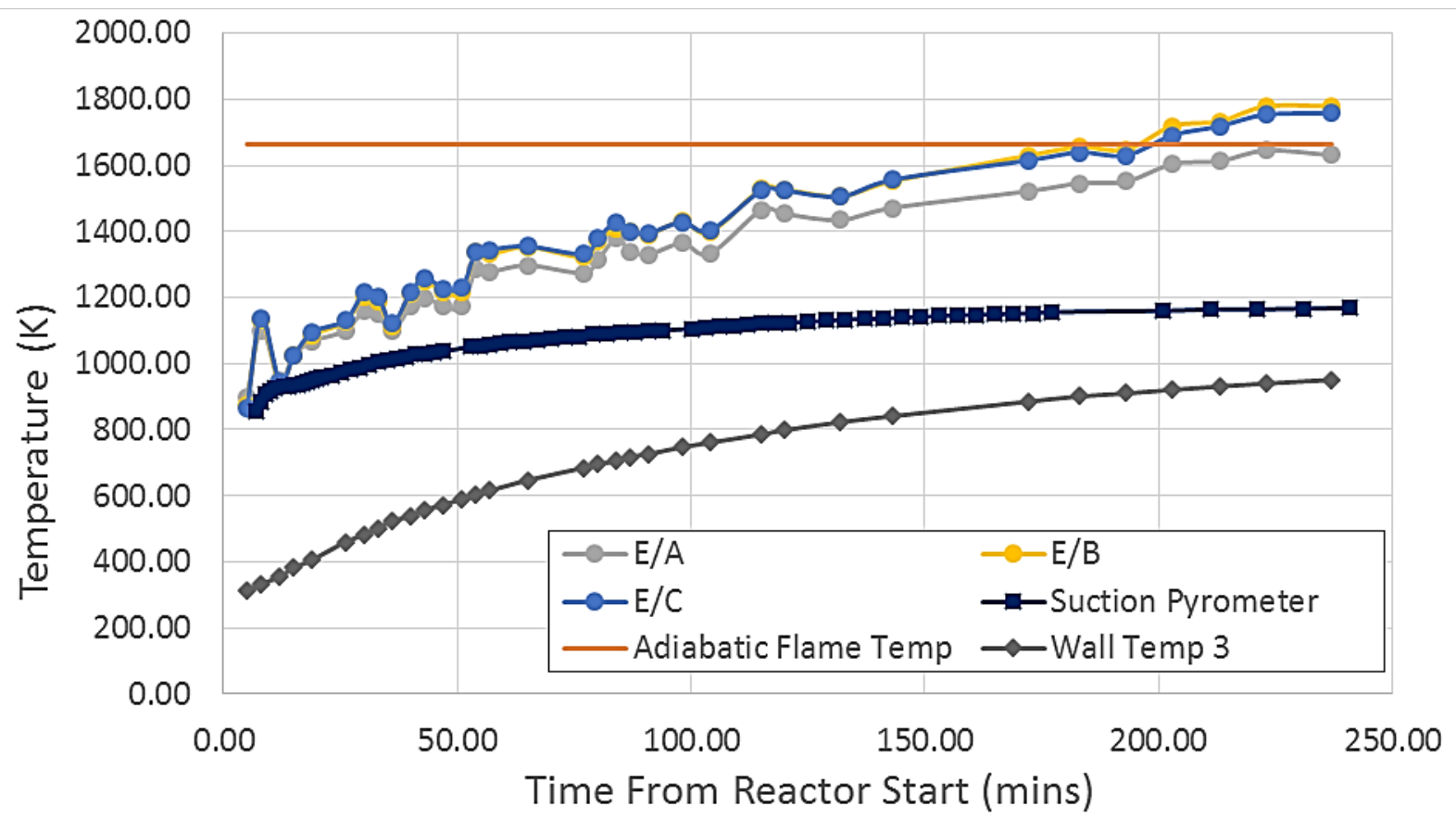

Figure 5.11 - Resultant temperatures for Condition 1 during a startup time progression for the three integrated ratio pairs without background correction compared to the suction pyrometer, adiabatic and wall temperature, time (x-axis) is from the initial ignition of the reactor

Figure 5.12 shows the same time progression for Condition 1 but with the broadband emission removed. Note that the temperatures determined for each of the three spectral pairs are now in good agreement, and they also follow the trend of the suction pyrometer rather than that of the wall temperature. The measured gas temperatures are well below the adiabatic flame temperatures as would be expected in a water-cooled reactor with relatively high surface area to volume ratio. The change in optically measured temperature with the removal technique is seen to be more significant at higher wall temperatures. The fluctuation in temperature at the beginning of startup is likely due to poor signal to noise ratio at lower gas temperatures for this condition. Tables for all time resolved data can be seen in the Appendix. 


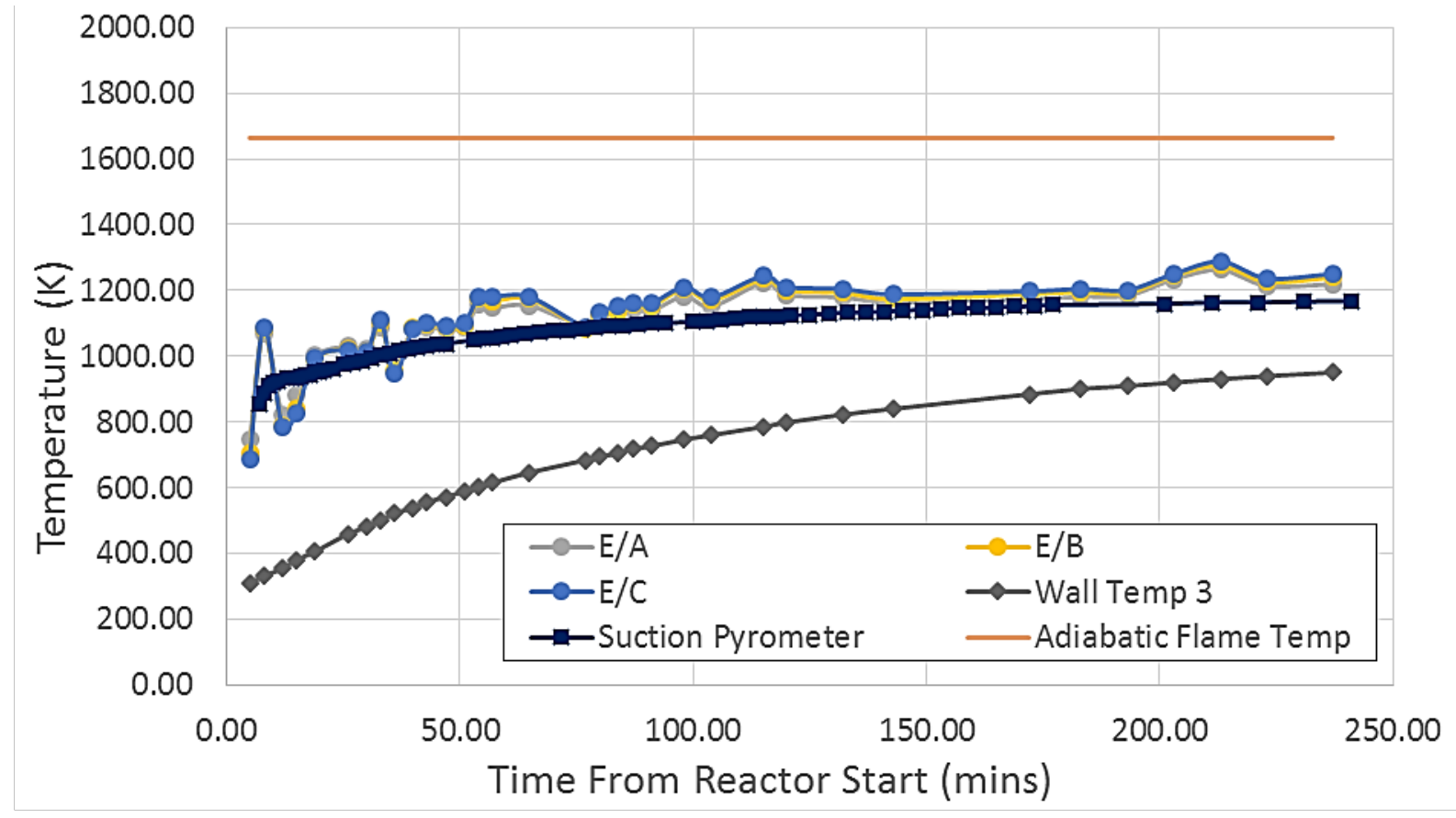

Figure 5.12 - Resultant temperatures for Condition 1 during a startup time progression for the three integrated ratio pairs with background correction compared to the suction pyrometer, adiabatic and wall temperature, time ( $x$-axis) is from the initial ignition of the reactor

The following figures show the same experiments performed at the remaining two conditions. Similar trends before and after background removal can be seen. Note that at higher temperatures, fluctuations in optically measured data are reduced due to the improved noise to signal ratio. The absence of data for Condition 2 between 200 and 250 minutes is due to a temporary failure of the FTIR during that time period. It is apparent that the background radiation present during this experiment had a significant effect on integrated ratios of intensity. As a result, all of the temperature calculations for these conditions require background removal and will be reported with the correction. 


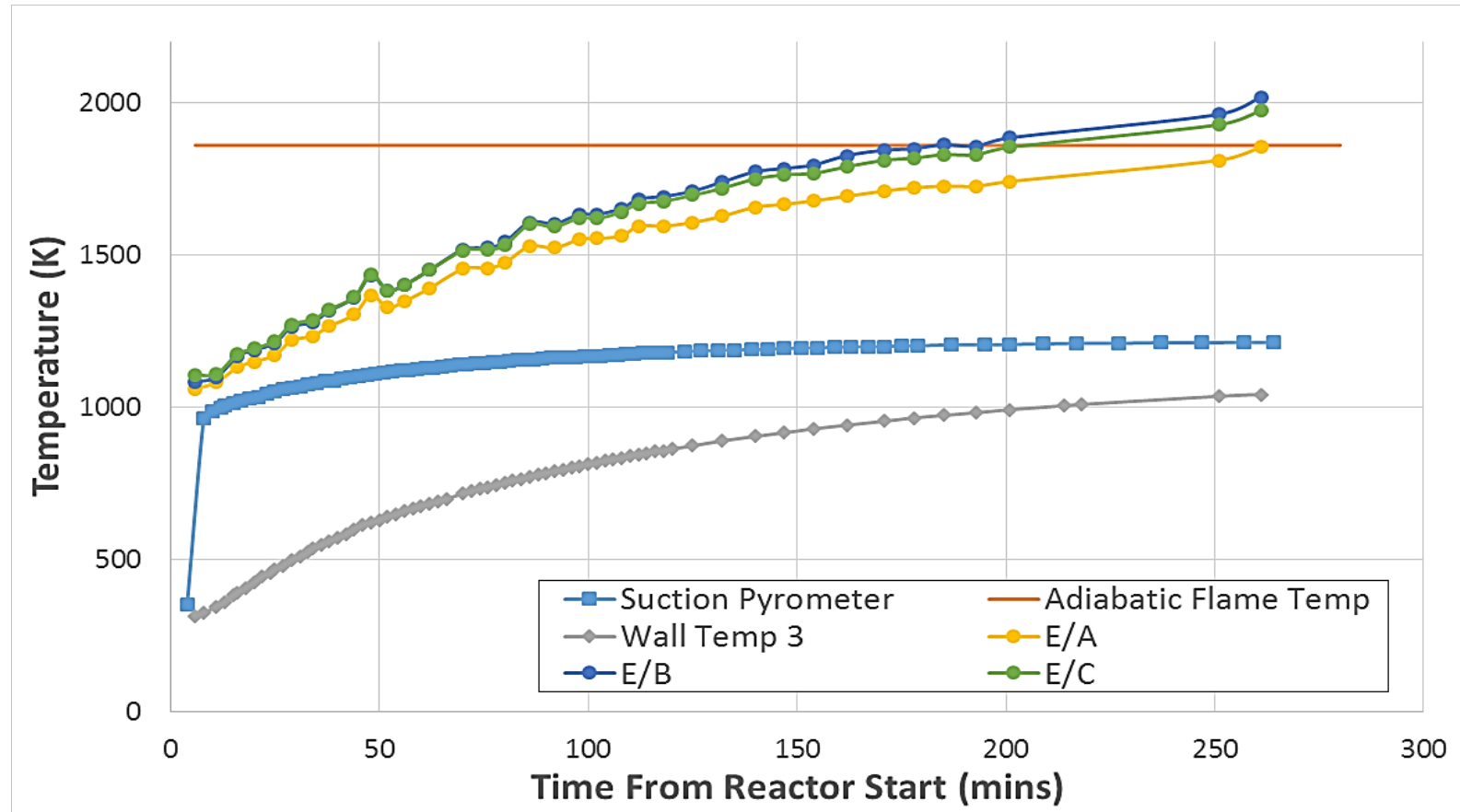

Figure 5.13 - Resultant temperatures for Condition 2 during a startup time progression for the three integrated ratio pairs without background correction compared to the suction pyrometer, adiabatic and wall temperature, time ( $x$-axis) is from the initial ignition of the reactor

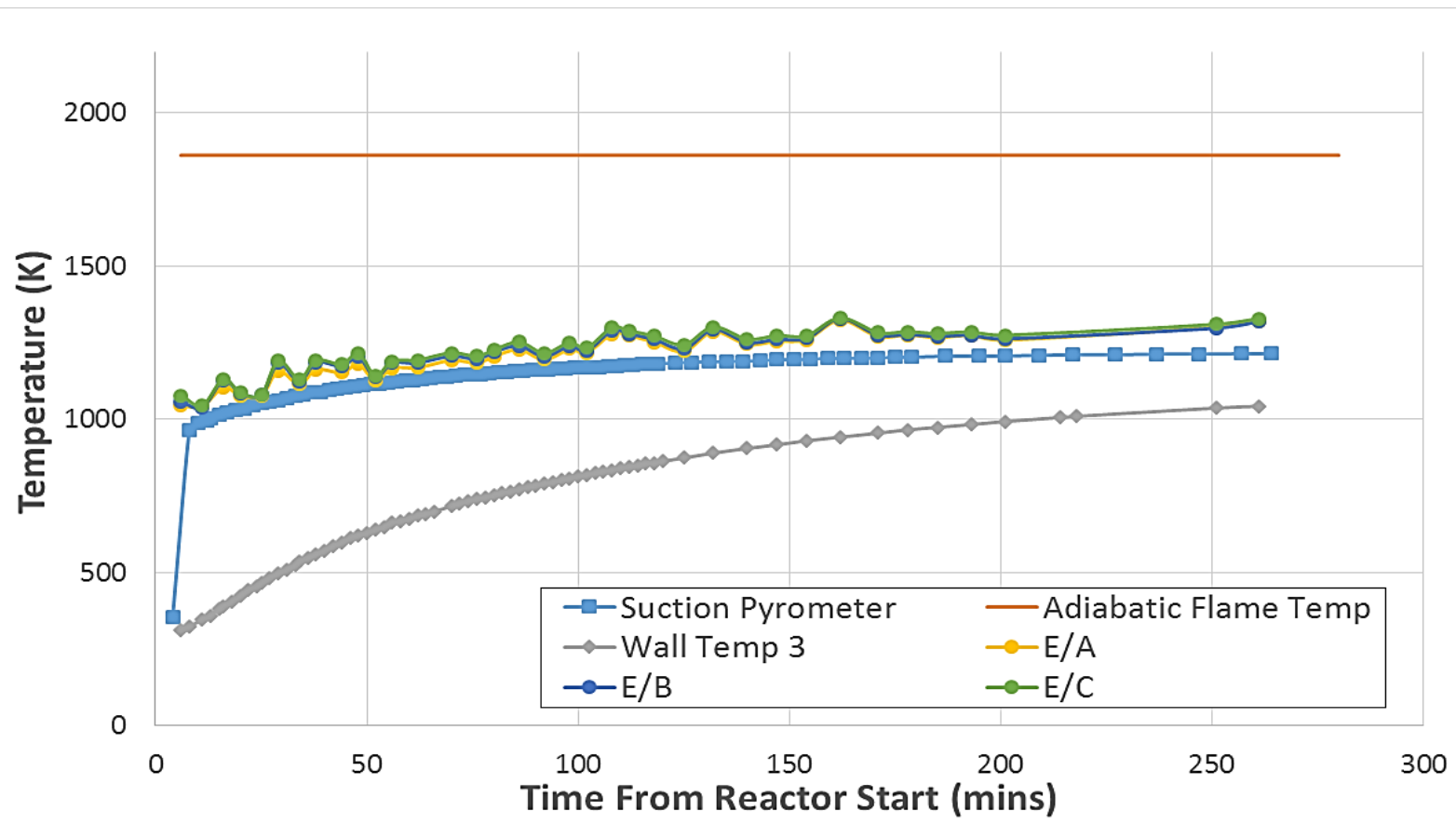

Figure 5.14 - Resultant temperatures for Condition 2 during a startup time progression for the three integrated ratio pairs with background correction compared to the suction pyrometer, adiabatic and wall temperature, time ( $x$-axis) is from the initial ignition of the reactor 


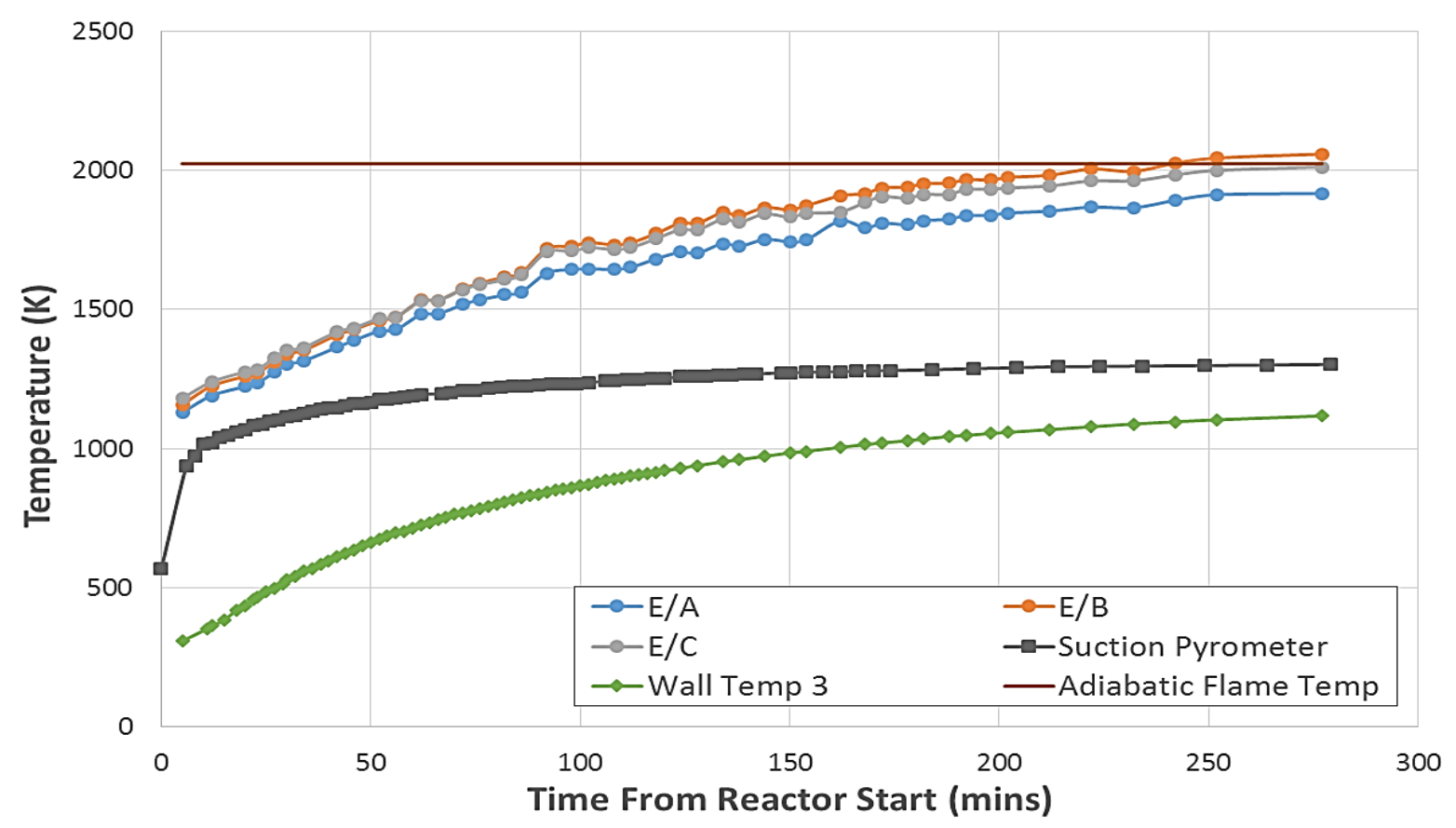

Figure 5.15 - Resultant temperatures for Condition 3 during a startup time progression for the three integrated ratio pairs without background correction compared to the suction pyrometer, adiabatic and wall temperature, time ( $x$-axis) is from the initial ignition of the reactor

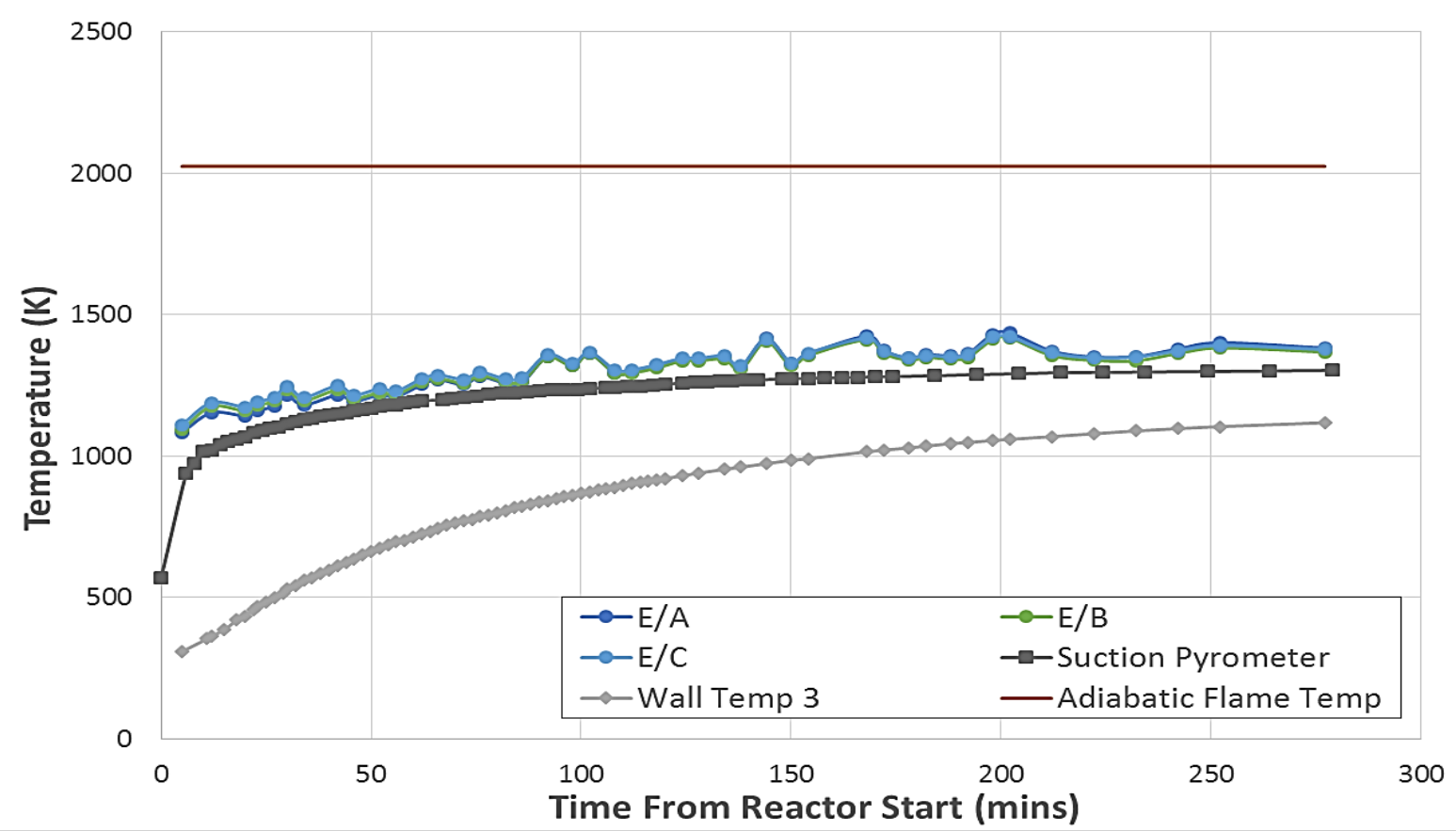

Figure 5.16 - Resultant temperatures for Condition 3 during a startup time progression for the three integrated ratio pairs with background correction compared to the suction pyrometer, adiabatic and wall temperature, time ( $x$-axis) is from the initial ignition of the reactor 
For the broadband removal process, a Planck curve is generated based off of a best fit with temperature and emissivity as dependent variables. Table 5.1 contains the average temperature determined for the Planck curve fit for each condition at steady state. Wall temperatures measured by a thermocouple embedded in the refractory below the slag layer is also listed. Because broadband radiation increased slowly over time and correlates with the increase in wall temperature, it make sense that the broadband radiation is coming mostly from the walls and the Planck temperature should be related but at higher equivalence ratios, the flame became elongated and soot radiation from the flame increased. This increased the probability that some of the broadband radiation could be coming from the soot or from a reflection of soot radiation off of the walls and into the probe line of sight. Given this possibility, the Planck curve fit temperatures seem very reasonable and could be useful in determining total radiation measurements.

Table 5.1 - Steady state values of the broadband removal temperature for all three conditions compared to the wall temperature

\begin{tabular}{|c|c|c|c|c|}
\hline Condition & Equivalence Ratio & Broadband Temp (K) & Wall Temp (K) & Difference (\%) \\
\hline 1 & 0.600 & 897 & 909 & $1.3 \%$ \\
\hline 2 & 0.715 & 964 & 974 & $1.0 \%$ \\
\hline 3 & 0.820 & 984 & 1095 & $10.2 \%$ \\
\hline
\end{tabular}

Table 5.2 contains a comparison of the optically measured and suction pyrometer temperature data at steady state for the three conditions. The relative percent difference between the optical measurement and the suction pyrometer is also listed. Excellent agreement is observed. In all cases the optical data are slightly higher than the suction pyrometer data as might be expected. The differences range from $3.2 \%$ to $3.6 \%$. 
Table 5.2 - Steady state values of the three integrated ratio pairs for all three conditions compared to suction pyrometer temperatures with background correction

\begin{tabular}{|c|c|c|c|c|}
\hline Condition & Equivalence Ratio & Optical Temp (K) & Suction Pyrometer Temp (K) & Difference (\%) \\
\hline 1 & 0.600 & 1200 & 1161 & $3.2 \%$ \\
\hline 2 & 0.715 & 1274 & 1228 & $3.6 \%$ \\
\hline 3 & 0.820 & 1337 & 1292 & $3.4 \%$ \\
\hline
\end{tabular}

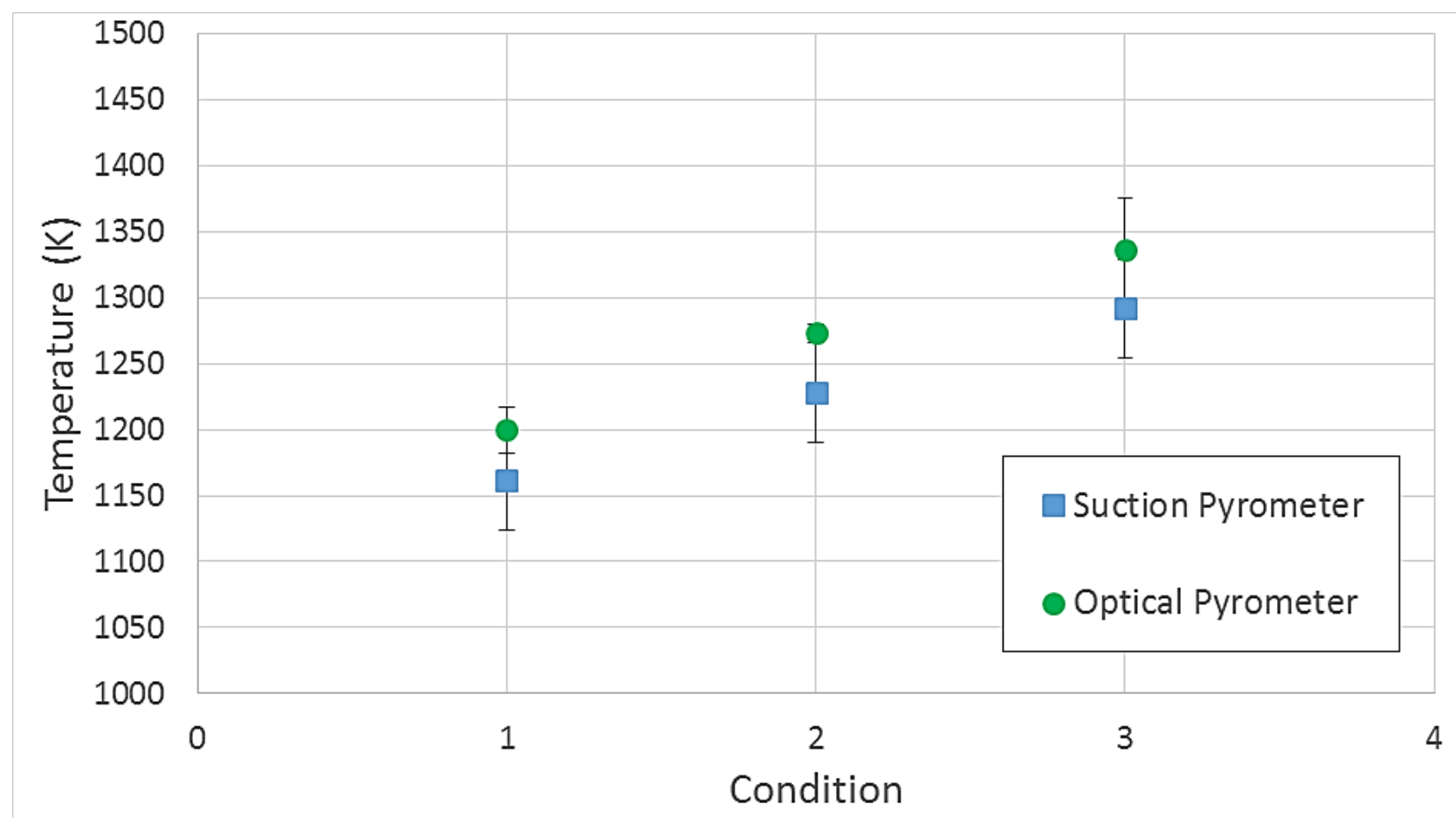

Figure 5.17 - Steady state data of the three integrated ratio pairs for all three conditions compared to suction pyrometer temperatures with background correction

Figure 5.17 shows the average of eight data points for each condition taken at steady state and compared to suction pyrometer temperatures taken at identical conditions. The error bars represent the magnitude of one standard deviation.

Although the error bars for the two methods overlap indicating no significant difference in the two measurements within their range of uncertainty, the optical measurements were consistently $3 \%$ higher than the suction pyrometer. As discussed in the literature review, suction pyrometers are expected to be lower than the actual gas temperature when wall temperatures are lower than gas temperatures because of radiation losses. In this case the velocity of gases passing 
over the shielded thermocouple were on the order of $50 \mathrm{~m} / \mathrm{s}$ which is well above the ASTM suggested velocity and therefore the suction pyrometer temperatures are expected to be reasonably accurate. Given this understanding of thermocouple temperature errors, it is possible that the optical temperature is more accurate than the suction pyrometer.

\subsubsection{Uncertainty}

Uncertainty in measurements consists of two components, bias error and random error. The bias error is related to the calibration accuracy and the amount of offset produced by interfering factors. For example, the broadband emission biased the emission from the $\mathrm{H}_{2} \mathrm{O}$ and caused considerable error before it was removed. Another potential source of bias error exists in the calibration process and subsequent changes to the optical system. For example, if the lens were to become dirty and transmit light differently during the measurement than during calibration. Another source of bias error is the unknown concentration of the $\mathrm{H}_{2} \mathrm{O}$. While taking the ratio of integrated intensities cancels most of the error associated with this issue, large uncertainties in $\mathrm{H}_{2} \mathrm{O}$ such as $40 \% \mathrm{H}_{2} \mathrm{O}$ vs $5 \% \mathrm{H}_{2} \mathrm{O}$ lead to uncertainties in the temperature of $0.25 \%$. The best measure of bias error that could be produced was to compare the optical result to the best known temperature of the gas which was obtained with the suction pyrometer. This uncertainty is on the order of $\pm 3 \%$ based on differences between the two measurements. Another method of looking at bias error is to consider the differences between the temperature calculated by two different band ratios, such as $\mathrm{E}$ and $\mathrm{A}$ vs. E and $\mathrm{B}$. Theoretically these bands should produce identical temperatures and the extent to which they are different is an indication of bias errors in the calibration and measurement or in the theoretical development. In the case of the data obtained here, this uncertainty was on the order of $1-2 \%$ which is smaller than the uncertainty obtained by comparing the optical and suction pyrometer techniques. 
The second type or error is due to random uncertainties produced by the noise or variations in the measurement. This can be evaluated by the assessing the repeatability of the measurement. Assuming the temperature to be changing in a smooth continuous fashion, the time progression data are a good indication of the random uncertainty. When temperatures are low, the variation in temperature from one time to the next is considerably larger than later time periods when the temperature is higher and the signal to noise ratio of the FTIR improves. Thus the random uncertainty is a function of the temperature being measured. At high temperatures $(1200 \mathrm{~K})$, this uncertainty is on the order of $1-2 \%$ as shown in Table 5.2 but the uncertainty becomes larger, $\pm 8 \%$ at lower temperatures $(850 \mathrm{~K})$.

In order to approximate a total uncertainty, the root mean square of bias and random uncertainties was calculated as shown in Table 5.3. The result is a total uncertainty of approximately 4\% for high temperatures (above $1200 \mathrm{~K}$ ) and approximately $9 \%$ for low temperatures on the order of $850 \mathrm{~K}$. At temperatures above $1000 \mathrm{~K}$, the uncertainty of this technique is a good as that of any other known temperature measurement technique.

Table 5.3 Calculation of the total uncertainty at two temperatures

\begin{tabular}{|l|c|c|}
\hline Source of Uncertainty & Error at $850 \mathrm{~K}$ & Error at $1200 \mathrm{~K}$ \\
\hline Calibration and Modeling & $3 \%$ & $3 \%$ \\
\hline Integrated Spectral Emission (Spectral Model) & $2 \%$ & $2 \%$ \\
\hline Random Signal to Noise & $8 \%$ & $2 \%$ \\
\hline Total Error (RMS) & $8.8 \%$ & $4.1 \%$ \\
\hline
\end{tabular}




\section{SUMMARY AND CONCLUSIONS}

A method for measuring temperature using the integrated intensity of $\mathrm{H}_{2} \mathrm{O}$ emission bands has been developed and demonstrated on a $150 \mathrm{~kW}$ th natural gas flame using a fiber optic based probe and FTIR. The development and demonstration produced the following results:

- A spectral model of $\mathrm{H}_{2} \mathrm{O}$ emission was developed from the spectral absorption coefficients produced by Pearson (2013). The model produced the emission along a line of sight of uniform temperature and $\mathrm{H}_{2} \mathrm{O}$ concentration.

- The model was used to investigate numerous spectral bands until several pairs were found which produce a monotonic relationship between the ratio of integrated band intensity and temperature.

- The ratio of spectral band intensities was found to be relatively insensitive to $\mathrm{H}_{2} \mathrm{O}$ concentration with differences on the order of $0.25 \%$ for a concentration range of 5 to $40 \%$.

- A collection probe was designed, fabricated and tested for the collection of gaseous emission along a line of sight using a lens and optical fiber within a water cooled jacket.

- A method was developed to provide a calibration transfer function relating FTIR output to radiative emission input. The transfer function was found to be dependent on the incident intensity and therefore iteration is required to determine the proper transfer function for a given temperature. 
- The optical probe was used to collect emission measurements from the combustion products of a methane flame at three equivalence ratios (temperatures). A suction pyrometer was used to collect temperature profiles at the same operating conditions.

- The optical emission measurement contained both gaseous and broadband emissions. A technique was developed to remove the broadband emission from the spectra and calculate the temperature based on only the gaseous emissions.

- The optical measurements produced temperatures approximately $3 \%$ higher than the suction pyrometer measurements at the three different conditions.

- The optical pyrometer is estimated to have an uncertainty of $\pm 4 \%$ for temperatures at or above $1200 \mathrm{~K}$ increasing to nearly $9 \%$ at $850 \mathrm{~K}$.

Future work will involve reducing the path length of the measurement volume in order to improve spatial resolution. This can be accomplished by increasing the diameter of the fiber optic cable in order to increase the signal as well as adding a background optical stop to limit the path length. The signal appears strong enough that smaller path lengths could be used with larger fibers, perhaps as low as $5-10 \mathrm{~cm}$. Another area of interest is to use the measurement to determine the relative importance of gaseous and solid particle emission. Once the temperature of the $\mathrm{H}_{2} \mathrm{O}$ is known, additional post processing and modeling of the data can be done to determine the $\mathrm{H}_{2} \mathrm{O}$ and $\mathrm{CO}_{2}$ concentrations and total gaseous emissions. This can be compared to the background broadband emission to determine the relative contributions of gas and solids emission. In addition to reducing the path length and improving the spatial resolution, the implementation of band pass filters and detectors can potentially remove the need to use an FTIR with this method, making response times of less than a second possible. 


\section{REFERENCES}

A. Z'Graggen, H.F., A. Steinfeld. 2007. "Gas temperature measurement in thermal radiating environments using a suction thermocouple apparatus." Measurement Science and Technology 18 (11).

A.H.K. Sato, M. Hasatani, S. Sugaiyama, J. Kimura. 1975. "A correctional calculation method for thermocouple measurements of temperatures in flames." Combustion and Flame 24: $35-41$.

Clausen, S. 1996. "Local measurement of gas temperature with an infrared fibre-optic probe." Meas. Sci. Technology 7: 888-896.

D. Backstrom, R. Johansson, K. Anderson, F. Johnsson, S. Clausen, A. Fateev. 2014.

"Measurement and modeling of particle radiation in coal flames." Energy Fuels 28: 21992210.

D. Bradley, K.J.M. 1968. "Measurement of high gas temperature with fine wire thermocouples." Journal of Mechanical Engineering Science 10 (4).

Evseev, Vadim, Fateev, Alexander, Clausen. 2012. "High resolution measurements of CO2 at high temperatures for industrial applications." Journal of Quantitative Spectroscopy and Radiative Transfer 113 (17): 2222-2233.

F.C. Lockwood, H.A.M. 1982. "Fluctuating temperature measurements in turbulent jet diffusion flame." Combustion and Flame 47: 291-314.

Heitor, M.V., Moreira, A.L.N. 1993. "Thermocouples and sample probes for combustion studies." Combustion Science p. 259-278.

J.S. Newman, P.A.C. 1979. "Simple aspirated thermocouple for use in fires." Journal of Fire and Flammability 10 (4): 326-336.

J.T. Pearson, B.W. Webb, V.P. Solovjov, J. Ma. 2014. "Effect of total pressure on the absorption line blackbody distribution function and radiative transfer in $\mathrm{H} 2 \mathrm{O}, \mathrm{CO} 2$, and CO." Journal of the Quantitative Spectroscopy and Radiative Transfer 143: 100-110. 
L.A. Gross, P.R. Griffiths. 1988. "Temperature estimation of carbon dioxide by infrared absorption spectrometry at medium resolution." Journal of Quantitative Spectroscopy and Radiative Transfer 39 (2): 131-138.

L.G. Blevins, W.M.P. 1999. "Modeling of bare and aspirated thermocouples in compartment fires." Fire Safety Journal 33 (4): 239-259.

L.S. Rothman. I.E.G, R.J. Barber, H. Dothe, R.R. Gamache, A. Goldman, V.I. Perevalov, S.A. Tashkun, J. Tennyson. 2010. "HITEMP, the high temperature molecular spectropic database." Journal of Quantitative Spectroscopy and Radiative Transfer 3: 2139-2150.

P.R. Solomon, P.L. Cheien, R.M. Garangelo, P.E. Best, J.R. Markham. 1988. "Application of FTIR emission/transmission spectroscopy to study coal combustion phenomena." Proceedings of the Combustion Institute. 211-221.

R. Viskanta, M.P.M. 1987. "Radiation heat transfer in combustion systems." Progress in Energy and Combustion Science 13 (2): 97-160.

R.J. Anderson, P.R. Griffiths. 1977. "Determination of rotational temperatures of diatomic molecules from absorption spectra measured at moderate resolution." Journal of Quantitative Spectroscopy and Radiative Transfer 17: 393-401.

R.L. Farrow, P.L. Mattern, L.A. Rahn. 1982. "Comparison between CARS and corrected thermocouple temperature measurements in a diffusion flame." Applied Optics 21 (17): 3119-3125.

S.C. Kim, A.H. 2008. "On the temperature measurement bias and time response of an aspirated thermocouple in fire environment." Journal of Fire Sciences 26 (6).

T. Draper, D. Zeltner, D. Tree, Y. Xue, R. Tsiava. 2012. "Two-dimensional flame temperature and emissivity measurements of pulverized oxy-coal flames." Applied Energy 95: 38-44.

T. Ren, T.A. Reeder, M.F. Modest. 2013. "An inverse radiation model for optical determination of temperature and $\mathrm{CO} 2$ concentration: development and validation." International Mechanical Engineering Congress and Exposition. San Diego, CA.

T.E. Parker, M.F. Miller, K.R. McManus, M.G. Allen, W.T. Rawlins. 1996. "Infrared emission from high-temperature $\mathrm{H} 2 \mathrm{O}$ : a diagnostic for concentration and temperature." AIAA Journal 34 (3): 500-507. 


\section{APPENDIX A. TTIR SETTINGS}

\section{FTIR Settings:}

Source: External

Type: Transmission Mid IR

Beam splitter: $\mathrm{KBr}$

Detector: MCT

Scans: 32

Resolution: 0.125

Data Spacing: $0.060 \mathrm{~cm}^{-1}$

Range: 5900-3600 $\mathrm{cm}^{-1}$

Gain: Auto

Optical Velocity: Auto

Aperture: Auto 


\section{APPENDIX B. OPTICAL TIME PROGRESSION DATA}

\section{Data of optical time progression:}

\begin{tabular}{|c|c|c|c|c|c|c|c|c|c|c|c|c|c|c|}
\hline \multicolumn{15}{|c|}{ Without background radiation correction } \\
\hline Condition Test & Epsilon & Planck Temp & $E / A$ & $E / B$ & $\mathrm{E} / \mathrm{C}$ & Average & St dev & Adiabatic & Time & Time From Start (mins) & TN1 & TN2 & TN3 & TN4 \\
\hline 1 & 1 & & 899.54 & 873.72 & 864.16 & 879.14 & 18.30 & 1664 & 1022.00 & 5.00 & 306.00 & 343.00 & 311.00 & 296.00 \\
\hline 1 & 2 & & 1101.82 & $2 \quad 1130.67$ & 1138.91 & 1123.80 & 19.48 & 1664 & 1025 & 8.00 & 326.00 & 391.00 & 332.00 & 296.00 \\
\hline 1 & 3 & & 951.03 & 937.88 & 945.60 & 944.84 & 6.61 & 1664 & 1029 & 12.00 & 351.00 & 439.00 & 356.00 & 298.00 \\
\hline 1 & 4 & & 1025.25 & 1024.65 & 1022.41 & 1024.10 & 1.50 & 1664 & 1032 & 15.00 & 378.00 & 482.00 & 382.00 & 299.00 \\
\hline 1 & 5 & & 1068.18 & $3 \quad 1085.90$ & 1095.63 & 1083.24 & 13.92 & 1664 & 1036 & 19.00 & 407.00 & 521.00 & 407.00 & 302.00 \\
\hline 1 & 7 & & 1099.92 & $\quad 1126.79$ & 1130.60 & 1119.10 & 16.72 & 1664 & 1043 & 26.00 & 465.00 & 589.00 & 460.00 & 311.00 \\
\hline 1 & 8 & & 1160.31 & $\begin{array}{l}1203.79 \\
\end{array}$ & 1215.08 & 1193.06 & 28.92 & 1664 & 1047 & 30.00 & 490.00 & 615.00 & 481.00 & 315.00 \\
\hline 1 & 9 & & 1149.71 & L 1190.09 & 1204.08 & 1181.29 & 28.23 & 1664 & 1050 & 33.00 & 513.00 & 640.00 & 502.00 & 321.00 \\
\hline 1 & 10 & & 1098.41 & 1115.63 & $1120.88^{\prime \prime}$ & 1111.64 & 11.75 & 1664 & 1053 & 36.00 & 535.00 & 665.00 & 523.00 & 328.00 \\
\hline 1 & 11 & & 1173.99 & \begin{tabular}{|l|l}
1211.79 \\
\end{tabular} & $1215.02^{\prime}$ & 1200.27 & 22.81 & 1664 & 1057 & 40.00 & 554.00 & 684.00 & 540.00 & 333.00 \\
\hline 1 & 12 & & 1199.99 & 1250.49 & $1260.39^{\prime \prime}$ & 1236.96 & 32.39 & 1664 & 1100 & 43.00 & 572.00 & 702.00 & 557.00 & 340.00 \\
\hline 1 & 13 & & 1173.50 & $\quad 1215.54$ & $1227.89^{\prime}$ & 1205.64 & 28.51 & 1664 & 1104 & 47.00 & 590.00 & 719.00 & 573.00 & 348.00 \\
\hline 1 & 14 & & 1172.99 & 1218.56 & $1231.59^{\prime}$ & 1207.71 & 30.77 & 1664 & 1108 & 51.00 & 609.00 & 736.00 & 590.00 & 356.00 \\
\hline 1 & 15 & & 1288.13 & $\begin{array}{l}3 \quad 1338.29 \\
\end{array}$ & $1338.42^{\prime \prime}$ & 1321.61 & 29.00 & 1664 & 1111 & 54.00 & 624.00 & 750.00 & 603.00 & 363.00 \\
\hline 1 & 16 & & 1278.47 & $\quad 1331.48$ & $1345.02^{\prime}$ & 1318.32 & 35.17 & 1664 & 1114 & 57.00 & 639.00 & 763.00 & 616.00 & 371.00 \\
\hline 1 & 17 & & 1297.64 & $\begin{array}{l}1353.13 \\
\end{array}$ & 1355.17' & 1335.31 & 32.64 & 1664 & 1122 & 65.00 & 675.00 & 795.00 & 647.00 & 390.00 \\
\hline 1 & 18 & & 1274.11 & $1 \quad 1323.03$ & $1332.05^{\prime}$ & 1309.73 & 31.18 & 1664 & 1134 & 77.00 & 720.00 & 833.00 & 685.00 & 415.00 \\
\hline 1 & 19 & & 1314.77 & 7 1371.74 & $1380.15^{\prime}$ & 1355.55 & 35.57 & 1664 & 1137 & 80.00 & 732.00 & 843.00 & 695.00 & 424.00 \\
\hline 1 & 20 & & 1379.00 & 1409.00 & $1427.32^{\prime \prime}$ & 1405.11 & 24.39 & 1664 & 1141 & 84.00 & 744.00 & 853.00 & 706.00 & 432.00 \\
\hline 1 & 21 & & 1340.13 & \begin{tabular}{|l|l} 
& 1398.80
\end{tabular} & 1399.37" & 1379.43 & 34.04 & 1664 & 1144 & 87.00 & 759.00 & 865.00 & 718.00 & 442.00 \\
\hline 1 & 22 & & 1330.77 & $7 \quad 1391.47$ & $1395.63^{\prime \prime}$ & 1372.62 & 36.30 & 1664 & 1148 & 91.00 & 769.00 & 874.00 & 727.00 & 449.00 \\
\hline 1 & 23 & & 1364.21 & $1 \quad 1430.23$ & $1427.90^{\prime}$ & 1407.45 & 37.46 & 1664 & 1155 & 98.00 & 793.00 & 892.00 & 747.00 & 466.00 \\
\hline 1 & 24 & & 1333.18 & 3 1397.85 & $1403.37^{\prime \prime}$ & 1378.13 & 39.03 & 1664 & 1201 & 104.00 & 809.00 & 904.00 & 761.00 & 479.00 \\
\hline 1 & 25 & & 1465.27 & 1528.88 & $1523.95^{\prime \prime}$ & 1506.03 & 35.39 & 1664 & 1212 & 115.00 & 838.00 & 927.00 & 786.00 & 503.00 \\
\hline 1 & 26 & & 1453.19 & 1527.08 & $1523.47^{\prime \prime}$ & 1501.24 & 41.66 & 1664 & 1217 & 120.00 & 852.00 & 937.00 & 799.00 & 515.00 \\
\hline 1 & 27 & & 1434.59 & $\begin{array}{l}9 \\
7506.07\end{array}$ & $1505.42^{\prime}$ & 1482.03 & 41.08 & 1664 & 1229 & 132.00 & 879.00 & 958.00 & 823.00 & 539.00 \\
\hline 1 & 28 & & 1471.48 & 3 1551.71 & 1556.21" & 1526.47 & 47.67 & 1664 & 1240 & 143.00 & 900.00 & 974.00 & 841.00 & 557.00 \\
\hline 1 & 31 & & 1521.74 & $\begin{array}{ll}4 & 1629.22\end{array}$ & $1615.10^{\prime \prime}$ & 1588.69 & 58.40 & 1664 & 109 & 172.00 & 949.00 & 1011.00 & 885.00 & 604.00 \\
\hline 1 & 32 & & 1545.83 & 1655.16 & 1639.48 & 1613.49 & 59.12 & 1664 & 120 & 183.00 & 966.00 & 1024.00 & 901.00 & 620.00 \\
\hline 1 & 33 & & 1551.21 & 1647.62 & $1630.44^{\prime \prime}$ & 1609.76 & 51.42 & 1664 & 130 & 193.00 & 977.00 & 1031.00 & 910.00 & 631.00 \\
\hline 1 & 34 & & 1604.60 & 1719.43 & 1691.46 & 1671.83 & 59.88 & 1664 & 140 & 203.00 & 987.00 & 1040.00 & 921.00 & 642.00 \\
\hline 1 & 35 & & 1612.89 & 1732.50 & $1718.38^{\prime}$ & 1687.93 & 65.37 & 1664 & 150 & 213.00 & 998.00 & 1048.00 & 931.00 & 653.00 \\
\hline 1 & 36 & & 1645.17 & \begin{tabular}{l|l|} 
& 1778.74
\end{tabular} & $1754.00^{\prime \prime}$ & 1725.97 & 71.06 & 1664 & 200 & 223.00 & 1008.00 & 1056.00 & 940.00 & 663.00 \\
\hline 1 & 37 & & 1631.02 & 1778.99 & $1757.03^{\prime \prime}$ & 1722.35 & 79.85 & 1664 & 214 & 237.00 & 1018.00 & 1063.00 & 951.00 & 675.00 \\
\hline
\end{tabular}




\begin{tabular}{|c|c|c|c|c|c|c|c|c|c|c|c|c|c|c|c|}
\hline \multicolumn{16}{|c|}{ With background radiation correction } \\
\hline Condition Test & & Epsilon & Planck Temp & $\mathrm{E} / \mathrm{A}$ & E/B & $\mathrm{E} / \mathrm{C}$ & Average & St dev & Adiabatic & Time & Time From Start (mins) & TN1 & TN2 & TN3 & TN4 \\
\hline 1 & 1 & 0.027268 & 700.65 & 747.26 & 706.18 & 686.80 & 713.41 & 30.88 & 1664 & 1022.00 & 5.00 & 306.00 & 343.00 & 311.00 & 296.00 \\
\hline 1 & 2 & 0.2 & 600.00 & 1069.79 & 1081.54 & $1086.23^{\prime}$ & 1079.19 & 8.47 & 1664 & 1025 & 8.00 & 326.00 & 391.00 & 332.00 & 296.00 \\
\hline 1 & 3 & 0.02078 & 749.23 & 824.07 & 789.28 & $786.47^{\prime \prime}$ & 799.94 & 20.94 & 1664 & 1029 & 12.00 & 351.00 & 439.00 & 356.00 & 298.00 \\
\hline 1 & 4 & 0.015224 & 805.03 & 882.88 & 843.29 & $827.87^{\prime}$ & 851.35 & 28.37 & 1664 & 1032 & 15.00 & 378.00 & 482.00 & 382.00 & 299.00 \\
\hline 1 & 5 & 0.020767 & 774.57 & 1001.98 & 990.70 & $993.21^{7}$ & 995.30 & 5.92 & 1664 & 1036 & 19.00 & 407.00 & 521.00 & 407.00 & 302.00 \\
\hline 1 & 7 & 0.069856 & 710.85 & 1030.60 & 1023.83 & $1020.08^{\prime}$ & 1024.84 & 5.33 & 1664 & 1043 & 26.00 & 465.00 & 589.00 & 460.00 & 311.00 \\
\hline 1 & 8 & 0.011362 & 909.52 & 1024.63 & 1011.04 & 1011.91" & 1015.86 & 7.60 & 1664 & 1047 & 30.00 & 490.00 & 615.00 & 481.00 & 315.00 \\
\hline 1 & 9 & 0.210859 & 655.08 & 1090.01 & 1103.02 & $1112.32^{\prime \prime}$ & 1101.79 & 11.21 & 1664 & 1050 & 33.00 & 513.00 & 640.00 & 502.00 & 321.00 \\
\hline 1 & 10 & 0.038067 & 783.47 & 987.30 & 955.61 & $948.80^{\prime \prime}$ & 963.90 & 20.55 & 1664 & 1053 & 36.00 & 535.00 & 665.00 & 523.00 & 328.00 \\
\hline 1 & 11 & 0.092867 & 726.31 & 1084.30 & 1086.53 & 1085.14 & 1085.33 & 1.13 & 1664 & 1057 & 40.00 & 554.00 & 684.00 & 540.00 & 333.00 \\
\hline 1 & 12 & 0.073938 & 755.41 & 1088.60 & 1097.20 & 1102.58 & 1096.13 & 7.05 & 1664 & 1100 & 43.00 & 572.00 & 702.00 & 557.00 & 340.00 \\
\hline 1 & 13 & 0.209375 & 679.69 & 1083.70 & 1087.98 & 1094.33" & 1088.67 & 5.34 & 1664 & 1104 & 47.00 & 590.00 & 719.00 & 573.00 & 348.00 \\
\hline 1 & 14 & 0.2125 & 680.00 & 1086.04 & 1094.50 & 1101.86 & 1094.13 & 7.92 & 1664 & 1108 & 51.00 & 609.00 & 736.00 & 590.00 & 356.00 \\
\hline 1 & 15 & 0.079731 & 761.00 & 1156.73 & 1175.55 & $1179.67^{\prime \prime}$ & 1170.65 & 12.23 & 1664 & 1111 & 54.00 & 624.00 & 750.00 & 603.00 & 363.00 \\
\hline 1 & 16 & 0.07883 & 777.68 & 1147.98 & 1168.08 & 1181.17" & 1165.74 & 16.72 & 1664 & 1114 & 57.00 & 639.00 & 763.00 & 616.00 & 371.00 \\
\hline 1 & 17 & 0.108943 & 762.98 & 1154.58 & 1174.63 & $1180.60^{\prime}$ & 1169.93 & 13.63 & 1664 & 1122 & 65.00 & 675.00 & 795.00 & 647.00 & 390.00 \\
\hline 1 & 18 & 0.055239 & 840.99 & 1087.39 & 1084.09 & $1089.79^{\prime}$ & 1087.09 & 2.86 & 1664 & 1134 & 77.00 & 720.00 & 833.00 & 685.00 & 415.00 \\
\hline 1 & 19 & 0.04679 & 861.45 & 1117.26 & 1126.23 & $1135.55^{\prime}$ & 1126.35 & 9.14 & 1664 & 1137 & 80.00 & 732.00 & 843.00 & 695.00 & 424.00 \\
\hline 1 & 20 & 0.038908 & 889.30 & 1133.20 & 1135.39 & $1151.85^{\prime \prime}$ & 1140.14 & 10.19 & 1664 & 1141 & 84.00 & 744.00 & 853.00 & 706.00 & 432.00 \\
\hline 1 & 21 & 0.092279 & 803.61 & 1143.39 & 1156.72 & $1163.19^{\prime \prime}$ & 1154.43 & 10.09 & 1664 & 1144 & 87.00 & 759.00 & 865.00 & 718.00 & 442.00 \\
\hline 1 & 22 & 0.085343 & 811.49 & 1138.20 & 1152.67 & $1160.93^{\prime}$ & 1150.60 & 11.51 & 1664 & 1148 & 91.00 & 769.00 & 874.00 & 727.00 & 449.00 \\
\hline 1 & 23 & 0.2 & 750.00 & 1182.77 & 1204.26 & $1210.60^{\prime \prime}$ & 1199.21 & 14.59 & 1664 & 1155 & 98.00 & 793.00 & 892.00 & 747.00 & 466.00 \\
\hline 1 & 24 & 0.206875 & 748.13 & 1152.49 & 1170.62 & $1179.96^{\prime \prime}$ & 1167.69 & 13.97 & 1664 & 1201 & 104.00 & 809.00 & 904.00 & 761.00 & 479.00 \\
\hline 1 & 25 & 0.114043 & 811.00 & 1223.45 & 1235.04 & 1244.11" & 1234.20 & 10.36 & 1664 & 1212 & 115.00 & 838.00 & 927.00 & 786.00 & 503.00 \\
\hline 1 & 26 & 0.091416 & 836.06 & 1186.38 & 1201.00 & $1210.92^{\prime \prime}$ & 1199.43 & 12.34 & 1664 & 1217 & 120.00 & 852.00 & 937.00 & 799.00 & 515.00 \\
\hline 1 & 27 & 0.112344 & 821.02 & 1179.46 & 1194.07 & $1204.58^{\prime}$ & 1192.70 & 12.62 & 1664 & 1229 & 132.00 & 879.00 & 958.00 & 823.00 & 539.00 \\
\hline 1 & 28 & 0.073484 & 877.60 & 1162.71 & 1174.24 & $1188.68^{\prime}$ & 1175.21 & 13.01 & 1664 & 1240 & 143.00 & 900.00 & 974.00 & 841.00 & 557.00 \\
\hline 1 & 31 & 0.083466 & 880.23 & 1172.66 & 1189.06 & $1197.72^{\prime \prime}$ & 1186.48 & 12.73 & 1664 & 109 & 172.00 & 949.00 & 1011.00 & 885.00 & 604.00 \\
\hline 1 & 32 & 0.08197 & 888.66 & 1181.09 & 1195.86 & $1204.88^{\prime \prime}$ & 1193.95 & 12.01 & 1664 & 120 & 183.00 & 966.00 & 1024.00 & 901.00 & 620.00 \\
\hline 1 & 33 & 0.083646 & 887.71 & 1184.43 & 1193.46 & $1201.52^{\prime}$ & 1193.14 & 8.55 & 1664 & 130 & 193.00 & 977.00 & 1031.00 & 910.00 & 631.00 \\
\hline 1 & 34 & 0.103868 & 869.00 & 1234.35 & 1245.37 & $1250.51^{\prime}$ & 1243.41 & 8.26 & 1664 & 140 & 203.00 & 987.00 & 1040.00 & 921.00 & 642.00 \\
\hline 1 & 35 & 0.116037 & 860.65 & 1263.08 & 1276.68 & $1288.29^{\prime \prime}$ & 1276.02 & 12.62 & 1664 & 150 & 213.00 & 998.00 & 1048.00 & 931.00 & 653.00 \\
\hline 1 & 36 & 0.06558 & 932.39 & 1214.33 & 1226.78 & $1236.72^{\prime \prime}$ & 1225.94 & 11.21 & 1664 & 200 & 223.00 & 1008.00 & 1056.00 & 940.00 & 663.00 \\
\hline 1 & 37 & 0.08231 & 908.01 & 1219.51 & 1239.93 & $1250.70^{\prime}$ & 1236.72 & 15.84 & 1664 & 214 & 237.00 & 1018.00 & 1063.00 & 951.00 & 675.00 \\
\hline
\end{tabular}


Without background radiation correction

\begin{tabular}{|c|c|c|c|c|c|c|c|c|c|c|c|c|c|c|c|c|c|}
\hline Condition Tes & & Temp & Epsilon & Planck Temp & $\mathrm{E} / \mathrm{A}$ & E/B & $\mathrm{E} / \mathrm{C}$ & Average & St dev & Adiabatic & & Time From Start (mins) TN1 & & TN2 & TN3 & TN4 & \\
\hline 2 & 1 & 1223 & & & 1062.00 & 1084.08 & 1106.89 & 1084.32 & 22.45 & 1862 & $11: 16$ & 6 & 306 & 348 & 312 & & 295 \\
\hline 2 & & & & & & & & & & 1862 & $11: 18$ & 8 & 318 & 377 & 325 & & 295 \\
\hline 2 & 2 & 1223 & & & $1.08 \mathrm{E}+03$ & $1.10 \mathrm{E}+03$ & $1.11 \mathrm{E}+03$ & & & 1862 & 11:21 & 11 & 338 & 420 & 345 & & 296 \\
\hline 2 & & & & & & & & & & 1862 & $11: 23$ & 13 & 353 & 450 & 360 & & 296 \\
\hline 2 & & & & & & & & & & 1862 & $11: 25$ & 15 & 377 & 486 & 383 & & 298 \\
\hline 2 & 3 & 1223 & & & $1.13 E+03$ & $1.17 \mathrm{E}+03$ & $1.17 \mathrm{E}+03$ & & & 1862 & $11: 26$ & 16 & 385 & 498 & 391 & & 298 \\
\hline 2 & & & & & & & & & & 1862 & $11: 28$ & 18 & 400 & 520 & 405 & & 299 \\
\hline 2 & 4 & 1223 & & & $1.15 E+03$ & $1.19 E+03$ & $1.19 E+03$ & & & 1862 & $11: 30$ & 20 & 421 & 549 & 425 & & 301 \\
\hline 2 & & & & & & & & & & 1862 & 11:32 & 22 & 442 & 576 & 444 & & 304 \\
\hline 2 & & & & & & & & & & 1862 & 11:34 & 24 & 454 & 594 & 456 & & 306 \\
\hline 2 & 5 & 1223 & & & $1.17 E+03$ & $1.21 \mathrm{E}+03$ & $1.22 \mathrm{E}+03$ & & & 1862 & 11:35 & 25 & 465 & 608 & 466 & & 307 \\
\hline 2 & & & & & & & & & & 1862 & 11:37 & 27 & 481 & 628 & 481 & & 310 \\
\hline 2 & 6 & 1223 & & & $1.22 \mathrm{E}+03$ & $1.26 \mathrm{E}+03$ & $1.27 \mathrm{E}+03$ & & & 1862 & 11:39 & 29 & 497 & 648 & 497 & & 313 \\
\hline 2 & & & & & & & & & & 1862 & 11:41 & 31 & 512 & 666 & 510 & & 316 \\
\hline 2 & & & & & & & & & & 1862 & 11:43 & 33 & 529 & 685 & 526 & & 320 \\
\hline 2 & 7 & 1223 & & & $1.24 E+03$ & $1.28 \mathrm{E}+03$ & $1.29 \mathrm{E}+03$ & & & 1862 & 11:44 & 34 & 540 & 697 & 536 & & 323 \\
\hline 2 & & & & & & & & & & 1862 & 11:46 & 36 & 553 & 711 & 547 & & 326 \\
\hline 2 & 8 & 1223 & & & $1.27 E+03$ & $1.32 \mathrm{E}+03$ & $1.32 \mathrm{E}+03$ & & & 1862 & 11:48 & 38 & 566 & 724 & 559 & & 330 \\
\hline 2 & & & & & & & & & & 1862 & $11: 50$ & 40 & 580 & 738 & 572 & & 334 \\
\hline 2 & & & & & & & & & & 1862 & 11:52 & 42 & 594 & 751 & 585 & & 338 \\
\hline 2 & 9 & 1223 & & & $1.31 \mathrm{E}+03$ & $1.36 \mathrm{E}+03$ & $1.36 \mathrm{E}+03$ & & & 1862 & 11:54 & 44 & 607 & 763 & 597 & & 343 \\
\hline 2 & & & & & & & & & & 1862 & $11: 56$ & 46 & 624 & 779 & 612 & & 350 \\
\hline 2 & 10 & 1223 & & & $1.37 E+03$ & $1.43 \mathrm{E}+03$ & $1.44 \mathrm{E}+03$ & & & 1862 & $11: 58$ & 48 & 634 & 790 & 622 & & 354 \\
\hline 2 & & & & & & & & & & 1862 & $12: 00$ & 50 & 644 & 797 & 629 & & 357 \\
\hline 2 & 11 & 1223 & & & $1.33 E+03$ & 3. $1.39 \mathrm{E}+03$ & $1.38 \mathrm{E}+03$ & & & 1862 & $12: 02$ & 52 & 658 & 810 & 641 & & 363 \\
\hline 2 & & & & & & & & & & 1862 & $12: 04$ & 54 & 668 & 818 & 649 & & 367 \\
\hline 2 & 12 & 1223 & & & $1.35 E+03$ & 3. $1.40 \mathrm{E}+03$ & $1.40 \mathrm{E}+03$ & & & 1862 & $12: 06$ & 56 & 682 & 830 & 662 & & 374 \\
\hline 2 & & & & & & & & & & 1862 & $12: 08$ & 58 & 690 & 836 & 668 & & 378 \\
\hline 2 & & & & & & & & & & 1862 & $12: 10$ & 60 & 699 & 844 & 676 & & 382 \\
\hline 2 & 13 & 1223 & & & $1.39 \mathrm{E}+03$ & 3. $1.45 \mathrm{E}+03$ & $1.45 E+03$ & & & 1862 & $12: 12$ & 62 & 709 & 852 & 685 & & 388 \\
\hline 2 & & & & & & & & & & 1862 & $12: 14$ & 64 & 719 & 860 & 692 & & 393 \\
\hline 2 & & & & & & & & & & 1862 & $12: 16$ & 66 & 728 & 868 & 700 & & 398 \\
\hline 2 & 14 & 1223 & & & $1.46 \mathrm{E}+03$ & 3. $1.52 \mathrm{E}+03$ & $1.51 E+03$ & & & 1862 & $12: 20$ & 70 & 748 & 883 & 716 & & 409 \\
\hline 2 & & & & & & & & & & 1862 & $12: 22$ & 72 & 756 & 890 & 724 & & 414 \\
\hline 2 & & & & & & & & & & 1862 & $12: 24$ & 74 & 766 & 898 & 732 & & 420 \\
\hline 2 & 15 & 1223 & & & $1.46 \mathrm{E}+03$ & $3 \quad 1.52 \mathrm{E}+03$ & $1.52 E+03$ & & & 1862 & $12: 26$ & 76 & 775 & 905 & 739 & & 426 \\
\hline 2 & & & & & & & & & & 1862 & $12: 28$ & 78 & 783 & 911 & 745 & & 431 \\
\hline 2 & 16 & 1223 & & & $1.48 \mathrm{E}+03$ & $1.54 \mathrm{E}+03$ & $1.53 E+03$ & & & 1862 & $12: 30$ & 80 & 791 & 917 & 753 & & 437 \\
\hline 2 & & & & & & & & & & 1862 & $12: 32$ & 82 & 800 & 924 & 759 & & 442 \\
\hline 2 & & & & & & & & & & 1862 & $12: 34$ & 84 & 807 & 929 & 765 & & 447 \\
\hline 2 & 17 & 1223 & & & $1.53 \mathrm{E}+03$ & $1.61 \mathrm{E}+03$ & $1.60 \mathrm{E}+03$ & & & 1862 & $12: 36$ & 86 & 817 & 937 & 773 & & 454 \\
\hline 2 & & & & & & & & & & 1862 & $12: 38$ & 88 & 825 & 943 & 780 & & 460 \\
\hline 2 & & & & & & & & & & 1862 & $12: 40$ & 90 & 830 & 947 & 785 & & 464 \\
\hline 2 & 18 & 1223 & & & $1.52 E+03$ & $1.60 E+03$ & $1.59 \mathrm{E}+03$ & & & 1862 & $12: 42$ & 92 & 838 & 954 & 792 & & 470 \\
\hline 2 & & & & & & & & & & 1862 & $12: 44$ & 94 & 844 & 958 & 796 & & 475 \\
\hline 2 & & & & & & & & & & 1862 & $12: 46$ & 96 & 850 & 963 & 802 & & 480 \\
\hline 2 & 19 & 1223 & & & $1.55 E+03$ & $1.64 \mathrm{E}+03$ & $1.62 \mathrm{E}+03$ & & & 1862 & $12: 48$ & 98 & 857 & 968 & 808 & & 486 \\
\hline 2 & & & & & & & & & & 1862 & $12: 50$ & 100 & 864 & 974 & 814 & & 491 \\
\hline 2 & 20 & 1223 & & & $1.56 \mathrm{E}+03$ & $1.63 \mathrm{E}+03$ & $1.62 \mathrm{E}+03$ & & & 1862 & 12:52 & 102 & 871 & 978 & 819 & & 497 \\
\hline 2 & & & & & & & & & & 1862 & 12:54 & 104 & 877 & 983 & 825 & & 502 \\
\hline 2 & & & & & & & & & & 1862 & $12: 56$ & 106 & 884 & 987 & 830 & & 507 \\
\hline 2 & 21 & 1223 & & & $1.56 \mathrm{E}+03$ & $1.65 E+03$ & $1.64 E+03$ & & & 1862 & $12: 58$ & 108 & 889 & 992 & 835 & & 512 \\
\hline 2 & & & & & & & & & & 1862 & $1: 00$ & 110 & 895 & 996 & 840 & & 517 \\
\hline 2 & 22 & 1223 & & & $1.60 \mathrm{E}+03$ & $1.68 \mathrm{E}+03$ & $1.67 \mathrm{E}+03$ & & & 1862 & 1:02 & 112 & 902 & 1001 & 846 & & 522 \\
\hline 2 & & & & & & & & & & 1862 & 1:04 & 114 & 906 & 1004 & 849 & & 526 \\
\hline 2 & & & & & & & & & & 1862 & 1:06 & 116 & 912 & 1010 & 855 & & 533 \\
\hline 2 & 23 & 1223 & & & $1.60 \mathrm{E}+03$ & $1.69 \mathrm{E}+03$ & $1.68 \mathrm{E}+03$ & & & 1862 & 1:08 & 118 & 916 & 1013 & 858 & & 535 \\
\hline 2 & & & & & & & & & & 1862 & $1: 10$ & 120 & 922 & 1017 & 863 & & 540 \\
\hline 2 & 24 & 1223 & & & $1.61 E+03$ & $1.71 \mathrm{E}+03$ & $1.70 \mathrm{E}+03$ & & & 1862 & 1:15 & 125 & 935 & 1026 & 874 & & 552 \\
\hline 2 & 25 & 1223 & & & $1.63 E+03$ & $1.74 \mathrm{E}+03$ & $1.72 \mathrm{E}+03$ & & & 1862 & $1: 22$ & 132 & 952 & 1039 & 890 & & 567 \\
\hline 2 & 26 & 1223 & & & $1.66 \mathrm{E}+03$ & $1.78 \mathrm{E}+03$ & $1.75 E+03$ & & & 1862 & $1: 30$ & 140 & 970 & 1052 & 905 & & 584 \\
\hline 2 & 27 & 1223 & & & $1.67 E+03$ & $1.79 \mathrm{E}+03$ & $1.76 \mathrm{E}+03$ & & & 1862 & $1: 37$ & 147 & 983 & 1062 & 917 & & 597 \\
\hline 2 & 28 & 1223 & & & $1.68 \mathrm{E}+03$ & $1.80 \mathrm{E}+03$ & $1.77 \mathrm{E}+03$ & & & 1862 & $1: 44$ & 154 & 997 & 1071 & 930 & & 611 \\
\hline 2 & 29 & 1223 & & & $1.69 \mathrm{E}+03$ & $1.83 \mathrm{E}+03$ & $1.79 E+03$ & & & 1862 & $1: 52$ & 162 & 1011 & 1082 & 942 & & 624 \\
\hline 2 & 30 & 1223 & & & $1.71 E+03$ & $1.85 \mathrm{E}+03$ & $1.81 \mathrm{E}+03$ & & & 1862 & 2:01 & 171 & 1025 & 1093 & 955 & & 639 \\
\hline 2 & 31 & 1223 & & & $1.72 \mathrm{E}+03$ & $1.85 \mathrm{E}+03$ & $1.82 \mathrm{E}+03$ & & & 1862 & $2: 08$ & 178 & 1036 & 1100 & 966 & & 649 \\
\hline 2 & 32 & 1223 & & & $1.73 E+03$ & $1.86 \mathrm{E}+03$ & $1.83 E+03$ & & & 1862 & 2:15 & 185 & 1046 & 1107 & 974 & & 659 \\
\hline 2 & 33 & 1223 & & & $1.73 E+03$ & $1.86 \mathrm{E}+03$ & $1.83 E+03$ & & & 1862 & $2: 23$ & 193 & 1056 & 1114 & 983 & & 670 \\
\hline 2 & 34 & 1223 & & & $1.74 E+03$ & $1.89 \mathrm{E}+03$ & $1.86 \mathrm{E}+03$ & & & 1862 & $2: 31$ & 201 & 1065 & 1122 & 993 & & 679 \\
\hline 2 & & & & & & & & & & 1862 & $2: 44$ & 214 & 1079 & 1132 & 1006 & & 693 \\
\hline 2 & & & & & & & & & & 1862 & $2: 48$ & 218 & 1083 & 1135 & 1010 & & 698 \\
\hline 2 & 35 & 1223 & & & $1.81 \mathrm{E}+03$ & $1.96 \mathrm{E}+03$ & $1.93 \mathrm{E}+03$ & & & 1862 & $3: 21$ & 251 & 1110 & 1155 & 1037 & & 727 \\
\hline 2 & 36 & 1223 & & & $1.86 \mathrm{E}+03$ & $2.02 \mathrm{E}+03$ & $1.98 \mathrm{E}+03$ & & & 1862 & $3: 31$ & 261 & 1116 & 1160 & 1043 & & 734 \\
\hline
\end{tabular}


With background radiation correction

\begin{tabular}{|c|c|c|c|c|c|c|c|c|c|c|c|c|c|c|c|c|c|}
\hline Condition Tes & & v Temp & Epsilon & Planck Temp & E/A & E/B & $\mathrm{E} / \mathrm{C}$ & Average & St dev & Adiabatic & & Time From Start (mins) TN1 & & TN2 & TN3 & TN4 & \\
\hline 2 & 1 & 1223 & 1.132522 & 2511.9610016 & 1045.15 & 1057.75 & 1078.25 & 1060.38 & 16.71 & 1862 & $11: 16$ & 6 & 306 & 348 & 312 & & 295 \\
\hline 2 & & & & & & & & & & 1862 & $11: 18$ & 8 & 318 & 377 & 325 & & 295 \\
\hline 2 & 2 & 1223 & 0.200395 & $5 \quad 643.328403$ & $1.04 \mathrm{E}+03$ & $1.04 \mathrm{E}+03$ & $1.04 \mathrm{E}+03$ & 1042.20 & & 1862 & $11: 21$ & 11 & 338 & 420 & 345 & & 296 \\
\hline 2 & & & & & & & & & & 1862 & $11: 23$ & 13 & 353 & 450 & 360 & & 296 \\
\hline 2 & & & & & & & & & & 1862 & $11: 25$ & 15 & 377 & 486 & 383 & & 298 \\
\hline 2 & 3 & 1223 & 1.14317 & $7 \quad 564.366703$ & $1.10 \mathrm{E}+03$ & $1.13 E+03$ & $1.13 \mathrm{E}+03$ & 1121.24 & & 1862 & $11: 26$ & 16 & 385 & 498 & 391 & & 298 \\
\hline 2 & & & & & & & & & & 1862 & $11: 28$ & 18 & 400 & 520 & 405 & & 299 \\
\hline 2 & 4 & 1223 & 0.033061 & 1817.4419289 & $1.08 \mathrm{E}+03$ & $1.09 E+03$ & $1.09 \mathrm{E}+03$ & 1083.73 & & 1862 & $11: 30$ & 20 & 421 & 549 & 425 & & 301 \\
\hline 2 & & & & & & & & & & 1862 & $11: 32$ & 22 & 442 & 576 & 444 & & 304 \\
\hline 2 & & & & & & & & & & 1862 & $11: 34$ & 24 & 454 & 594 & 456 & & 306 \\
\hline 2 & 5 & 1223 & 0.041947 & 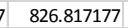 & $1.08 \mathrm{E}+03$ & $1.08 \mathrm{E}+03$ & $1.08 E+03$ & 1078.85 & & 1862 & $11: 35$ & 25 & 465 & 608 & 466 & & 307 \\
\hline 2 & & & & & & & & & & 1862 & 11:37 & 27 & 481 & 628 & 481 & & 310 \\
\hline 2 & 6 & 1223 & 0.545976 & $\begin{array}{ll}6 \quad 642.5039237\end{array}$ & $1.16 \mathrm{E}+03$ & $1.18 \mathrm{E}+03$ & $1.19 E+03$ & 1177.50 & & 1862 & $11: 39$ & 29 & 497 & 648 & 497 & & 313 \\
\hline 2 & & & & & & & & & & 1862 & 11:41 & 31 & 512 & 666 & 510 & & 316 \\
\hline 2 & & & & & & & & & & 1862 & 11:43 & 33 & 529 & 685 & 526 & & 320 \\
\hline 2 & 7 & 1223 & 0.0613 & $\begin{array}{ll}3 & 826.6493974\end{array}$ & + $1.11 \mathrm{E}+03$ & $1.12 \mathrm{E}+03$ & $1.13 E+03$ & 1123.27 & & 1862 & $11: 44$ & 34 & 540 & 697 & 536 & & 323 \\
\hline 2 & & & & & & & & & & 1862 & $11: 46$ & 36 & 553 & 711 & 547 & & 326 \\
\hline 2 & 8 & 1223 & 0.205 & 731.25 & $1.16 \mathrm{E}+03$ & $1.19 \mathrm{E}+03$ & $1.19 E+03$ & 1180.55 & & 1862 & $11: 48$ & 38 & 566 & 724 & 559 & & 330 \\
\hline 2 & & & & & & & & & & 1862 & $11: 50$ & 40 & 580 & 738 & 572 & & 334 \\
\hline 2 & & & & & & & & & & 1862 & 11:52 & 42 & 594 & 751 & 585 & & 338 \\
\hline 2 & 9 & 1223 & \begin{tabular}{|l|}
0.061698 \\
\end{tabular} & $8 \quad 853.1455321$ & $1.15 E+03$ & 3.17E+03 & $1.18 \mathrm{E}+03$ & 1168.76 & & 1862 & 11:54 & 44 & 607 & 763 & 597 & & 343 \\
\hline 2 & & & & & & & & & & 1862 & $11: 56$ & 46 & 624 & 779 & 612 & & 350 \\
\hline 2 & 10 & 1223 & 0.064513 & $\begin{array}{ll}3 & 866.8173995\end{array}$ & $1.18 \mathrm{E}+03$ & $1.20 \mathrm{E}+03$ & $1.21 E+03$ & 1199.30 & & 1862 & 11:58 & 48 & 634 & 790 & 622 & & 354 \\
\hline 2 & & & & & & & & & & 1862 & $12: 00$ & 50 & 644 & 797 & 629 & & 357 \\
\hline 2 & 11 & 1223 & 0.05787 & 7888.1813826 & $\begin{array}{ll}5 & 1.13 E+03\end{array}$ & $1.14 \mathrm{E}+03$ & $1.14 \mathrm{E}+03$ & 1135.40 & & 1862 & $12: 02$ & 52 & 658 & 810 & 641 & & 363 \\
\hline 2 & & & & & & & & & & 1862 & 12:04 & 54 & 668 & 818 & 649 & & 367 \\
\hline 2 & 12 & 1223 & 0.142035 & $\begin{array}{ll}5804.4015094 \\
\end{array}$ & + $1.17 \mathrm{E}+03$ & 3. $1.18 \mathrm{E}+03$ & $1.19 \mathrm{E}+03$ & 1180.16 & & 1862 & $12: 06$ & 56 & 682 & 830 & 662 & & 374 \\
\hline 2 & & & & & & & & & & 1862 & $12: 08$ & 58 & 690 & 836 & 668 & & 378 \\
\hline 2 & & & & & & & & & & 1862 & $12: 10$ & 60 & 699 & 844 & 676 & & 382 \\
\hline 2 & 13 & 1223 & 0.090546 & $\begin{array}{ll}6862.8161776\end{array}$ & 1.17E+03 & 3. $1.18 \mathrm{E}+03$ & $1.19 \mathrm{E}+03$ & 1182.31 & & 1862 & $12: 12$ & 62 & 709 & 852 & 685 & & 388 \\
\hline 2 & & & & & & & & & & 1862 & $12: 14$ & 64 & 719 & 860 & 692 & & 393 \\
\hline 2 & & & & & & & & & & 1862 & $12: 16$ & 66 & 728 & 868 & 700 & & 398 \\
\hline 2 & 14 & 1223 & 0.065243 & $\begin{array}{ll}3 & 911.3762075\end{array}$ & $1.19 \mathrm{E}+03$ & 3. $1.21 \mathrm{E}+03$ & $1.22 \mathrm{E}+03$ & 1205.60 & & 1862 & $12: 20$ & 70 & 748 & 883 & 716 & & 409 \\
\hline 2 & & & & & & & & & & 1862 & $12: 22$ & 72 & 756 & 890 & 724 & & 414 \\
\hline 2 & & & & & & & & & & 1862 & $12: 24$ & 74 & 766 & 898 & 732 & & 420 \\
\hline 2 & 15 & 1223 & 0.077376 & $\begin{array}{ll}5901.9450375\end{array}$ & $1.18 \mathrm{E}+03$ & $1.20 \mathrm{E}+03$ & $1.21 \mathrm{E}+03$ & 1195.60 & & 1862 & $12: 26$ & 76 & 775 & 905 & 739 & & 426 \\
\hline 2 & & & & & & & & & & 1862 & $12: 28$ & 78 & 783 & 911 & 745 & & 431 \\
\hline 2 & 16 & 1223 & 0.087989 & 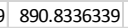 & $1.21 E+03$ & $1.22 \mathrm{E}+03$ & $1.23 E+03$ & 1216.94 & & 1862 & $12: 30$ & 80 & 791 & 917 & 753 & & 437 \\
\hline 2 & & & & & & & & & & 1862 & $12: 32$ & 82 & 800 & 924 & 759 & & 442 \\
\hline 2 & & & & & & & & & & 1862 & $12: 34$ & 84 & 807 & 929 & 765 & & 447 \\
\hline 2 & 17 & 1223 & 0.078355 & 5913.9796415 & $1.23 \mathrm{E}+03$ & $1.24 \mathrm{E}+03$ & $1.25 \mathrm{E}+03^{\prime}$ & 1240.37 & & 1862 & $12: 36$ & 86 & 817 & 937 & 773 & & 454 \\
\hline 2 & & & & & & & & & & 1862 & $12: 38$ & 88 & 825 & 943 & 780 & & 460 \\
\hline 2 & & & & & & & & & & 1862 & $12: 40$ & 90 & 830 & 947 & 785 & & 464 \\
\hline 2 & 18 & 1223 & 0.069 & 9938.4827163 & $1.19 \mathrm{E}+03$ & $1.21 \mathrm{E}+03$ & $1.22 \mathrm{E}+03^{r}$ & 1205.25 & & 1862 & $12: 42$ & 92 & 838 & 954 & 792 & & 470 \\
\hline 2 & & & & & & & & & & 1862 & $12: 44$ & 94 & 844 & 958 & 796 & & 475 \\
\hline 2 & & & & & & & & & & 1862 & $12: 46$ & 96 & 850 & 963 & 802 & & 480 \\
\hline 2 & 19 & 1223 & \begin{tabular}{|l|}
0.077269 \\
\end{tabular} & 9931.9389129 & $1.23 \mathrm{E}+03$ & $1.24 \mathrm{E}+03$ & $1.25 E+03^{2}$ & 1240.03 & & 1862 & $12: 48$ & 98 & 857 & 968 & 808 & & 486 \\
\hline 2 & & & & & & & & & & 1862 & $12: 50$ & 100 & 864 & 974 & 814 & & 491 \\
\hline 2 & 20 & 1223 & \begin{tabular}{|l|}
0.093082 \\
\end{tabular} & \begin{tabular}{l|l}
2914.7964767
\end{tabular} & $1.22 \mathrm{E}+03$ & $1.22 \mathrm{E}+03$ & $1.23 E+03^{2}$ & 1224.46 & & 1862 & $12: 52$ & 102 & 871 & 978 & 819 & & 497 \\
\hline 2 & & & & & & & & & & 1862 & $12: 54$ & 104 & 877 & 983 & 825 & & 502 \\
\hline 2 & & & & & & & & & & 1862 & $12: 56$ & 106 & 884 & 987 & 830 & & 507 \\
\hline 2 & 21 & 1223 & \begin{tabular}{|l|} 
\\
0.210859 \\
\end{tabular} & 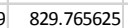 & $1.28 \mathrm{E}+03$ & $1.29 \mathrm{E}+03$ & $1.30 E+03$ & 1289.57 & & 1862 & $12: 58$ & 108 & 889 & 992 & 835 & & 512 \\
\hline 2 & & & & & & & & & & 1862 & $1: 00$ & 110 & 895 & 996 & 840 & & 517 \\
\hline 2 & 22 & 1223 & \begin{tabular}{|l|l|}
0.119794 \\
\end{tabular} & $\begin{array}{l}4894.7892596 \\
\end{array}$ & $1.27 \mathrm{E}+03$ & $1.28 \mathrm{E}+03$ & $1.29 \mathrm{E}+03^{2}$ & 1280.54 & & 1862 & 1:02 & 112 & 902 & 1001 & 846 & & 522 \\
\hline 2 & & & & & & & & & & 1862 & 1:04 & 114 & 906 & 1004 & 849 & & 526 \\
\hline 2 & & & & & & & & & & 1862 & 1:06 & 116 & 912 & 1010 & 855 & & 533 \\
\hline 2 & 23 & 1223 & 0.105484 & 4913.5719267 & $1.25 \mathrm{E}+03$ & $1.26 \mathrm{E}+03$ & $1.27 \mathrm{E}+03^{\prime}$ & 1261.61 & & 1862 & 1:08 & 118 & 916 & 1013 & 858 & & 535 \\
\hline 2 & & & & & & & & & & 1862 & $1: 10$ & 120 & 922 & 1017 & 863 & & 540 \\
\hline 2 & 24 & 1223 & 0.089842 & 2943.065638 & $1.22 \mathrm{E}+03$ & $1.23 \mathrm{E}+03$ & $1.24 E+03^{r}$ & 1231.59 & & 1862 & 1:15 & 125 & 935 & 1026 & 874 & & 552 \\
\hline 2 & 25 & 1223 & 0.2125 & 850 & $1.29 \mathrm{E}+03$ & $1.29 \mathrm{E}+03$ & $1.30 E+03$ & 1293.76 & & 1862 & $1: 22$ & 132 & 952 & 1039 & 890 & & 567 \\
\hline 2 & 26 & 1223 & 0.089502 & 2951.8707875 & $1.24 \mathrm{E}+03$ & $1.25 \mathrm{E}+03$ & $1.26 \mathrm{E}+03^{2}$ & 1252.56 & & 1862 & $1: 30$ & 140 & 970 & 1052 & 905 & & 584 \\
\hline 2 & 27 & 1223 & 0.091955 & $\begin{array}{ll}5 & 953.2740387\end{array}$ & $1.26 \mathrm{E}+03$ & $1.26 \mathrm{E}+03$ & $1.27 \mathrm{E}+03$ & 1263.19 & & 1862 & $1: 37$ & 147 & 983 & 1062 & 917 & & 597 \\
\hline 2 & 28 & 1223 & 0.094332 & 2955.8257801 & $1.26 \mathrm{E}+03$ & $1.26 \mathrm{E}+03$ & $1.27 \mathrm{E}+03$ & 1265.70 & & 1862 & $1: 44$ & 154 & 997 & 1071 & 930 & & 611 \\
\hline 2 & 29 & 1223 & 0.211406 & 865.625 & $1.32 \mathrm{E}+03$ & $1.33 \mathrm{E}+03$ & $1.33 \mathrm{E}+03^{2}$ & 1327.87 & & 1862 & $1: 52$ & 162 & 1011 & 1082 & 942 & & 624 \\
\hline 2 & 30 & 1223 & $\begin{array}{l}0.100582 \\
\end{array}$ & 2952.8514777 & $1.27 \mathrm{E}+03$ & $1.28 \mathrm{E}+03$ & $1.28 \mathrm{E}+03^{\prime}$ & 1276.33 & & 1862 & 2:01 & 171 & 1025 & 1093 & 955 & & 639 \\
\hline 2 & 31 & 1223 & \begin{tabular}{|l|}
0.095671 \\
\end{tabular} & 1963.6872683 & $1.28 \mathrm{E}+03$ & $1.28 \mathrm{E}+03$ & $1.29 \mathrm{E}+03^{2}$ & 1279.53 & & 1862 & $2: 08$ & 178 & 1036 & 1100 & 966 & & 649 \\
\hline 2 & 32 & 1223 & 0.089933 & $\begin{array}{ll}3975.2898958\end{array}$ & 3. $1.27 \mathrm{E}+03$ & $1.27 \mathrm{E}+03$ & $1.28 \mathrm{E}+03$ & 1272.70 & & 1862 & $2: 15$ & 185 & 1046 & 1107 & 974 & & 659 \\
\hline 2 & 33 & 1223 & 0.11641 & \begin{tabular}{l|l}
1 & 947.2118427
\end{tabular} & $1.27 \mathrm{E}+03$ & $1.28 \mathrm{E}+03$ & $1.29 E+03^{2}$ & 1278.39 & & 1862 & $2: 23$ & 193 & 1056 & 1114 & 983 & & 670 \\
\hline 2 & 34 & 1223 & 0.092353 & $\begin{array}{l}3983.9022282 \\
\end{array}$ & $1.26 \mathrm{E}+03$ & $1.26 \mathrm{E}+03$ & $1.27 \mathrm{E}+03^{-}$ & 1265.52 & & 1862 & $2: 31$ & 201 & 1065 & 1122 & 993 & & 679 \\
\hline 2 & & & & & & & & & & 1862 & $2: 44$ & 214 & 1079 & 1132 & 1006 & & 693 \\
\hline 2 & & & & & & & & & & 1862 & $2: 48$ & 218 & 1083 & 1135 & 1010 & & 698 \\
\hline 2 & 35 & 1223 & 0.093109 & 9969.2962958 & $1.30 \mathrm{E}+03$ & $1.30 \mathrm{E}+03$ & $1.31 E+03$ & 1303.09 & & 1862 & $3: 21$ & 251 & 1110 & 1155 & 1037 & & 727 \\
\hline 2 & 36 & 1223 & 0.086665 & $5 \quad 981.9772648$ & $1.32 \mathrm{E}+03$ & $1.32 \mathrm{E}+03$ & $1.33 \mathrm{E}+03^{\prime}$ & 1323.02 & & 1862 & $3: 31$ & 261 & 1116 & 1160 & 1043 & & 734 \\
\hline
\end{tabular}




\begin{tabular}{|c|c|c|c|c|c|c|c|c|c|c|c|c|c|c|c|c|}
\hline & & & & & & & Without & t backgrounc & nd radiation & n correction & & & & & & \\
\hline Condition Test & & Cv Temp & Epsilon & Planck Temp & $\mathrm{E} / \mathrm{A}$ & $E / B$ & $E / C$ & Average $\mathrm{s}$ & St dev & Adiabatic T & Time & Time From Start (mins) & TN1 & $\mathrm{TN} 2$ & TN3 & TN4 \\
\hline 3 & 1 & 1223 & & & 1130.15 & 1158.56 & 1181.00 & 1156.57 & 25.48 & 2024 & 11:24 & 5 & 300 & 338 & 309 & 295 \\
\hline 3 & & & & & & & & & & 2024 & $11: 30$ & 11 & 334 & 434 & 354 & 296 \\
\hline 3 & 2 & 1223 & & & 1190.77 & 1225.34 & 1239.79 & 1218.63 & 25.19 & 2024 & 11:31 & 12 & 343 & 452 & 364 & 297 \\
\hline 3 & & & & & & & & & & 2024 & 11:33 & 15 & 362 & 487 & 385 & 298 \\
\hline 3 & & & & & & & & & & 2024 & $11: 36$ & 18 & 395 & 540 & 420 & 300 \\
\hline 3 & 3 & 1223 & & & 1223.63 & $\begin{array}{l}3 \\
1260.63\end{array}$ & 3 1275.81 & $1253.35^{\circ}$ & 26.84 & 2024 & $11: 38$ & 20 & 409 & 561 & 435 & 302 \\
\hline 3 & & & & & & & & & & 2024 & $11: 40$ & 22 & 434 & 594 & 458 & 305 \\
\hline 3 & 4 & 1223 & & & 1237.07 & 1273.48 & $3 \quad 1285.36$ & $1265.30^{\prime}$ & 25.16 & 2024 & 11:41 & 23 & 445 & 608 & 468 & 306 \\
\hline 3 & & & & & & & & & & 2024 & 11:43 & 25 & 464 & 631 & 485 & 309 \\
\hline 3 & 5 & 1223 & & & 1275.12 & 1310.42 & $=1325.49^{\prime}$ & 1303.68 & 25.85 & 2024 & 11:45 & 27 & 479 & 650 & 499 & 312 \\
\hline 3 & & & & & & & & & & 2024 & 11:47 & 29 & 497 & 672 & 516 & 315 \\
\hline 3 & 6 & 1223 & & & 1303.53 & 1340.44 & $1353.00^{\prime}$ & 1332.33 & 25.71 & 2024 & 11:48 & 30 & 513 & 689 & 530 & 318 \\
\hline 3 & & & & & & & & & & 2024 & 11:50 & 32 & 528 & 707 & 543 & 322 \\
\hline 3 & 7 & 1223 & & & 1315.97 & 7 1353.95 & 1364.01 & 1344.64 & 25.34 & 2024 & 11:52 & 34 & 548 & 728 & 561 & 326 \\
\hline 3 & & & & & & & & & & 2024 & 11:54 & 36 & 558 & 739 & 571 & 329 \\
\hline 3 & & & & & & & & & & 2024 & 11:56 & 38 & 574 & 755 & 585 & 334 \\
\hline 3 & & & & & & & & & & 2024 & 11:58 & 40 & 590 & 770 & 598 & 338 \\
\hline 3 & 8 & 1223 & & & 1364.90 & 1409.44 & $1420.01^{\prime}$ & 1398.12 & 29.25 & 2024 & $12: 00$ & 42 & 607 & 786 & 613 & 344 \\
\hline 3 & & & & & & & & & & 2024 & 12:02 & 44 & 620 & 798 & 625 & 349 \\
\hline 3 & 9 & 1223 & & & 1389.37 & 1428.47 & 1434.21 & $1417.35^{5}$ & 24.40 & 2024 & $12: 04$ & 46 & 635 & 812 & 637 & 35 \\
\hline 3 & & & & & & & & & & 2024 & 12:06 & 48 & 648 & 825 & 650 & 360 \\
\hline 3 & & & & & & & & & & 2024 & $12: 08$ & 50 & 664 & 837 & 662 & 366 \\
\hline 3 & 10 & 1223 & & & 1422.53 & $\begin{array}{ll}3 & 1461.01\end{array}$ & I 1467.21 & 1450.25 & 24.21 & 2024 & $12: 10$ & 52 & 677 & 849 & 674 & 371 \\
\hline 3 & & & & & & & & & & 2024 & $12: 12$ & 54 & 692 & 863 & 687 & 378 \\
\hline 3 & 11 & 1223 & & & 1427.91 & 1471.79 & 1473.96 & $1457.88^{\prime}$ & 25.98 & 2024 & $12: 14$ & 56 & 706 & 873 & 698 & 38 \\
\hline 3 & & & & & & & & & & 2024 & $12: 16$ & 58 & 713 & 880 & 703 & 388 \\
\hline 3 & & & & & & & & & & 2024 & $12: 18$ & 60 & 727 & 891 & 715 & 395 \\
\hline 3 & 12 & 1223 & & & 1482.61 & l $\quad 1533.66$ & 5 $\quad 1532.14$ & $\begin{array}{l}1516.14 \\
\end{array}$ & 29.05 & 2024 & $12: 20$ & 62 & 738 & 900 & 725 & 40 \\
\hline 3 & & & & & & & & & & 2024 & $12: 22$ & 64 & 748 & 908 & 733 & 407 \\
\hline 3 & 13 & 1223 & & & 1484.30 & 1532.82 & ? $\quad 1533.13$ & $\begin{array}{l}3 \\
3\end{array}$ & 28.10 & 2024 & $12: 24$ & 66 & 761 & 918 & 744 & 414 \\
\hline 3 & & & & & & & & & & 2024 & $12: 26$ & 68 & 774 & 929 & 755 & 42 \\
\hline 3 & & & & & & & & & & 2024 & $12: 28$ & 70 & 786 & 939 & 764 & $42 \mathrm{C}$ \\
\hline 3 & 14 & 1223 & & & 1518.49 & a 1574.42 & $=1572.37$ & 1555.09 & 31.72 & 2024 & $12: 30$ & 72 & 792 & 943 & 770 & 432 \\
\hline 3 & & & & & & & & & & 2024 & $12: 32$ & 74 & 800 & 950 & 777 & 438 \\
\hline 3 & 15 & 1223 & & & 1534.56 & $5 \quad 1594.71$ & 1 1589.23 & $\begin{array}{l}3572.83 \\
\end{array}$ & 33.26 & 2024 & $12: 34$ & 76 & 812 & 959 & 786 & 446 \\
\hline 3 & & & & & & & & & & 2024 & $12: 36$ & 78 & 819 & 965 & 792 & 450 \\
\hline 3 & & & & & & & & & & 2024 & $12: 38$ & 80 & 828 & 972 & 800 & 457 \\
\hline 3 & 16 & 1223 & & & 1552.91 & 1617.58 & 1608.21 & 1592.90 & 34.95 & 2024 & $12: 40$ & 82 & 837 & 979 & 808 & 463 \\
\hline 3 & & & & & & & & & & 2024 & 12:42 & 84 & 847 & 987 & 817 & 470 \\
\hline 3 & 17 & 1223 & & & 1563.54 & 1632.14 & 1625.13 & 1606.94 & 37.75 & 2024 & 12:44 & 86 & 855 & 993 & 823 & 476 \\
\hline 3 & & & & & & & & & & 2024 & 12:46 & 88 & 864 & 999 & 831 & 482 \\
\hline 3 & & & & & & & & & & 2024 & $12: 48$ & 90 & 873 & 1006 & 838 & 485 \\
\hline 3 & 18 & 1223 & & & 1631.06 & 1718.25 & 1706.62 & 1685.31 & 47.34 & 2024 & $12: 50$ & 92 & 879 & 1011 & 843 & 494 \\
\hline 3 & & & & & & & & & & 2024 & 12:52 & 94 & 888 & 1017 & 850 & 501 \\
\hline 3 & & & & & & & & & & 2024 & 12:54 & 96 & 895 & 1023 & 856 & 507 \\
\hline 3 & 19 & 1223 & & & 1644.01 & 1726.88 & $3 \quad 1709.97$ & 1693.62 & 43.79 & 2024 & 12:56 & 98 & 901 & 1027 & 861 & 511 \\
\hline 3 & & & & & & & & & & 2024 & 12:58 & 100 & 909 & 1033 & 868 & 510 \\
\hline 3 & 20 & 1223 & & & 1646.03 & 1740.77 & 1722.49 & 1703.10 & 50.26 & 2024 & 1:00 & 102 & 915 & 1038 & 873 & 523 \\
\hline 3 & & & & & & & & & & 2024 & 1:02 & 104 & 923 & 1043 & 879 & $52 \mathrm{c}$ \\
\hline 3 & & & & & & & & & & 2024 & 1:04 & 106 & 930 & 1049 & 886 & 535 \\
\hline 3 & 21 & 1223 & & & 1644.95 & 1732.69 & 1716.33 & 1697.99 & 46.66 & 2024 & 1:06 & 108 & 935 & 1052 & 890 & 540 \\
\hline 3 & & & & & & & & & & 2024 & 1:08 & 110 & 943 & 1058 & 896 & 547 \\
\hline 3 & 22 & 1223 & & & 1651.33 & 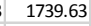 & 1722.54 & 1704.50 & 46.83 & 2024 & $1: 10$ & 112 & 949 & 1063 & 902 & 552 \\
\hline 3 & & & & & & & & & & 2024 & 1:12 & 114 & 954 & 1066 & 906 & 556 \\
\hline 3 & & & & & & & & & & 2024 & 1:14 & 116 & 961 & 1071 & 911 & 562 \\
\hline 3 & 23 & 1223 & & & 1681.77 & 1772.75 & 1754.35 & 1736.29 & 48.10 & 2024 & 1:16 & 118 & 967 & 1075 & 916 & 567 \\
\hline 3 & & & & & & & & & & 2024 & 1:18 & 120 & 972 & 1079 & 921 & 572 \\
\hline 3 & 24 & 1223 & & & 1706.93 & 1811.28 & $\begin{array}{l}3 \\
3\end{array}$ & 1768.82 & 54.82 & 2024 & 1:22 & 124 & 983 & 1087 & 930 & 582 \\
\hline 3 & 25 & 1223 & & & 1702.43 & 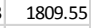 & $\quad 1786.11$ & 1766.03 & 56.31 & 2024 & 1:26 & 128 & 994 & 1095 & 940 & 592 \\
\hline 3 & 26 & 1223 & & & 1737.32 & 1848.77 & 1824.95 & 1803.68 & 58.69 & 2024 & 1:32 & 134 & 1009 & 1106 & 953 & 60 \\
\hline 3 & 27 & 1223 & & & 1727.15 & 1837.21 & 1813.68 & $\quad 1792.68$ & 57.96 & 2024 & 1:36 & 138 & 1018 & 1112 & 961 & 61 \\
\hline 3 & 28 & 1223 & & & 1751.64 & $\begin{array}{l}1865.95 \\
\end{array}$ & 1843.57 & 1820.39 & 60.58 & 2024 & 1:42 & 144 & 1032 & 1123 & 973 & 62 \\
\hline 3 & 29 & 1223 & & & 1744.04 & 1858.63 & 3 1831.96 & 1811.54 & 59.96 & 2024 & $1: 48$ & 150 & 1046 & 1132 & 985 & 64 \\
\hline 3 & 30 & 1223 & & & 1751.02 & 2. 1873.44 & $\begin{array}{l}1845.93 \\
\end{array}$ & 1823.46 & 64.22 & 2024 & 1:52 & 154 & 1053 & 1137 & 991 & 64 \\
\hline 3 & 31 & 1223 & & & 1818.20 & 1908.75 & 1850.76 & 1859.24 & 45.87 & 2024 & 2:00 & 162 & 1068 & 1148 & 1005 & 66 \\
\hline 3 & 32 & 1223 & & & 1793.24 & $\begin{array}{r}1916.58 \\
\end{array}$ & $\begin{array}{l}3 \\
3\end{array}$ & 1865.02 & 64.11 & 2024 & 2:06 & 168 & 1079 & 1156 & 1015 & 67 \\
\hline 3 & 33 & 1223 & & & 1810.04 & $\begin{array}{l}1937.66 \\
\end{array}$ & 1905.97 & 1884.56 & 66.45 & 2024 & $2: 10$ & 172 & 1085 & 1161 & 1021 & 67 \\
\hline 3 & 34 & 1223 & & & 1805.41 & l. 1939.77 & 1899.97 & 1881.71 & 69.02 & 2024 & $2: 16$ & 178 & 1095 & 1168 & 1029 & 68 \\
\hline 3 & 35 & 1223 & & & 1819.55 & ; 1952.06 & ; 1913.29 & 1894.96 & 68.13 & 2024 & $2: 20$ & 182 & 1102 & 1172 & 1035 & 69 \\
\hline 3 & 36 & 1223 & & & 1824.19 & 1953.74 & 1913.54 & 1897.15 & 66.31 & 2024 & $2: 26$ & 188 & 1111 & 1180 & 1044 & 70 \\
\hline 3 & 37 & 1223 & & & 1837.71 & . 1966.14 & 1931.24 & 1911.69 & 66.41 & 2024 & $2: 30$ & 192 & 1116 & 1183 & 1048 & 70 \\
\hline 3 & 38 & 1223 & & & 1838.73 & \begin{tabular}{l|l}
3 & 1965.58
\end{tabular} & 3 1932.01 & 1912.11 & 65.73 & 2024 & $2: 36$ & 198 & 1123 & 1188 & 1055 & 71 \\
\hline 3 & 39 & 1223 & & & 1846.99 & 1974.48 & $\begin{array}{l}3 \\
3\end{array}$ & 1919.45 & 65.51 & 2024 & $2: 40$ & 202 & 1128 & 1192 & 1059 & 72 \\
\hline 3 & 40 & 1223 & & & 1853.72 & 1982.77 & 1944.27 & 1926.92 & 66.25 & 2024 & $2: 50$ & 212 & 1138 & 1200 & 1069 & 73 \\
\hline 3 & 41 & 1223 & & & 1868.13 & $\begin{array}{ll}3 & 2004.87\end{array}$ & 1962.26 & 1945.09 & 69.97 & 2024 & 3:00 & 222 & 1148 & 1208 & 1079 & 74 \\
\hline 3 & 42 & 1223 & & & 1865.61 & \begin{tabular}{l|l}
1996.54 \\
\end{tabular} & 1962.09 & 1941.42 & 67.87 & 2024 & $3: 10$ & 232 & 1158 & 1215 & 1089 & 75 \\
\hline 3 & 43 & 1223 & & & 1892.41 & | 2026.04 & 1983.86 & 1967.44 & 68.31 & 2024 & $3: 20$ & 242 & 1166 & 1221 & 1097 & 76 \\
\hline 3 & 44 & 1223 & & & 1912.39 & $\quad 2044.42$ & 1999.99 & 1985.60 & 67.18 & 2024 & $3: 30$ & 252 & 1174 & 1227 & 1104 & 77 \\
\hline 3 & 46 & 1223 & & & 1917.48 & \begin{tabular}{l|l|}
3 & 2058.57
\end{tabular} & 2012.07 & 1996.04 & 71.90 & 2024 & 3:55 & 277 & 1190 & 1240 & 1117.95 & 788.7 \\
\hline
\end{tabular}


With background radiation correction

\begin{tabular}{|c|c|c|c|c|c|c|c|c|c|c|c|c|c|c|c|c|}
\hline Condition Tes & & Temp & Epsilon & Planck Temp & E/A & $E / B$ & $E / C$ & Average $\mathrm{S}$ & St dev & Adiabatic Time & & Time From Start (mins) & TN1 & TN2 & TN3 & TN4 \\
\hline 3 & 1 & 1223 & 30.029574 & 777.45 & 1084.64 & 1093.13 & 1111.30 & 1096.35 & 13.62 & 2024 & $11: 24$ & 5 & 300 & 338 & 309 & 295 \\
\hline 3 & & & & & & & & & & 2024 & $11: 30$ & 11 & 334 & 434 & 354 & 296 \\
\hline 3 & 2 & 1223 & $\begin{array}{ll}3 & 0.215625\end{array}$ & 662.50 & 1152.95 & 1175.51 & 1188.54 & 1172.33 & 18.01 & 2024 & 11:31 & 12 & 343 & 452 & 364 & 297 \\
\hline 3 & & & & & & & & & & 2024 & 11:33 & 15 & 362 & 487 & 385 & 298 \\
\hline 3 & & & & & & & & & & 2024 & $11: 36$ & 18 & 395 & 540 & 420 & 300 \\
\hline 3 & 3 & 1223 & $\begin{array}{ll}3 & 0.035884\end{array}$ & 835.69 & 1142.47 & 1159.59 & 1173.00 & 1158.35 & 15.30 & 2024 & $11: 38$ & 20 & 409 & 561 & 435 & 302 \\
\hline 3 & & & & & & & & & & 2024 & $11: 40$ & 22 & 434 & 594 & 458 & 305 \\
\hline 3 & 4 & 1223 & $\begin{array}{ll}3 & 0.084916\end{array}$ & 773.41 & 1160.50 & 1179.28 & 1190.61 & 1176.80 & 15.21 & 2024 & 11:41 & 23 & 445 & 608 & 468 & 306 \\
\hline 3 & & & & & & & & & & 2024 & $11: 43$ & 25 & 464 & 631 & 485 & 309 \\
\hline 3 & 5 & 1223 & $\begin{array}{ll}3 & 0.074146\end{array}$ & 798.73 & 1177.09 & 1193.96 & ; 1208.77 & 1193.27 & 15.85 & 2024 & $11: 45$ & 27 & 479 & 650 & 499 & 312 \\
\hline 3 & & & & & & & & & & 2024 & 11:47 & 29 & 497 & 672 & 516 & 315 \\
\hline 3 & 6 & 1223 & \begin{tabular}{l|l}
3 & 0.209961
\end{tabular} & 726.60 & 1213.62 & 1232.78 & $3 \quad 1246.49$ & 1230.96 & 16.51 & 2024 & 11:48 & 30 & 513 & 689 & 530 & 318 \\
\hline 3 & & & & & & & & & & 2024 & 11:50 & 32 & 528 & 707 & 543 & 322 \\
\hline 3 & 7 & 1223 & $\begin{array}{ll}3 & 0.063946\end{array}$ & 847.49 & 1180.76 & 1195.99 & 1208.37 & 1195.04 & 13.83 & 2024 & 11:52 & 34 & 548 & 728 & 561 & 326 \\
\hline 3 & & & & & & & & & & 2024 & 11:54 & 36 & 558 & 739 & 571 & 329 \\
\hline 3 & & & & & & & & & & 2024 & 11:56 & 38 & 574 & 755 & 585 & 334 \\
\hline 3 & & & & & & & & & & 2024 & $11: 58$ & 40 & 590 & 770 & 598 & 338 \\
\hline 3 & 8 & 1223 & $\begin{array}{ll}3 & 0.097981\end{array}$ & 822.62 & 1215.63 & 1233.51 & 1248.07 & 1232.40 & 16.25 & 2024 & $12: 00$ & 42 & 607 & 786 & 613 & 344 \\
\hline 3 & & & & & & & & & & 2024 & 12:02 & 44 & 620 & 798 & 625 & 349 \\
\hline 3 & 9 & 1223 & $\begin{array}{ll}3 & 0.053603\end{array}$ & 906.59 & 1192.99 & 1203.38 & $\begin{array}{ll}3 & 1215.69\end{array}$ & 1204.02 & 11.37 & 2024 & 12:04 & 46 & 635 & 812 & 637 & 354 \\
\hline 3 & & & & & & & & & & 2024 & $12: 06$ & 48 & 648 & 825 & 650 & 360 \\
\hline 3 & & & & & & & & & & 2024 & $12: 08$ & 50 & 664 & 837 & 662 & 366 \\
\hline 3 & 10 & 1223 & \begin{tabular}{l|l}
3 & 0.067619
\end{tabular} & 889.74 & 1216.65 & 1224.69 & 1238.45 & 1226.60 & 11.03 & 2024 & $12: 10$ & 52 & 677 & 849 & 674 & 371 \\
\hline 3 & & & & & & & & & & 2024 & $12: 12$ & 54 & 692 & 863 & 687 & 378 \\
\hline 3 & 11 & 1223 & $\begin{array}{ll}3 & 0.082249\end{array}$ & 880.37 & 1209.17 & 1218.20 & 1229.87 & 1219.08 & 10.38 & 2024 & $12: 14$ & 56 & 706 & 873 & 698 & 384 \\
\hline 3 & & & & & & & & & & 2024 & $12: 16$ & 58 & 713 & 880 & 703 & 388 \\
\hline 3 & & & & & & & & & & 2024 & $12: 18$ & 60 & 727 & 891 & 715 & 395 \\
\hline 3 & 12 & 1223 & $\begin{array}{ll}3 & 0.08117\end{array}$ & 893.25 & 1252.39 & 1261.07 & 1272.70 & 1262.05 & 10.19 & 2024 & $12: 20$ & 62 & 738 & 900 & 725 & 401 \\
\hline 3 & & & & & & & & & & 2024 & $12: 22$ & 64 & 748 & 908 & 733 & 407 \\
\hline 3 & 13 & 1223 & 0.2125 & 807.50 & 1270.81 & 1274.96 & 1286.65 & 1277.47 & 8.21 & 2024 & $12: 24$ & 66 & 761 & 918 & 744 & 414 \\
\hline 3 & & & & & & & & & & 2024 & $12: 26$ & 68 & 774 & 929 & 755 & 421 \\
\hline 3 & & & & & & & & & & 2024 & $12: 28$ & 70 & 786 & 939 & 764 & 429 \\
\hline 3 & 14 & 1223 & $\begin{array}{ll}3 & 0.082416\end{array}$ & 912.68 & 1252.72 & 1258.13 & 3 1271.18 & 1260.68 & 9.49 & 2024 & $12: 30$ & 72 & 792 & 943 & 770 & 432 \\
\hline 3 & & & & & & & & & & 2024 & $12: 32$ & 74 & 800 & 950 & 777 & 438 \\
\hline 3 & 15 & 1223 & \begin{tabular}{l|l}
3 & 0.127829
\end{tabular} & 870.12 & 1281.14 & 1285.38 & 3. 1296.37 & 1287.63 & 7.86 & 2024 & $12: 34$ & 76 & 812 & 959 & 786 & 446 \\
\hline 3 & & & & & & & & & & 2024 & $12: 36$ & 78 & 819 & 965 & 792 & 450 \\
\hline 3 & & & & & & & & & & 2024 & $12: 38$ & 80 & 828 & 972 & 800 & 457 \\
\hline 3 & 16 & 1223 & $\begin{array}{ll}3 & 0.087628\end{array}$ & 920.26 & 1257.65 & 1261.44 & 1272.16 & 1263.75 & 7.53 & 2024 & $12: 40$ & 82 & 837 & 979 & 808 & 463 \\
\hline 3 & & & & & & & & & & 2024 & $12: 42$ & 84 & 847 & 987 & 817 & 470 \\
\hline 3 & 17 & 1223 & \begin{tabular}{l|l}
3 & 0.092101
\end{tabular} & 921.41 & 1261.72 & 1265.61 & 1278.08 & 1268.47 & 8.55 & 2024 & $12: 44$ & 86 & 855 & 993 & 823 & 476 \\
\hline 3 & & & & & & & & & & 2024 & $12: 46$ & 88 & 864 & 999 & 831 & 482 \\
\hline 3 & & & & & & & & & & 2024 & $12: 48$ & 90 & 873 & 1006 & 838 & 489 \\
\hline 3 & 18 & 1223 & 0.2 & 850.00 & 1350.42 & 1349.28 & 1359.37 & 1353.02 & 5.53 & 2024 & 12:50 & 92 & 879 & 1011 & 843 & 494 \\
\hline 3 & & & & & & & & & & 2024 & 12:52 & 94 & 888 & 1017 & 850 & 501 \\
\hline 3 & & & & & & & & & & 2024 & 12:54 & 96 & 895 & 1023 & 856 & 507 \\
\hline 3 & 19 & 1223 & $\begin{array}{ll}3 & 0.09401\end{array}$ & 934.98 & 1321.64 & 1318.78 & 1328.39 & 1322.94 & 4.94 & 2024 & 12:56 & 98 & 901 & 1027 & 861 & 511 \\
\hline 3 & & & & & & & & & & 2024 & 12:58 & 100 & 909 & 1033 & 868 & 519 \\
\hline 3 & 20 & 1223 & 0.2125 & 850.00 & 1361.53 & 1361.59 & 1368.04 & 1363.72 & 3.74 & 2024 & 1:00 & 102 & 915 & 1038 & 873 & 523 \\
\hline 3 & & & & & & & & & & 2024 & 1:02 & 104 & 923 & 1043 & 879 & 529 \\
\hline 3 & & & & & & & & & & 2024 & 1:04 & 106 & 930 & 1049 & 886 & 535 \\
\hline 3 & 21 & 1223 & \begin{tabular}{l|l}
3 & 0.090663
\end{tabular} & 951.74 & 1294.68 & 1293.77 & 1304.95 & 1297.80 & 6.21 & 2024 & 1:06 & 108 & 935 & 1052 & 890 & 540 \\
\hline 3 & & & & & & & & & & 2024 & 1:08 & 110 & 943 & 1058 & 896 & 547 \\
\hline 3 & 22 & 1223 & \begin{tabular}{l|l|l}
3 & 0.098996
\end{tabular} & 947.27 & 1296.14 & 1293.82 & 1304.85 & 1298.27 & 5.82 & 2024 & $1: 10$ & 112 & 949 & 1063 & 902 & 552 \\
\hline 3 & & & & & & & & & & 2024 & 1:12 & 114 & 954 & 1066 & 906 & 556 \\
\hline 3 & & & & & & & & & & 2024 & $1: 14$ & 116 & 961 & 1071 & 911 & 562 \\
\hline 3 & 23 & 1223 & \begin{tabular}{l|l}
3 & 0.100527
\end{tabular} & 948.24 & 1318.62 & 1311.66 & 1322.86 & 1317.71 & 5.66 & 2024 & 1:16 & 118 & 967 & 1075 & 916 & 567 \\
\hline 3 & & & & & & & & & & 2024 & 1:18 & 120 & 972 & 1079 & 921 & 572 \\
\hline 3 & 24 & 1223 & $\begin{array}{ll}3 & 0.10149\end{array}$ & 948.92 & 1341.08 & 1336.45 & 1345.91 & 1341.15 & 4.73 & 2024 & $1: 22$ & 124 & 983 & 1087 & 930 & 582 \\
\hline 3 & 25 & 1223 & \begin{tabular}{l|l}
3 & 0.120274
\end{tabular} & 930.45 & 1340.13 & 1336.54 & 1345.44 & 1340.70 & 4.48 & 2024 & $1: 26$ & 128 & 994 & 1095 & 940 & 592 \\
\hline 3 & 26 & 1223 & \begin{tabular}{l|l}
3 & 0.094738
\end{tabular} & 967.57 & 1349.00 & 1343.00 & 1353.79 & 1348.60 & 5.41 & 2024 & $1: 32$ & 134 & 1009 & 1106 & 953 & 606 \\
\hline 3 & 27 & 1223 & $\begin{array}{ll}3 & 0.088105\end{array}$ & 983.11 & 1311.79 & 1306.58 & 1318.48 & 1312.28 & 5.97 & 2024 & $1: 36$ & 138 & 1018 & 1112 & 961 & 614 \\
\hline 3 & 28 & 1223 & $\begin{array}{ll}3 & 0.228672\end{array}$ & 871.17 & 1415.70 & 1404.58 & 1412.82 & 1411.03 & 5.77 & 2024 & $1: 42$ & 144 & 1032 & 1123 & 973 & 627 \\
\hline 3 & 29 & 1223 & $\begin{array}{ll}3 & 0.103447\end{array}$ & 969.70 & 1325.88 & 1318.94 & $1329.58^{\prime \prime}$ & $1324.80^{\prime}$ & 5.40 & 2024 & $1: 48$ & 150 & 1046 & 1132 & 985 & 641 \\
\hline 3 & 30 & 1223 & \begin{tabular}{l|l}
3 & 0.125316
\end{tabular} & 944.79 & 1359.62 & 1355.23 & $1364.29^{\prime}$ & 1359.71 & 4.53 & 2024 & $1: 52$ & 154 & 1053 & 1137 & 991 & 647 \\
\hline 3 & 32 & 1223 & 0.2125 & 892.50 & 1424.09 & 1411.17 & $1416.47^{\prime}$ & 1417.24 & 6.50 & 2024 & $2: 06$ & 168 & 1079 & 1156 & 1015 & 673 \\
\hline 3 & 33 & 1223 & $\begin{array}{ll}3 & 0.117962\end{array}$ & 965.77 & 1373.21 & 1362.17 & $1372.19^{\prime \prime}$ & 1369.19 & 6.10 & 2024 & $2: 10$ & 172 & 1085 & 1161 & 1021 & 679 \\
\hline 3 & 34 & 1223 & 3 0.105006 & 982.30 & 1345.69 & 1338.87 & $1345.80^{\circ}$ & 1343.45 & 3.97 & 2024 & $2: 16$ & 178 & 1095 & 1168 & 1029 & 689 \\
\hline 3 & 35 & 1223 & \begin{tabular}{l|l}
3 & 0.107317
\end{tabular} & 981.02 & 1358.62 & 1349.00 & 1356.64 & 1354.75 & 5.08 & 2024 & $2: 20$ & 182 & 1102 & 1172 & 1035 & 695 \\
\hline 3 & 36 & 1223 & \begin{tabular}{l|l}
3 & 0.101135
\end{tabular} & 992.91 & 1353.77 & 1342.68 & 1350.12 & 1348.86 & 5.65 & 2024 & $2: 26$ & 188 & 1111 & 1180 & 1044 & 705 \\
\hline 3 & 37 & 1223 & \begin{tabular}{l|l|}
3 & 0.099125
\end{tabular} & 996.03 & 1361.14 & 1348.03 & $1358.86^{\prime}$ & $1356.01^{\prime}$ & 7.01 & 2024 & $2: 30$ & 192 & 1116 & 1183 & 1048 & 709 \\
\hline 3 & 38 & 1223 & \begin{tabular}{l|l}
3 & 0.199355
\end{tabular} & 912.48 & 1430.38 & 1412.77 & $1419.81^{\prime}$ & $1420.99^{\prime}$ & 8.86 & 2024 & $2: 36$ & 198 & 1123 & 1188 & 1055 & 717 \\
\hline 3 & 39 & 1223 & 0.199355 & 912.48 & 1435.70 & 1417.54 & $1422.29^{\prime}$ & $1425.18^{\prime}$ & 9.42 & 2024 & $2: 40$ & 202 & 1128 & 1192 & 1059 & 722 \\
\hline 3 & 40 & 1223 & $\begin{array}{ll}3 & 0.111704\end{array}$ & 987.12 & 1371.15 & 1355.65 & 1364.94 & $1363.92^{\prime}$ & 7.80 & 2024 & $2: 50$ & 212 & 1138 & 1200 & 1069 & 734 \\
\hline 3 & 41 & 1223 & $\begin{array}{ll}3 & 0.099347\end{array}$ & 1011.90 & 1350.42 & 1338.41 & $1347.85^{\circ}$ & $1345.56^{\prime}$ & 6.33 & 2024 & $3: 00$ & 222 & 1148 & 1208 & 1079 & 744 \\
\hline 3 & 42 & 1223 & \begin{tabular}{l|l} 
& 0.100689
\end{tabular} & 1009.70 & 1351.44 & 1336.65 & $1350.05^{\prime \prime}$ & $1346.05^{\prime}$ & 8.17 & 2024 & $3: 10$ & 232 & 1158 & 1215 & 1089 & 754 \\
\hline 3 & 43 & 1223 & \begin{tabular}{|l|l} 
& 0.107478
\end{tabular} & 1005.53 & 1378.32 & 1362.69 & $1372.42^{\prime}$ & $1371.15^{\prime}$ & 7.89 & 2024 & $3: 20$ & 242 & 1166 & 1221 & 1097 & 762 \\
\hline 3 & 44 & 1223 & \begin{tabular}{l|l} 
& 0.119438
\end{tabular} & 993.28 & 1400.85 & 1382.45 & $1390.87^{\prime \prime}$ & $1391.39^{\prime}$ & 9.21 & 2024 & $3: 30$ & 252 & 1174 & 1227 & 1104 & 770 \\
\hline 3 & 46 & 1223 & $\begin{array}{lll}3 & 0.114606\end{array}$ & 1004.34 & 1382.15 & 1368.04 & $1377.08^{\prime \prime}$ & 1375.75 & 7.15 & 2024 & $3: 55$ & 277 & 1190 & 1240 & 1117.95 & 788.75 \\
\hline
\end{tabular}

